\title{
NADPH-generating systems in bacteria and archaea
}

\author{
Sebastiaan K. Spaans ${ }^{1}$, Ruud A. Weusthuis ${ }^{2}$, John van der Oost ${ }^{1}$ and \\ Servé W. M. Kengen ${ }^{1 *}$
}

1 Laboratory of Microbiology, Wageningen University, Wageningen, Netherlands, ${ }^{2}$ Bioprocess Engineering, Wageningen

University, Wageningen, Netherlands

OPEN ACCESS

Edited by:

Biswarup Mukhopadhyay,

Virginia Polytechnic Institute and State

University, USA

Reviewed by:

Barny Whitman,

University of Georgia, USA

Marianne Guiral,

Centre National de la Recherche

Scientifique, France

Armen Trchounian,

Yerevan State University, Armenia

John Leigh

University of Washington, USA

*Correspondence:

Servé W. M. Kengen,

Laboratory of Microbiology,

Wageningen University, Stippeneng 4, 6708 WE, Wageningen, Netherlands

serve.kengen@wur.nl

Specialty section:

This article was submitted to Microbial Physiology and Metabolism,

a section of the journal

Frontiers in Microbiology

Received: 04 May 2015

Accepted: 06 July 2015

Published: 29 July 2015

Citation:

Spaans SK, Weusthuis RA, van der Oost $J$ and Kengen SWM (2015)

$\mathrm{NADPH}$-generating systems in bacteria and archaea.

Front. Microbiol. 6:742

doi: $10.3389 /$ fmicb.2015.00742
Reduced nicotinamide adenine dinucleotide phosphate (NADPH) is an essential electron donor in all organisms. It provides the reducing power that drives numerous anabolic reactions, including those responsible for the biosynthesis of all major cell components and many products in biotechnology. The efficient synthesis of many of these products, however, is limited by the rate of NADPH regeneration. Hence, a thorough understanding of the reactions involved in the generation of $\mathrm{NADPH}$ is required to increase its turnover through rational strain improvement. Traditionally, the main engineering targets for increasing NADPH availability have included the dehydrogenase reactions of the oxidative pentose phosphate pathway and the isocitrate dehydrogenase step of the tricarboxylic acid (TCA) cycle. However, the importance of alternative NADPH-generating reactions has recently become evident. In the current review, the major canonical and non-canonical reactions involved in the production and regeneration of NADPH in prokaryotes are described, and their key enzymes are discussed. In addition, an overview of how different enzymes have been applied to increase NADPH availability and thereby enhance productivity is provided.

Keywords: NADPH regeneration, pentose phosphate pathway, isocitrate dehydrogenase, malic enzyme, transhydrogenase, GAPN, ferredoxin:NADP+ oxidoreductase, hydrogenase

\section{Introduction}

Reduced nicotinamide adenine dinucleotide phosphate (NADPH) is an essential electron donor in all eukaryotes, bacteria, and archaea. Not only is NADPH vital for the generation of reactive oxygen species (ROS) (Foreman et al., 2003; Brown and Griendling, 2009; Bylund et al., 2010; Nakamura et al., 2012) and the anti-oxidative defense mechanisms of most organisms (Nordberg and Arnér, 2001; Minard and Mcalister-Henn, 2005; Singh et al., 2008), most importantly, it is also the driving force of most biosynthetic enzymatic reactions, including those responsible for the biosynthesis of all major cell components, such as DNA and lipids (Arnér and Holmgren, 2000; Nordberg and Arnér, 2001; Hügler et al., 2002; Koh et al., 2004; Minard and Mcalister-Henn, 2005; Singh et al., 2008; Miller and Auchus, 2011). Owing to this essential role in biosynthesis, NADPH availability has been of major interest to industry (Papagianni, 2012; Lee et al., 2013b). Many natural products of industrial importance are complex secondary metabolites, the production of which often involves NADPH-dependent enzymes. To synthesize such products using purified enzyme systems in vitro would require the addition of huge amounts of NADPH in order to sustain production. From an industrial point of view, this would be too expensive. Hence, in situ NADPH 
regeneration from its oxidized counterpart $\left(\mathrm{NADP}^{+}\right)$is required (Chenault et al., 1988; Wandrey, 2004; Wichmann and VasicRacki, 2005; Zhang and Xu, 2010; Uppada et al., 2014).

Regeneration of NADPH in situ can be achieved by various strategies, including chemical, electrochemical, photochemical, and enzyme-based methods (Chenault and Whitesides, 1987; Zhao and Van Der Donk, 2003; Wichmann and Vasic-Racki, 2005; Liu and Wang, 2007; Zhang and Xu, 2010; Uppada et al., 2014). NADPH can be regenerated enzymatically by complementing the in vitro system with additional enzymatic reactions or by using substrate-coupled reaction systems. The latter system employs enzymes that use both $\mathrm{NADP}^{+}$and $\mathrm{NADPH}$ and that are able to catalyze the synthesis of the desired product from one substrate and cofactor regeneration with another substrate (Chenault et al., 1988; Van Der Donk and Zhao, 2003; Liu and Wang, 2007). However, reduced productivity compared to systems without in situ regeneration and problems associated with enzyme stability make these options unattractive.

Microbial in vivo production systems also provide in situ NADPH regeneration and have several advantages when compared to in vitro systems. For example, microbes are able to grow on inexpensive renewable feedstocks that provide the organisms with reductant for the regeneration of NADPH. They also contain numerous pathways, involving stable and highly specific enzymes, thus obviating the need for expensive enzyme purification. In addition, our knowledge of natural metabolic pathways is rapidly advancing, allowing for rational design toward product formation (Chemler et al., 2010; Siedler et al., 2011; Papagianni, 2012; Lee et al., 2013b). Therefore, it is not surprising that microbial conversion is the preferred method for the synthesis of a range of products.

With the possibility of engineering microbial metabolism to facilitate product formation, it became clear that NADPH availability remains a major hurdle in the efficient generation of many products. These products range from medicinal compounds (Chemler et al., 2010; Siedler et al., 2011; Zhao et al., 2011) and (essential) amino acids (Becker et al., 2007; Papagianni, 2012) to molecules used as biofuels (Asadollahi et al., 2009; Kim et al., 2011; Peralta-Yahya et al., 2012) and building blocks for biodegradable plastic (Kabir and Shimizu, 2003). Given its involvement in a multitude of crucial biological functions and its importance in biosynthesis, NADPH is without question an essential molecule. Hence, a key question arises: what are the major NADPH-generating reactions and systems?

Traditionally, the dehydrogenase reactions of the oxidative pentose phosphate pathway (oxPPP), the Entner-Doudoroff (ED) pathway, and the isocitrate dehydrogenase step of the tricarboxylic acid (TCA) cycle have been considered the major sources of NADPH. However, the importance of other NADPHgenerating enzymes, such as transhydrogenases, glucose dehydrogenases, and non-phosphorylating glyceraldehyde 3phosphate dehydrogenase (GAPN), is becoming clear, indicating that the traditional view is over-simplistic (Sauer et al., 2004; Matsubara et al., 2011; Brasen et al., 2014).

In this review, we describe the major canonical and non-canonical biochemical mechanisms that are involved in the production and regeneration of NADPH in prokaryotes and discuss the key enzymes involved. We have divided the mechanisms into those that are directly coupled to central carbon metabolism and those that are not (Table 1). In addition, we briefly address how different enzymes have been applied to increase NADPH availability and thereby enhance NADPHdependent biotransformation processes.

\section{Biosynthesis of NADP ${ }^{+}$}

To maintain a sufficient quantity of $\mathrm{NADP}^{+}$for the generation of NADPH, $\mathrm{NADP}^{+}$biosynthesis is essential. While the necessity for $\mathrm{NADP}^{+}$synthesis during cell proliferation is clear, the requirement for $\mathrm{NADP}^{+}$synthesis in non-dividing cells might not be obvious. $\mathrm{NADP}(\mathrm{H})$ is generally thought of solely as a redox carrier that facilitates the transfer of electrons between two redox couples, a role that does not account for the need for constant resynthesis. The constant need to resynthesize $\mathrm{NADP}^{+}$ arises from its participation in other crucial biological processes (Agledal et al., 2010). In eukaryotes, for example, $\mathrm{NADP}^{+}$ serves as the substrate in the synthesis of nicotinic acid-adenine dinucleotide phosphate (NAADP), an important intracellular $\mathrm{Ca}^{2+}$-mobilizing messenger (Lee, 1997; Chini and De Toledo, 2002; Churamani et al., 2004; Patel et al., 2011). Although NAADP has also been found in bacteria (Churamani et al., 2004), its physiological relevance in these organisms remains to be established.

The enzymes responsible for $\mathrm{NADP}^{+}$resynthesis, best studied in eukaryotes, mainly include $\mathrm{NAD}(\mathrm{P})^{+}$nucleosidase $(\mathrm{Vu}$ et al., 1996; Ying, 2008), $\mathrm{NADP}^{+}$phosphatase, and NADPH phosphatase. The enzymes in prokaryotes are less well-studied, but similar activities and proteins have been found in this domain (Mather and Knight, 1972; Everse et al., 1975; Davis, 1980; Penyige et al., 1996; Pollak et al., 2007; Kawai and Murata, 2008; Ghosh et al., 2010). NADP ${ }^{+}$phosphatase and $\mathrm{NADPH}$ phosphatase, together with $\mathrm{NAD}(\mathrm{H})$ kinase, regulate the intracellular balance of $\mathrm{NAD}(\mathrm{H})$ and $\mathrm{NADP}(\mathrm{H})$ (Kawai and Murata, 2008). Like NADPH, NADH mainly serves to transfer electrons from one molecule to another. However, unlike $\mathrm{NADPH}, \mathrm{NADH}$ is primarily involved in catabolic reactions (Ying, 2008). In addition to its redox function, $\mathrm{NAD}^{+}$serves as a substrate for mono- and poly-ADP ribosylation, participates in histone deacetylation, and contributes to the production of the signaling molecule cyclic ADP-ribose. Most of these reactions have been characterized in eukaryotes, but the ribosylation reactions also play a role in toxin production by pathogenic bacteria (Ziegler, 2000; Pollak et al., 2007). The consumption of $\mathrm{NADP}^{+}$is thus connected to the consumption of $\mathrm{NAD}^{+}$and to the regulation of various major biological activities such as DNA repair, gene expression, apoptosis, nitrogen fixation, and calcium homeostasis (Ziegler, 2000; Pollak et al., 2007; Kawai and Murata, 2008; Ying, 2008; Agledal et al., 2010).

Given that the intracellular balance between $\mathrm{NAD}(\mathrm{H})$ and $\operatorname{NADP}(\mathrm{H})$ is regulated via the addition or removal of a phosphate group by $\mathrm{NAD}(\mathrm{H})$ kinase or $\mathrm{NADP}(\mathrm{H})$ phosphatase, respectively, it is clear that the biosynthesis of $\mathrm{NAD}^{+}$plays a crucial role in the metabolism of $\mathrm{NADP}^{+}$. Two principal $\mathrm{NAD}^{+}$biosynthesis pathways have been characterized: (1) the de novo pathway and 
TABLE 1 | Overview of major canonical and non-canonical NADPH-generating enzymes.

\begin{tabular}{|c|c|c|c|c|c|c|c|c|}
\hline & Enzyme & EC:number & Pathway & $\begin{array}{c}\text { Bacteria* } \\
\text { (\%) }\end{array}$ & $\begin{array}{c}\text { Archaea* } \\
(\%)\end{array}$ & $\begin{array}{l}\text { Additional } \\
\text { cofactors }\end{array}$ & Applied $^{\star \star}$ & $\begin{array}{c}\Delta_{r} \mathrm{G}^{\prime \mathrm{m}} * * * \\
(\mathrm{~kJ} / \mathrm{mol})\end{array}$ \\
\hline \multirow{7}{*}{$\begin{array}{l}\text { NADPH- } \\
\text { generating } \\
\text { enzymes coupled } \\
\text { to central carbon } \\
\text { metabolism }\end{array}$} & G6PDH & EC:1.1.1.49 & oxPPP, ED & 66 & 0 & n.a. & yes & $-2.3 \pm 2.6$ \\
\hline & 6PGDH & EC:1.1.1.44 & oxPPP & 62 & 27 & n.a. & yes & $-6.0 \pm 6.3$ \\
\hline & $\mathrm{IDH}$ & EC:1.1.1.42 & TCA cycle & 82 & 59 & n.a. & yes & $-10.7 \pm 6.3$ \\
\hline & $\mathrm{ME}$ & EC:1.1.1.40 & Anaplerotic node & 47 & 25 & n.a. & no & $-3.1 \pm 6.2$ \\
\hline & GAPN & EC:1.2.1.9 & EMP & 12 & 31 & n.a. & yes & $-36.1 \pm 1.1$ \\
\hline & $\mathrm{NADP}^{+}{ }_{-\mathrm{GAPDH}}$ & EC:1.2.1.13 & EMP & n.d. & n.d. & n.a. & yes & $25.9 \pm 1.0$ \\
\hline & GDHs & $\begin{array}{l}\text { EC:1.1.1.47, } \\
\text { EC:1.1.1.119 }\end{array}$ & Modified EDs & $\begin{array}{l}18 \\
\text { n.d. }\end{array}$ & $\begin{array}{l}10 \\
\text { n.d. }\end{array}$ & $\begin{array}{l}\text { n.a. } \\
\text { n.a. }\end{array}$ & yes & $-2.4 \pm 2.2$ \\
\hline \multirow{5}{*}{$\begin{array}{l}\text { NADPH- } \\
\text { generating } \\
\text { enzymes not } \\
\text { coupled to central } \\
\text { carbon } \\
\text { metabolism }\end{array}$} & STH & EC:1.6.1.1 & n.a. & 19 & 0 & NADH, FAD & yes & $1.0 \pm 0.7$ \\
\hline & $\mathrm{H}^{+}-\mathrm{TH}$ & EC:1.6.1.2 & n.a. & 50 & 5 & $\mathrm{NADH}$ & yes & $1.0 \pm 0.7$ \\
\hline & FNR & EC:1.18.1.2 & n.a. & 63 & 29 & FAD or FMN, Fdred & no & $-15.6 \pm 11.7$ \\
\hline & $\mathrm{SH}$ & EC:1.12.1.3 & n.a. & 10 & 6 & FAD or FMN & no & $-16.5 \pm 5.9$ \\
\hline & NADK & EC:2.7.1.23 & n.a. & 96 & 98 & $\begin{array}{l}\text { NTP or poly }(\mathrm{P}), \\
\mathrm{NAD}^{+} \text {or } \mathrm{NADH}\end{array}$ & yes & n.a. \\
\hline
\end{tabular}

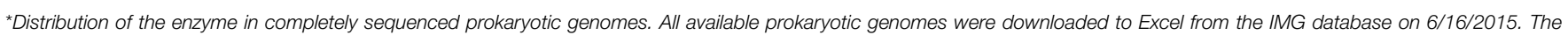

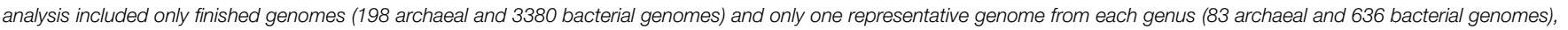

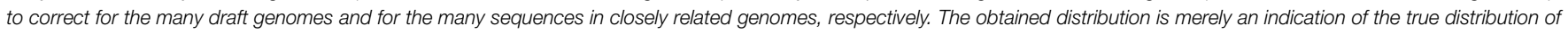
the respective enzymes among prokaryotes because the database is incomplete and gene functions are often automatically annotated.

${ }^{\star *}$ Use of the enzyme in metabolic engineering to increase NADPH availability and enhance biotransformation processes.

${ }^{\star \star \star}$ Gibbs free energies $\left(\Delta_{r} G^{\prime m}\right)$ calculated using the biochemical thermodynamics calculator eQuilibrator 2.0 (Flamholz et al., 2012; Noor et al., 2012, 2013), which calculates $\Delta_{r} G^{\prime m}$.

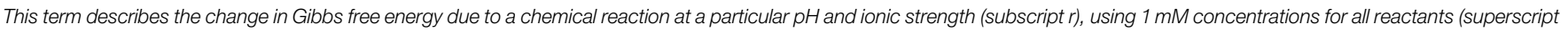
m). Default settings ( $\mathrm{pH} 7$ and ionic strength $0.1 \mathrm{M}$ ) were used for all reactions.

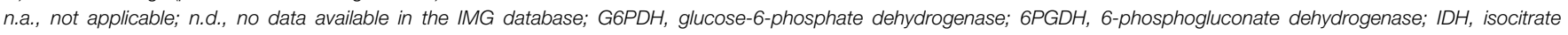

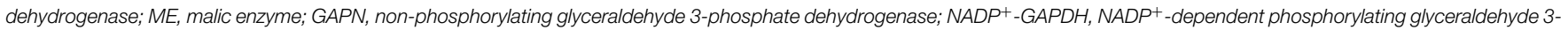

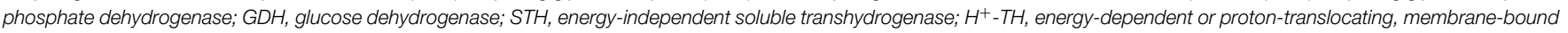
transhydrogenase; FNR, ferredoxin:NADP+ oxidoreductase; SH, cytosolic NADP ${ }^{+}$-reducing hydrogenase; NADK, NAD ${ }^{+}$kinase.

(2) the salvage pathway (Magni et al., 1999, 2004; Begley et al., 2001). Both pathways have been reviewed recently (Pollak et al., 2007; Ying, 2008; Gazzaniga et al., 2009; Gossmann et al., 2012). In the de novo pathway, $\mathrm{NAD}^{+}$is generated from quinolinic acid, which in prokaryotes is produced from either L-aspartate or L-tryptophan (Magni et al., 1999; Sakuraba et al., 2002; Kurnasov et al., 2003). In the salvage pathway, degradation products containing a pyridine ring, namely nicotinic acid and nicotinamide, are utilized to regenerate $\mathrm{NAD}^{+}$(Figure 1A) (Magni et al., 1999; Gazzaniga et al., 2009).

A portion of the synthesized $\mathrm{NAD}^{+}$can be converted into $\mathrm{NADP}^{+}$by NAD kinase (NADK) (Figure 1B). In the $\mathrm{NAD}^{+}$ synthesis pathways, several variations exist and multiple enzymes are involved (Bi et al., 2011; Gossmann et al., 2012). In contrast, $\mathrm{NADK}$ is the sole enzyme able to generate $\mathrm{NADP}^{+}$de novo. NAD kinase is found in archaea (Sakuraba et al., 2005), bacteria (Kawai et al., 2000, 2001; Ochiai et al., 2004), and eukaryotes (Tseng et al., 1979; Butler and Mcguinness, 1982) and has been proven to be essential in prokaryotes (Kobayashi et al., 2003; Sassetti et al., 2003). According to the literature, only one species not able to synthesize $\mathrm{NADP}^{+}$from $\mathrm{NAD}^{+}$has been identified: Chlamydia trachomatis (Kawai and Murata, 2008; Szaszák et al., 2011). The intracellular parasite appears to lack NADK and hence relies completely on the metabolism of its host cell.

According to Kawai and Murata (2008), NADK orthologs can be classified into three types according to their substrate specificity: (I) NADKs that utilize both ATP and inorganic polyphosphate $(\operatorname{poly}(\mathrm{P}))$ as a phosphoryl donor and phosphorylate both $\mathrm{NAD}^{+}$and NADH. This type of NADK has been identified in gram-positive bacteria and archaea. (II) NADKs that utilize ATP but not poly $(\mathrm{P})$ and phosphorylate both $\mathrm{NAD}^{+}$and NADH. This type has been identified in eukaryotes. (III) NADKs that utilize ATP but not poly(P) and phosphorylate $\mathrm{NAD}^{+}$but not NADH. The latter type of NADK has been identified in gram-negative bacteria. Because of its vital role in $\mathrm{NADP}^{+}$synthesis, NADK has received much attention since its discovery in 1950 (Kornberg, 1950). Hence, many papers about its structure, function, and application are available, including reviews by Kawai and Murata (2008), Shi et al. (2009), and Agledal et al. (2010).

\section{Redox Potential of NADP ${ }^{+} /$NADPH}

The redox potential of $\mathrm{NADP}^{+} / \mathrm{NADPH}$ at standard physiological conditions is identical to that of $\mathrm{NAD}^{+} / \mathrm{NADH}$ $\left(\mathrm{E}_{0}^{\prime}:-320 \mathrm{mV}\right)$. However, the function of the cofactors is different. $\mathrm{NADP}^{+} / \mathrm{NADPH}$ is used for anabolic redox reactions, whereas $\mathrm{NAD}^{+} / \mathrm{NADH}$ is used for oxidation reactions. This is possible because $\mathrm{NADP}^{+} / \mathrm{NADPH}$ is generally maintained in a reduced state and $\mathrm{NAD}^{+} / \mathrm{NADH}$ in an oxidized state (Harold, 1986). The ratios for the electron carriers have been reported, and the values can differ by several orders of magnitude, 


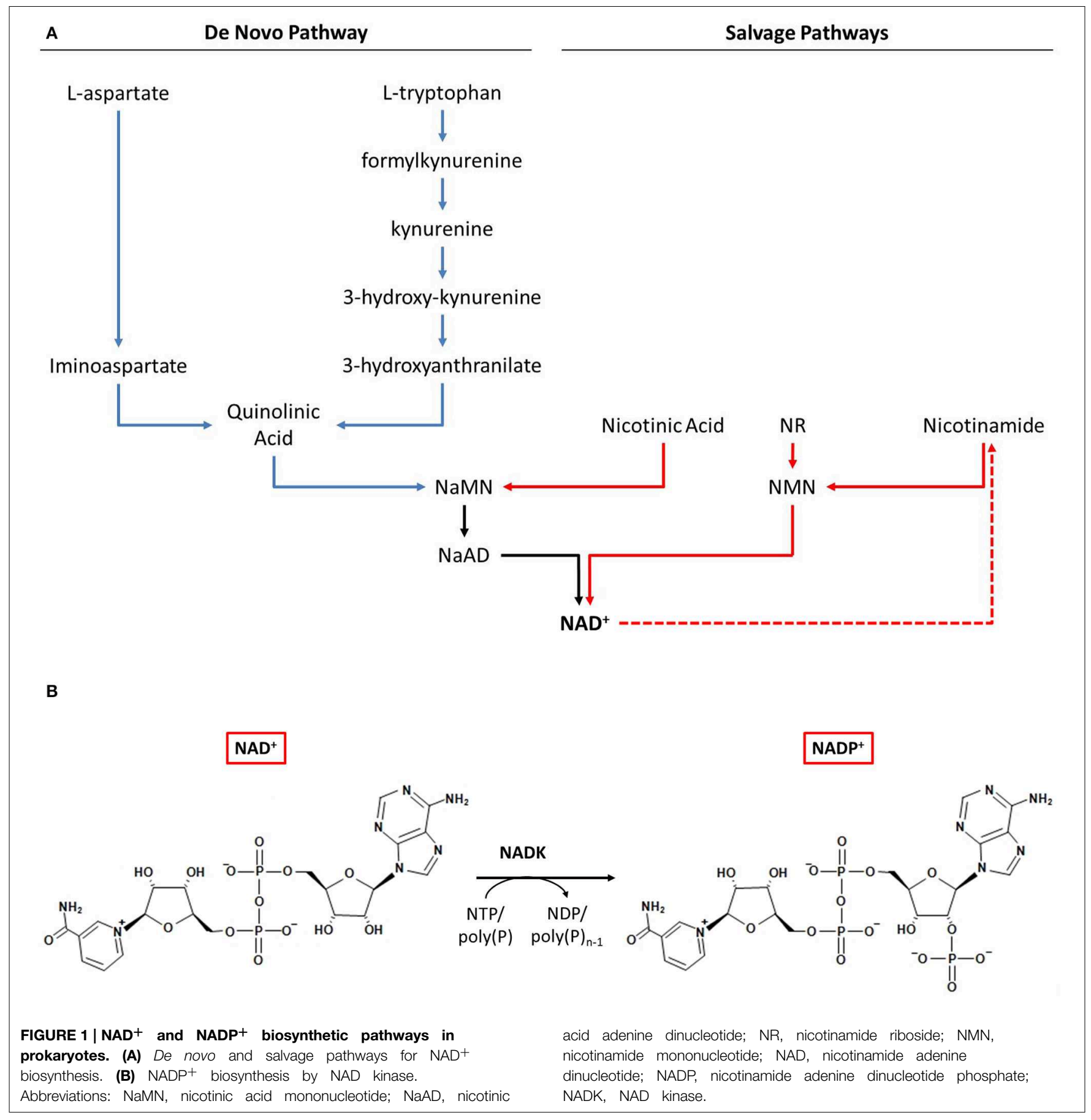

depending on the organism and growth conditions. For example, reported $\mathrm{NAD}^{+} / \mathrm{NADH}$ values range from 3.74 to 31.3 for bacterial cells (Andersen and von Meyenburg, 1977; Thauer et al., 1977; Bennett et al., 2009; Amador-Noguez et al., 2011) and reach 1820 for mammalian cells (Veech et al., 1969), whereas $\mathrm{NADP}^{+} / \mathrm{NADPH}$ values range from 0.017 to 0.95 (Andersen and von Meyenburg, 1977; Thauer et al., 1977; Bennett et al., 2009; Amador-Noguez et al., 2011). This indicates that the actual redox potential of both redox couples can deviate significantly from the standard potential (i.e., generally more negative/positive than $-320 \mathrm{mV}$ for $\left(\mathrm{NADP}^{+} / \mathrm{NADPH}\right) /\left(\mathrm{NAD}^{+} / \mathrm{NADH}\right)$, respectively). Such deviation affects the Gibbs energy of the NADPH-generating reactions and the feasibility of converting $\mathrm{NADH}$ into NADPH. To assess the feasibility of various $\mathrm{NADPH}$-generating reactions, we calculated the Gibbs energies $\left(\Delta_{r} \mathrm{G}^{\prime \mathrm{m}}\right)$ using the biochemical thermodynamics calculator eQuilibrator 2.0 (Flamholz et al., 2012; Noor et al., 2012, 2013), setting all reactants at a physiological concentration of $1 \mathrm{mM}$ (Table 1). However, even under these conditions, several reactions appeared to be at equilibrium or even slightly 
endergonic. At $\mathrm{NADP}^{+} / \mathrm{NADPH}$ ratios lower than 1 , the reaction becomes even less feasible, indicating that the actual concentration of the reaction components must be substantially different for NADPH generation to proceed.

\section{Systems for NADPH Generation}

$\mathrm{NADP}^{+}$synthesized by NADK or generated by NADPHoxidizing reactions is eventually reduced to NADPH. To ensure that the cellular redox balance is maintained in the absence of de novo $\mathrm{NADP}^{+}$synthesis and $\mathrm{NADP}^{+}$consumption, the catabolic fluxes through the NADPH-regenerating reactions must be matched to the anabolic demand. However, this is generally not the case (Fuhrer and Sauer, 2009). In addition, the precise NADPH formation rate depends on fluxes through the generating pathways, which in turn vary with different growth conditions (Dauner et al., 2001; Zhao et al., 2004a; Kanai et al., 2011). Therefore, prokaryotes must have other network-wide biochemical mechanisms that maintain the cellular redox balance (Fuhrer and Sauer, 2009). The exact mechanisms are not fully understood and are beyond the scope of this review, but papers about the topic are available (Singh et al., 2008; Fuhrer and Sauer, 2009).

Although numerous reactions reduce $\mathrm{NADP}^{+}$to $\mathrm{NADPH}$ (at least 143 reactions according to the MetaCyc database, accessed on $03 / 30 / 15$ ), only a few have been thought to contribute significantly. However, new studies have demonstrated the importance of other NADPH-generating reactions. The present review provides a general overview of the known major $\mathrm{NADPH}$-generating reactions and discusses the key enzymes involved. We have divided the reactions into (I) those that are directly coupled to central carbon metabolism and (II) those that are not (Table 1). The enzymes that comprise the first group are the oxPPP enzymes glucose-6-phosphate dehydrogenase and 6-phosphogluconate dehydrogenase; isocitrate dehydrogenase of the TCA cycle; malic enzyme; and three enzymes involved in non-canonical NADPH-generating reactions: phosphorylating GAP dehydrogenase $\left(\mathrm{NADP}^{+}\right.$GAPDH), non-phosphorylating GAP dehydrogenase (GAPN), and glucose dehydrogenase. The enzymes in the second group are transhydrogenases (NADH:NADP ${ }^{+}$), ferredoxin:NADP ${ }^{+}$ oxidoreductase, hydrogenases $\left(\mathrm{H}_{2}: \mathrm{NADP}^{+}\right)$, and $\mathrm{NAD}(\mathrm{H})$ kinase, although the latter is a de novo $\mathrm{NADP}^{+} / \mathrm{NADPH}-$ synthesizing enzyme rather than an NADPH-regenerating enzyme. $\mathrm{NAD}(\mathrm{H})$ kinase is included because it plays an essential role in $\mathrm{NADP}^{+}$biosynthesis and the regulation of the $\mathrm{NAD}(\mathrm{H}) / \mathrm{NADP}(\mathrm{H})$ balance offers a potential strategy for improving the biosynthesis of industrially valuable metabolites.

\section{NADPH-Generating Reactions Coupled to Central Carbon Metabolism}

\section{Glucose-6-phosphate Dehydrogenase and 6-phosphogluconate Dehydrogenase}

The oxidative pentose phosphate pathway (oxPPP) enzymes glucose-6-phosphate dehydrogenase (G6PDH, EC:1.1.1.49) and 6-phosphogluconate dehydrogenase (6PGDH, EC:1.1.1.44) have a central role in metabolism in many microbes (Table 1 ). The enzymes are involved in the conversion of glucose-6-phosphate into ribulose-5-phosphate (Figure 2), a precursor of important molecules such as nucleic acids, and are generally considered a major source of NADPH. The importance of the oxPPP enzymes as a source of NADPH has been demonstrated in various organisms (Summers et al., 1995; Christiansen et al., 2002; Sauer et al., 2004). Flux through these enzymes reportedly increases when NADPH requirements are high (Obanye et al., 1996; Christiansen et al., 2002; Bartek et al., 2011; Celton et al., 2012) and decreases when NADPH requirements are low (Marx et al., 1999; Jonsbu et al., 2001). This is consistent with the anticipated anabolic role of the oxPPP as a supplier of pentoses and NADPH for biosynthesis. The key enzyme with regard to the control of PPP flux is thought to be G6PDH (Kletzien et al., 1994; Moritz et al., 2000; Saliola et al., 2012). However, in addition to its role in the oxPPP, G6PDH can also participate in the classical phosphorylated version of the Entner-Doudoroff (ED) pathway (Figure 2). The ED pathway can be considered an alternative to the Embden-Meyerhof-Parnas (EMP) glycolytic pathway, because both catabolize glucose to pyruvate (Conway, 1992; Sato and Atomi, 2011). The ED pathway is mainly present in prokaryotes, although some eukaryotes possess a functional ED pathway as well (Fabris et al., 2012). A generally held view is that the ED pathway is less important than the EMP pathway with respect to glucose catabolism. However, Fuhrer et al. have shown that this might be a misconception and that the ED pathway might be a major pathway for glucose catabolism even in species that possess both pathways (Fuhrer et al., 2005).

G6PDHs and 6PGDHs have been widely studied with respect to cofactor specificity. Although some bacterial G6PDHs and 6PGDHs show dual cofactor specificity (Stournaras et al., 1983; Sung and Lee, 2007; Fuhrer and Sauer, 2009) or have a strong preference for $\mathrm{NAD}^{+}$(Stournaras et al., 1983; Sung and Lee, 2007) or other cofactors such as the flavin derivative $\mathrm{F}_{420}$ (Purwantini et al., 1997), most are $\mathrm{NADP}^{+}$-dependent (Levy, 1979; Fuhrer and Sauer, 2009; Olavarría et al., 2012). In addition, the dual cofactor specificity that some G6PDHs show is often observed in vitro under saturated conditions. However, physiological in vivo conditions often result in higher specificities for $\mathrm{NADP}^{+}$(Fuhrer and Sauer, 2009). Therefore, G6PDHs and 6PGDHs are generally considered to catalyze the following reactions:

$$
\begin{aligned}
& \text { glucose-6-phosphate }+\mathrm{NADP}^{+} \rightarrow \\
& \text { 6-phospho-D-glucono-1,5-lactone }+\mathrm{NADPH}+\mathrm{H}^{+} \\
& \Delta_{r} G^{\prime \mathrm{m}}=-2.3 \pm 2.6 \mathrm{~kJ} / \mathrm{mol}
\end{aligned}
$$

and

$$
\begin{aligned}
& \text { 6-phosphogluconate }+\mathrm{NADP}^{+} \rightarrow \text { ribulose 5-phosphate } \\
& +\mathrm{CO}_{2}+\mathrm{NADPH}+\mathrm{H}^{+} \\
& \Delta_{r} G^{\prime \mathrm{m}}=-6.0 \pm 6.3 \mathrm{~kJ} / \mathrm{mol}
\end{aligned}
$$

Like eukaryotes, some prokaryotes possess multiple G6PDH (Butler et al., 2002; Singh et al., 2005; Sung and Lee, 2007) 
ED

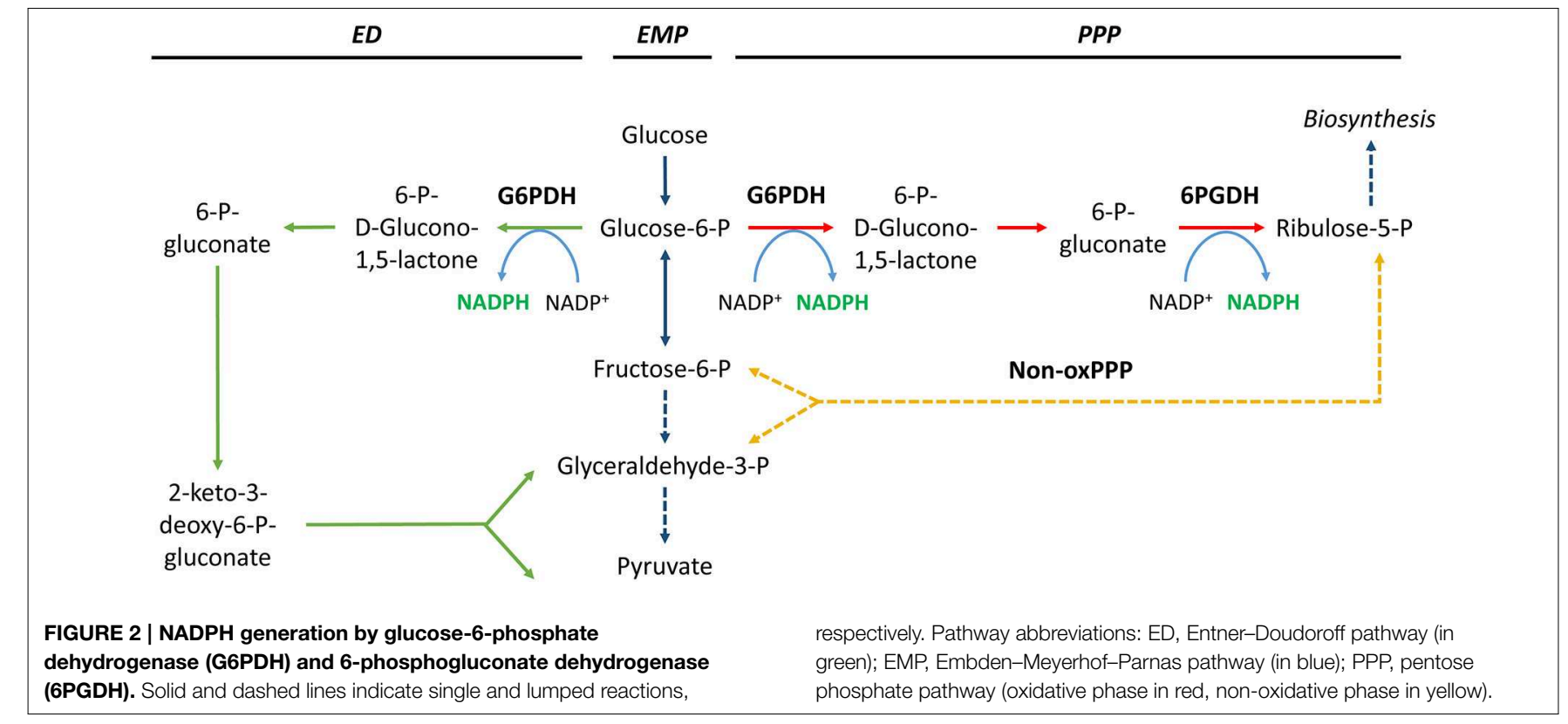

EMP

Glucose

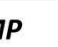

PPP

or 6PGDH isozymes (Zamboni et al., 2004). In general, these isozymes are similar, with the same cofactor preferences, but exceptions exist. Mycobacterium smegmatis, for example, has two G6PDH isozymes, one of which is $\mathrm{NADP}^{+}$-dependent. The other is $\mathrm{F}_{420}$-dependent and does not utilize $\mathrm{NAD}^{+}$or $\mathrm{NADP}^{+}$ (Purwantini and Daniels, 1996). In addition, cell-free extracts of several other Mycobacterium and Nocardia species contain both $\mathrm{F}_{420}$-dependent and $\mathrm{NADP}^{+}$-dependent $\mathrm{G6PDH}$ activity (Purwantini et al., 1997), indicating that the genomes of these species likely encode both variants. Similarly, exceptions among 6PGDH isozymes have been identified. The genome of Bacillus subtilis, for example, encodes three functional 6PGDH isozymes; two prefer $\mathrm{NAD}^{+}$, and one prefers $\mathrm{NADP}^{+}$(Zamboni et al., 2004). As discussed by Zamboni et al., the presence of isozymes with different cofactor preferences would, in principle, enable $\mathrm{NADP}^{+}, \mathrm{NAD}^{+}$, and $\mathrm{F}_{420}$ reduction in the oxPPP to adjust to the overall metabolic requirements of the cell (Zamboni et al., 2004). However, the exact functional roles of these isozymes remains to be determined.

The availability of NADPH is of principal importance for various industrially important classes of products, including amino acids, proteins, antibiotics, organic acids, and highvalue metabolites. The apparent relationship between the rate of NADPH generation and actual carbon fluxes through the oxPPP suggests that the oxPPP can be a target for metabolic engineering for overproduction of NADPH. The oxPPP has been engineered to increase the $\mathrm{NADPH} / \mathrm{NADP}^{+}$ratio, through overexpression of oxPPP enzymes (Lim et al., 2002; Choi et al., 2003; Becker et al., 2007; Lee et al., 2007a) and through redirection of the carbon flux from glycolysis to the oxPPP, by disrupting phosphoglucose isomerase (Kabir and Shimizu, 2003; Marx et al., 2003; Chemler et al., 2010) or phosphofructokinase (Chin and Cirino, 2011; Wang et al., 2013d), overexpressing fructose 1,6bisphosphatase (Becker et al., 2005), or introducing glucose dehydrogenase (Zhang et al., 2011). Both strategies have been applied successfully in various prokaryotes, but reduction in growth is a common side effect (Lim et al., 2002; Lee et al., 2003; Marx et al., 2003). However, the opposite effect was observed with an archaeal strain recently developed in our lab: introduction of the oxPPP increased the hydrogen yield and significantly improved the growth rate (unpublished data).

Although both strategies have been applied successfully in various prokaryotes, they are not effective in every organism (Poulsen et al., 2005; Smith et al., 2010). Moreover, as mentioned above, G6PDH is a key enzyme not only for control of the PPP flux but also for control of the ED pathway. Overexpressing G6PDH could therefore affect the flux of both pathways simultaneously. However, this is generally not observed. Cells apparently possess the ability to regulate fluxes to ensure a network-wide balancing of NADPH supply and demand (Nicolas et al., 2007; Fuhrer and Sauer, 2009).

The effects of G6PDH and 6PGDH disruption have also been investigated. The exact effects are strongly dependent on the organism, the genetic background of the parent strain, and the environmental growth conditions (Summers et al., 1995; Butler et al., 2002; Hua et al., 2003; Zamboni et al., 2004; Zhao et al., 2004b; Richhardt et al., 2013). However, in general, G6PDH-deficient and 6PGDH-deficient prokaryotes exhibit remarkably mild phenotypes. Their growth rates are similar to or somewhat lower than those of the parent strain, and they are more sensitive to oxidative stress. Flux through the oxPPP and ED pathways is lower in G6PDH-deficient strains. To compensate for this and to ensure a sufficient supply of anabolic precursors and NADPH, flux rerouting via the EMP pathway and the non-oxPPP is generally observed (Figure 2). In addition, glucose-grown mutants generally display enhanced TCA cycle activity. In contrast, acetate- or pyruvate-grown cells generally display decreased TCA cycle activity (Zhao et al., 2004a,b). 
Like G6PDH-deficient strains, 6PGDH-deficient strains exhibit a strong reduction in oxPPP flux, but not in ED pathway flux. In contrast, prokaryotes with a functional ED pathway generally respond to 6PGDH knockout by rerouting through the ED pathway and by reversing the direction of the non-oxPPP, slightly increasing the flux through the EMP pathway, and activating malic enzyme (Jiao et al., 2003; Zhao et al., 2004b). Prokaryotes that lack a functional ED pathway display a similar response, but instead of rerouting the flux through the ED pathway, they increase flux through the EMP pathway (Zamboni et al., 2004). Thus, in general, prokaryotes can compensate for disruption of G6PDH or 6PGDH.

\section{Isocitrate Dehydrogenase}

Isocitrate dehydrogenase (IDH, EC:1.1.1.42) is a component of the TCA cycle that catalyzes the decarboxylation of isocitrate to 2-oxoglutarate (also known as $\alpha$-ketoglutarate), with the release of $\mathrm{CO}_{2}$ and NADPH (Figure 3). The IDH reaction is important for the generation of reducing power. Through the generation of 2-oxoglutarate, the reaction also links nitrogen and carbon metabolism and plays an important role in the cellular defense against oxidative damage and detoxification of ROS (MuroPastor et al., 2005; Mailloux et al., 2007; Paul et al., 2007). Together with isocitrate lyase, IDH is a branching point between the TCA cycle and the glyoxylate shunt (Figure 3), a pathway needed for growth on non-fermentative carbon sources such as acetate and ethanol. IDH activity is important in controlling the metabolic flux between both pathways and is affected by various regulatory factors, such as metal ions (Murakami et al., 1997; Yoon et al., 2003), PEP concentration (Ogawa et al., 2007), and phosphorylation/dephosphorylation (Walsh and Koshland, 1985; Cozzone, 1998). In addition, IDH is a component of the reductive tricarboxylic acid (RTCA) cycle. The RTCA cycle is a $\mathrm{CO}_{2}$ fixation pathway, present in some bacteria and archaea, in which four molecules of $\mathrm{CO}_{2}$ are fixed to produce one molecule of oxaloacetate (Shiba et al., 1985; Beh et al., 1993; Kanao et al., 2002). Obviously, IDH cannot act as a source of NADPH under these conditions.

In contrast to eukaryotes, prokaryotes are generally thought to possess only $\mathrm{NADP}^{+}$-dependent IDHs. Although this is true for most prokaryotes, a small but increasing number of reports have described bacterial and archaeal $\mathrm{NAD}^{+}$-dependent IDHs, such as the one found in Hydrogenobacter thermophilus (Lloyd and Weitzman, 1988; Chen and Jeong, 2000; Steen et al., 2001; Inoue et al., 2002; Aoshima et al., 2004; Stokke et al., 2007; Wang et al., 2011b, 2012, 2013a). Moreover, a survey of sequenced prokaryotic genomes by $\mathrm{Zhu}$ et al. identified nine additional species that likely contain $\mathrm{NAD}^{+}$-dependent IDHs (Zhu et al., 2005). However, although the IDH of $H$. thermophilus was originally described as an $\mathrm{NAD}^{+}$-dependent IDH, Aoshima and Igarashi later showed it was not a conventional decarboxylating IDH but a novel non-decarboxylating enzyme that catalyzes the conversion between isocitrate and oxalosuccinate. They therefore proposed that the enzyme should not be categorized as an IDH (Aoshima and Igarashi, 2008).

With the exception of the few $\mathrm{NAD}^{+}$-preferring IDHs, prokaryotic IDHs generally catalyze the following

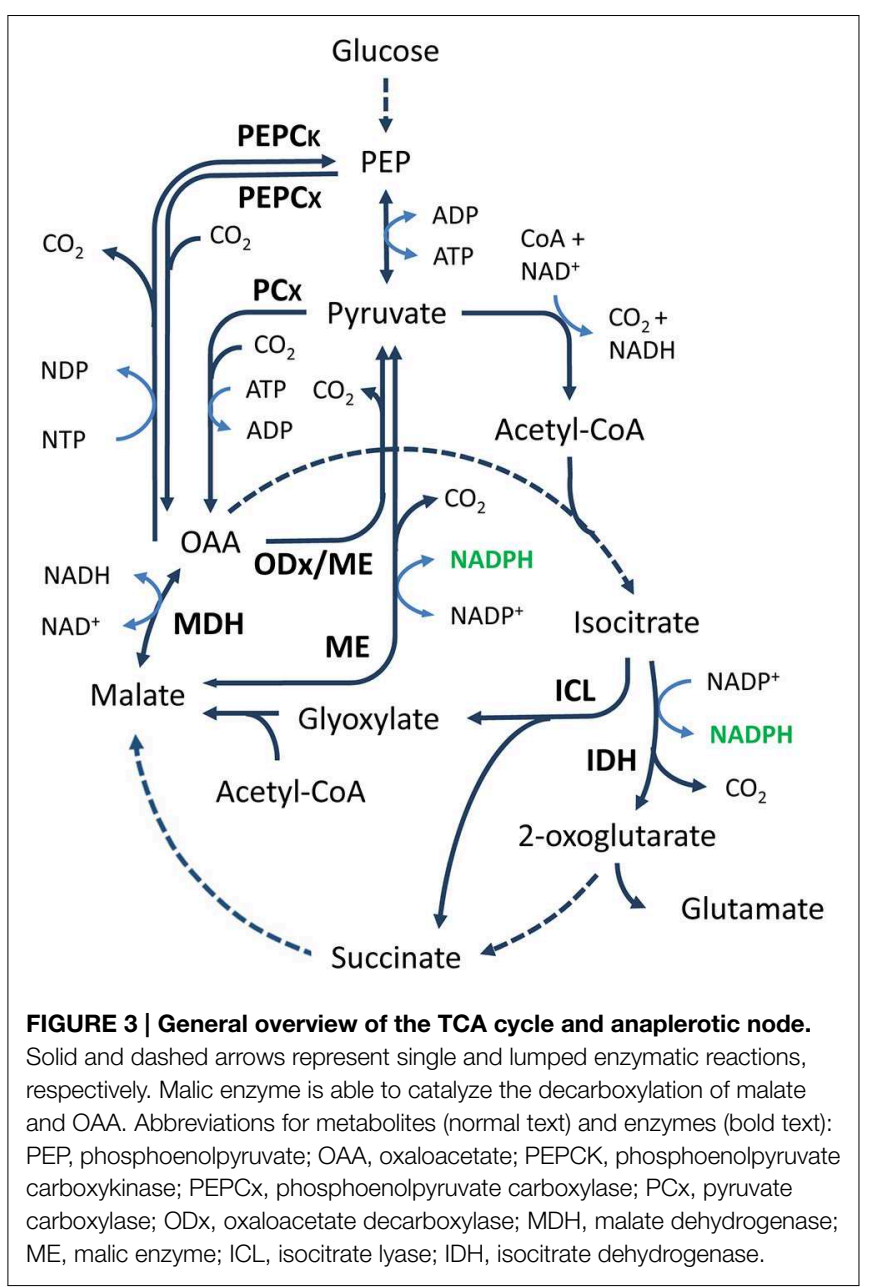

decarboxylating reaction:

$$
\begin{aligned}
& \begin{array}{l}
\text { isocitrate }+\mathrm{NADP}^{+} \rightarrow \text { 2-oxoglutarate }+\mathrm{CO}_{2} \\
+\mathrm{NADPH}+\mathrm{H}^{+} \\
\Delta_{r} G^{\prime \mathrm{m}}=-10.7 \pm 6.3 \mathrm{~kJ} / \mathrm{mol}
\end{array}
\end{aligned}
$$

In addition to the cofactor $\mathrm{NADP}^{+}$, IDH also needs divalent cations, particularly $\mathrm{Mg}^{2+}$ or $\mathrm{Mn}^{2+}$. Although most IDHs have a strong requirement for either $\mathrm{Mg}^{2+}$ or $\mathrm{Mn}^{2+}$, substitution of other divalent cations, or even univalent ions such as $\mathrm{Na}^{+}$, is sometimes possible. However, in most cases, this leads to little or no activity (Murakami et al., 1997; Steen et al., 1997; Yoon et al., 2003; Banerjee et al., 2005).

Like G6PDH and 6PGDH, IDH is an important source of NADPH (Hua et al., 2003; Sauer et al., 2004). In wildtype Escherichia coli aerobically grown in chemostats under glucose- or ammonia-limited conditions, the IDH reaction was the major producer of $\mathrm{NADPH}$, accounting for more than $60 \%$ of the total NADPH production (Hua et al., 2003). Accordingly, overexpression of IDH resulted in a $31 \%$ increase in the production of GDP-L-fucose, whose formation is $\mathrm{NADPH}$-dependent. While this is a significant improvement, the 
biosynthesis of GDP-L-fucose in the IDH overexpression strain was not better than that in a G6PDH overexpression strain (Lee et al., 2011). This suggests that, under the applied conditions, IDH is not a better option than G6PDH for NADPH regeneration in biotransformation reactions (Lee et al., 2013b). The ability of IDH overexpression to enhance glutamate formation in Corynebacterium glutamicum has also been tested (Eikmanns et al., 1995). C. glutamicum secretes glutamate under certain conditions. Because IDH supplies 2-oxoglutarate, the direct precursor of glutamate, overexpression of IDH was an obvious choice. However, overexpression of IDH, even in combination with glutamate dehydrogenase, did not enhance glutamate production.

Disruption of IDH has also been investigated. The exact effects of IDH disruption were dependent on the specific conditions and species used, but some general trends were apparent (Mcdermott and Kahn, 1992; Muro-Pastor and Florencio, 1994; Eikmanns et al., 1995; Kabir and Shimizu, 2004; Becker et al., 2009). First, all IDH mutants investigated were glutamate auxotrophs. Second, although glutamate-containing cultivation media sustained the growth of IDH mutants, their growth was slower than that of the parental strains. The reduced specific growth rate was most likely due to a lower ATP/ADP ratio and a lower NADPH/NADP ${ }^{+}$ ratio, as shown in an E. coli IDH disruption strain grown on glucose under aerobic conditions (Kabir and Shimizu, 2004). Moreover, other significant effects observed in the mutant $E$. coli strain included upregulation of oxPPP enzymes and the anaplerotic glyoxylate pathway. Similarly, redirection from the TCA cycle to anaplerosis has also been reported for an IDH knockdown of C. glutamicum (Becker et al., 2009). However, with respect to citrate synthase, contradictory results have been obtained. Kabir and Shimizu (2004) found upregulation of citrate synthase, but an earlier study of E. coli IDH mutants (Lakshmi and Helling, 1976) and a study of Rhizobium meliloti (Mcdermott and Kahn, 1992) found that IDH mutants spontaneously gave rise to IDH-citrate synthase double mutants.

\section{Malic Enzyme}

The TCA cycle-associated malic enzyme (ME, EC:1.1.1.40) catalyzes the $\mathrm{NAD}(\mathrm{P})^{+}$-dependent oxidative decarboxylation of malate to pyruvate (Figure 3). Confusingly, malic enzyme is also known as "malate dehydrogenase (oxaloacetatedecarboxylating)," while true malate dehydrogenases, enzymes that catalyze the non-decarboxylating reaction between malate and oxaloacetate (Figure 3), are sometimes referred to as malic enzyme. In addition, various classes of $\mathrm{ME}$ that differ in their preference for $\mathrm{NAD}^{+}$or $\mathrm{NADP}^{+}$and in their ability to decarboxylate oxaloacetate have also been characterized (Frenkel, 1975). Enzymes in the first ME class (EC:1.1.1.38) use $\mathrm{NAD}^{+}$ and can decarboxylate oxaloacetate as well as malate. Enzymes in the second class (EC:1.1.1.39) also prefer $\mathrm{NAD}^{+}$, but they are unable to decarboxylate oxaloacetate. Enzymes in the third class (EC:1.1.1.40) are $\mathrm{NADP}^{+}$-dependent; they can catalyze the decarboxylation of malate and oxaloacetate. Moreover, MEs that do not fit the general classification scheme exactly, such as those from the gram-negative bacterium Rhizobium meliloti and the hyperthermophilic archaeon Thermococcus kodakarensis, have been described as well (Voegele et al., 1999; Fukuda et al., 2005). The latter, for example, prefers $\mathrm{NADP}^{+}$but, unlike normal $\mathrm{NADP}^{+}$-dependent MEs, is not able to decarboxylate oxaloacetate.

Although malic enzymes (MEs) are widely distributed amongst prokaryotes (Table 1), most ME-containing species possess an ME that belongs to the third class (Sauer and Eikmanns, 2005; Lerondel et al., 2006) and catalyzes the following reaction:

$$
\begin{aligned}
& \text { malate }+\mathrm{NADP}^{+} \rightarrow \text { pyruvate }+\mathrm{CO}_{2}+\mathrm{NADPH}+\mathrm{H}^{+} \\
& \Delta_{r} G^{\prime \mathrm{m}}=-3.1 \pm 6.2 \mathrm{~kJ} / \mathrm{mol}
\end{aligned}
$$

However, prokaryotes without an ME or with only an $\mathrm{NAD}^{+}$. dependent ME, such as lactic acid bacteria (London et al., 1971; Kawai et al., 1996; Landete et al., 2010; Espariz et al., 2011), or prokaryotes with both $\mathrm{NAD}^{+}$- and $\mathrm{NADP}^{+}$-dependent MEs have also been characterized (Iwakura et al., 1978; Voegele et al., 1999; Sauer and Eikmanns, 2005; Lerondel et al., 2006; Bologna et al., 2007). Moreover, Morimoto et al. recently showed that directed evolution could easily alter the cofactor preference of an ME from T. kodakarensis (Morimoto et al., 2014). Thus, $\mathrm{NAD}^{+} / \mathrm{NADP}^{+}$specificity seems to depend only on a few specific, highly conserved residues (Kuo et al., 2000; Yang et al., 2002; Chang and Tong, 2003; Fukuda et al., 2005; Lerondel et al., 2006; Hsieh and Hung, 2009).

All MEs require a divalent cation as a cofactor. Maximum activity is generally observed in the presence of $\mathrm{Mn}^{2+}$, followed closely by $\mathrm{Mg}^{2+}$. Divalent cations such as $\mathrm{Co}^{2+}$ and $\mathrm{Ni}^{2+}$ are usually only partially able to replace $\mathrm{Mn}^{2+}$, while others such as $\mathrm{Ca}^{2+}, \mathrm{Cu}^{2+}$, or $\mathrm{Sr}^{2+}$ cannot replace $\mathrm{Mn}^{2+}$ at all (Gourdon et al., 2000; Fukuda et al., 2005; Wang et al., 2011a). In addition, the MEs of various prokaryotes also require a monovalent cation for activity, preferably $\mathrm{NH}_{4}^{+}$and $\mathrm{K}^{+}$(Lamed and Zeikus, 1981; Garrido-Pertierra et al., 1983; Kawai et al., 1996; Driscoll and Finan, 1997; Gourdon et al., 2000).

In many aerobic and facultative anaerobic organisms, the TCA cycle-associated ME is part of the PEP-pyruvateoxaloacetate node, also referred to as the anaplerotic node (Figure 3). This node represents the metabolic link between glycolysis/gluconeogenesis and the TCA cycle (Owen et al., 2002; Sauer and Eikmanns, 2005). As such, ME is involved in the interconversion of $\mathrm{C} 4$ and $\mathrm{C} 3$ compounds, which is important for maintaining the levels of TCA cycle intermediates (anaplerotic reactions) and for growth on $\mathrm{C} 4$ and $\mathrm{C} 3$ compounds and substrates that enter central metabolism via acetyl-CoA, such as acetate, fatty acids, and ethanol. Although ME can catalyze C3-carboxylation and C4-decarboxylation reactions, it is generally involved in the latter (decarboxylation of malate to pyruvate with the concomitant formation of NADPH) (Voegele et al., 1999; Gourdon et al., 2000; Sauer and Eikmanns, 2005; Lerondel et al., 2006; Wang et al., 2011a). However, examples of prokaryotic MEs without a preference for either (Fukuda et al., 2005) and MEs with a preference for the C3-carboxylation reaction have been identified (Matula et al., 1969). To determine the exact contribution of ME to the cellular NADPH pool, the physiological direction and flux through the enzyme needs 
to be established. However, regulation of the carbon flux at the anaplerotic node involves a complex interplay between the enzymes involved and depends on the growth conditions and species (Petersen et al., 2000; Dauner et al., 2001; Fischer and Sauer, 2003; Netzer et al., 2004). A detailed discussion of this complex regulation is beyond the scope of this review, but comprehensive reviews, such as those by Owen et al. (2002) and Sauer and Eikmanns (2005), are available.

To understand the physiological role of ME in the metabolism of prokaryotes, the disruption of ME and alternative pathways has been studied. The significance of the latter is clearly demonstrated by the absence of a detectable phenotype in Campylobacter jejuni and E. coli ME disruption strains (Velayudhan and Kelly, 2002; Kao et al., 2005). The lack of a clear phenotype can be explained by the presence of alternative pathways and enzymes, such as the malate dehydrogenasephosphoenolpyruvate carboxykinase pathway (mdh-PEPCK) and isocitrate dehydrogenase, that can fulfill the pyruvate/PEP and NADPH requirements, respectively (Figure 3) (Hansen and Juni, 1975; Oh et al., 2002; Velayudhan and Kelly, 2002; Wang et al., 2011a). Because of the wide distribution of such alternatives in prokaryotes, it is likely that ME gene disruption in other species will yield similar results. Nevertheless, species in which ME gene disruption yields a phenotype, such as Corynebacterium glutamicum, Bacillus subtilis, and various lactic acid bacteria, have been identified (Gourdon et al., 2000; Lerondel et al., 2006; Landete et al., 2010; Espariz et al., 2011).

Analysis of various disruption strains created to understand the physiological role of ME in prokaryotes has shown that it is crucial to take the genetic background of a strain into consideration because the exact physiological role of ME differs from species to species (Riedel et al., 2001; Velayudhan and Kelly, 2002; Kao et al., 2005; Landete et al., 2010; Meyer and Stulke, 2013). Analysis has also shown that the effect of ME disruption can be subtle and/or heavily dependent on the cultivation conditions (Gourdon et al., 2000; Lerondel et al., 2006). A C. glutamicum ME disruption strain, for example, showed no detectable phenotype during growth on either acetate or glucose, but showed a significantly modified growth behavior during lactate metabolism (Gourdon et al., 2000). Moreover, the physiological role of $\mathrm{NAD}^{+}$- and $\mathrm{NADP}^{+}$-dependent MEs appears to be different (Lerondel et al., 2006; Bologna et al., 2007; Landete et al., 2010; Espariz et al., 2011; Wang et al., 2011a; Meyer and Stulke, 2013). Whereas $\mathrm{NAD}^{+}$-dependent MEs generally play a role in malate catabolism, $\mathrm{NADP}^{+}$dependent MEs function either as gluconeogenic enzymes, by supplying pyruvate from $\mathrm{C}_{4}$-dicarboxylic acids, or as NADPHgenerating systems needed for various biosynthetic purposes. It is interesting in this respect that the concerted action of $\mathrm{ME}, \mathrm{MDH}$, and pyruvate carboxylase ( $\mathrm{PCx}$ ) can act as a kind of transhydrogenase. The combined action of these enzymes enables the ATP-dependent conversion of pyruvate to OAA and malate and back to pyruvate, while converting NADH into NADPH (Figure 3) (Sauer and Eikmanns, 2005). A similar reaction sequence can involve PEP carboxylase (PEPCx) instead of pyruvate carboxylase, which also enables conversion of $\mathrm{NADH}$ into NADPH. This so-called malate shunt was recently described in Clostridium thermocellum (Zhou et al., 2013).

$\mathrm{NAD}^{+}$- and $\mathrm{NADP}^{+}$-dependent MEs have also been used in metabolic engineering approaches to improve specific biotechnological applications. However, to our knowledge, no prokaryotic $\mathrm{ME}$ has been used to increase intracellular NADPH levels, as has been done in the yeast Saccharomyces cerevisiae (Moreira Dos Santos et al., 2004; Matsuda et al., 2013). Instead, prokaryotic MEs have been overexpressed for the formation of $\mathrm{C}_{4}$-dicarboxylic acids from glucose or pyruvate (Stols and Donnelly, 1997; Hong and Lee, 2001; Shin et al., 2007; Zheng et al., 2009). These acids are important intermediates in the production of tetrapyrroles (Shin et al., 2007) and amino acids (Sahm et al., 2000), for example, and they can be chemically converted into common intermediates in the petrochemical industry. Hence, $\mathrm{C}_{4}$-dicarboxylic acids are important intermediates in the production of commodity chemicals from renewable carbohydrate feedstocks (Jain et al., 1989; Szmant, 1989). However, to produce these acids from glucose or pyruvate, one has to reverse the physiological direction of ME. This has been accomplished in different ways (Stols and Donnelly, 1997; Hong and Lee, 2001; Zheng et al., 2009).

\section{NADP $^{+}$-dependent Glyceraldehyde-3-phosphate Dehydrogenases}

$\mathrm{NADP}^{+}$-dependent glyceraldehyde-3-phosphate dehydrogenases belong to the aldehyde dehydrogenase (ALDH) superfamily, a divergently related group of enzymes widely distributed among all three domains of life (Sophos et al., 2001; Sophos and Vasiliou, 2003). Enzymes in this group metabolize a broad spectrum of endogenous and exogenous aldehydes, which are oxidized to the corresponding carboxylic acid, using $\mathrm{NAD}^{+}$or $\mathrm{NADP}^{+}$as a cofactor (Lindahl, 1992; Vasiliou et al., 2000):

$$
\begin{aligned}
\mathrm{RCHO} \text { (aldehyde) }+\mathrm{NADP}^{+}+\mathrm{H}_{2} \mathrm{O} & \rightarrow \mathrm{RCOOH}(\text { acid) } \\
& +\mathrm{NADPH}+\mathrm{H}^{+}
\end{aligned}
$$

As such, the enzymes play essential roles in processes such as intermediary metabolism and detoxification (Talfournier et al., 2011; Esser et al., 2013). Although many ALDHs are $\mathrm{NADP}^{+}$-dependent, only the $\mathrm{NADP}^{+}$-dependent glyceraldehyde-3-phosphate dehydrogenases will be addressed here, because these enzymes contribute significantly to NADPH levels in certain prokaryotes. Moreover, extensive reviews of the ALDH superfamily are available (Sophos et al., 2001; Sophos and Vasiliou, 2003; Marchitti et al., 2008; Jackson et al., 2011).

While most glyceraldehyde-3-phosphate dehydrogenases (GAPDH, EC:1.2.1.12) are $\mathrm{NAD}^{+}$-dependent enzymes responsible for the reversible oxidation of GAP into 1,3bisphosphoglycerate (1,3-BPG) as part of the classical EMP pathway, $\mathrm{NADP}^{+}$-dependent variants exist as well. In fact, there are two different types of $\mathrm{NADP}^{+}$-dependent GAPDHs, a phosphorylating type $\left(\mathrm{NADP}^{+}{ }^{-} \mathrm{GAPDH}, \mathrm{EC}: 1.2 .1 .13\right)$, producing 1,3-BPG, and a non-phosphorylating type (GAPN, EC:1.2.1.9), unidirectionally producing 3-phosphoglycerate (3-PG) (Figure 4). However, the term $\mathrm{NADP}^{+}{ }_{-} \mathrm{GAPDH}$ is used inconsistently in different studies to denote either the 


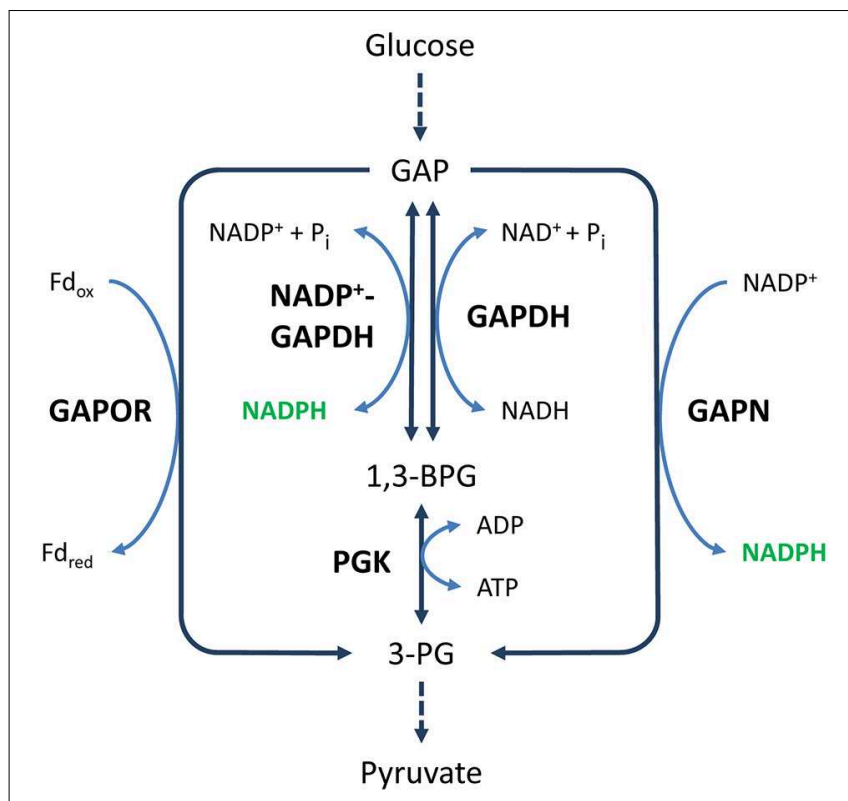

FIGURE 4 | NADPH generation by GAP dehydrogenases. Solid and dashed arrows represent single and lumped enzymatic reactions, respectively. Abbreviations for metabolites (normal text) and enzymes (bold text): GAP, glyceraldehyde 3-phosphate; 1,3-BPG, 1,3-bisphosphoglycerate; 3-PG, 3-phosphoglycerate; GAPOR, GAP:ferredoxin oxidoreductase; GAPDH, glyceraldehyde-3-phosphate dehydrogenase; GAPN, non-phosphorylating GAPDH; PGK, phosphoglycerate kinase.

phosphorylating or non-phosphorylating type or both types, thus generating confusion.

GAPN was originally thought to be present only in photosynthetic eukaryotes (Kelly and Gibbs, 1973; Mateos and Serrano, 1992). However, early reports of GAPN activity in Streptococcus mutans were later confirmed by the characterization of the first prokaryotic GAPN (Crow and Wittenberger, 1979; Boyd et al., 1995). Since then, GAPN has also been found in various (hyper)thermophilic archaea, such as Thermococcus kodakarensis, Thermoproteus tenax, and Sulfolobus solfataricus (Brunner et al., 1998; Ettema et al., 2008; Matsubara et al., 2011), and several gram-positive bacteria, such as Clostridium acetobutylicum, Streptococcus pyogenes, and Bacillus halodurans (Table 1) (Iddar et al., 2002, 2003, 2005; Sophos and Vasiliou, 2003; Agledal et al., 2010). GAPN catalyzes the irreversible, non-phosphorylating oxidation of GAP to 3-PG with the concurrent reduction of $\mathrm{NADP}^{+}$to $\mathrm{NADPH}$ :

$$
\begin{aligned}
& \mathrm{GAP}+\mathrm{NADP}^{+}+\mathrm{H}_{2} \mathrm{O} \rightarrow \begin{array}{c}
\text { 3-phosphoglycerate }+\mathrm{NADPH} \\
+\mathrm{H}^{+}
\end{array} \\
& \Delta_{r} G^{\prime \mathrm{m}}=-36.1 \pm 1.1 \mathrm{~kJ} / \mathrm{mol}
\end{aligned}
$$

In this reaction, 1,3-BPG is not formed, and the oxidation of GAP is not coupled to the generation of ATP (Figure 4). Such modifications of the classical EMP or ED pathway are regularly found in archaea (Ahmed et al., 2005; Siebers and Schonheit, 2005; Ettema et al., 2008; Matsubara et al., 2011; Brasen et al.,
2014). Interestingly, GAPN has been reported to have a key function in the regulation of these modified pathways (Brunner et al., 1998; Brunner and Hensel, 2001; Lorentzen et al., 2004; Ettema et al., 2008).

With the exception of the GAPN in T. tenax, which has a preference for $\mathrm{NAD}^{+}$, prokaryotic GAPNs, in general, have a clear preference for $\mathrm{NADP}^{+}$. However, although the GAPN of T. tenax was shown to be $\mathrm{NAD}^{+}$-dependent, it was later shown to be allosterically regulated, shifting its cofactor preference from $\mathrm{NAD}^{+}$to $\mathrm{NADP}^{+}$in the presence of activators such as F6P and G1P (Lorentzen et al., 2004). Based on sequence similarity, similar allosteric regulation might also exist for GAPNs in a number of other hyperthermophiles (Lorentzen et al., 2004; Ito et al., 2012). Aside from $\mathrm{NADP}^{+}$, GAPNs do not require other cofactors or metals.

While the physiological significance of GAPN might vary between organisms, the enzyme is an important and essential source of NADPH in the bacterium $S$. mutans and the archaeon T. kodakarensis, respectively (Boyd et al., 1995; Matsubara et al., 2011; Arutyunov et al., 2013). Moreover, the ability to use GAPN as a source of NADPH has been demonstrated in a mutant $E$. coli strain in which the endogenous $\mathrm{NAD}^{+}$-dependent glyceraldehyde-3-phosphate dehydrogenase $\left(\mathrm{NAD}^{+}{ }_{-} \mathrm{GAPDH}\right)$ was replaced by the GAPN of $S$. mutans. Transcriptional analysis of this strain revealed upregulation of the transhydrogenase and downregulation of the PPP and TCA cycle, which together indicate a response to avoid NADPH excess (Centeno-Leija et al., 2013). In addition, GAPN has been used successfully in metabolic engineering efforts intended to improve the production of metabolites whose biosynthesis depends on NADPH, such as Llysine or poly-3-hydroxybutyrate, or to decrease the formation of undesired by-products such as glycerol in industrial ethanol production strains (Takeno et al., 2010; Guo et al., 2011; CentenoLeija et al., 2014).

In contrast to GAPN, NADP ${ }^{+}-\mathrm{GAPDH}$ produces $1,3-\mathrm{BPG}$. It is therefore more similar to $\mathrm{NAD}^{+}{ }_{-} \mathrm{GAPDH}$ (Figure 4).

$$
\begin{aligned}
& \mathrm{GAP}+\mathrm{NADP}^{+}+\mathrm{Pi} \rightarrow \begin{array}{r}
1,3-\text { bisphosphoglycerate } \\
\\
+\mathrm{NADPH}+\mathrm{H}^{+}
\end{array} \\
& \Delta_{r} G^{\prime \mathrm{m}}=25.9 \pm 1.0 \mathrm{~kJ} / \mathrm{mol}
\end{aligned}
$$

The generation of 1,3-BPG is an important difference between the reactions catalyzed by $\mathrm{NADP}^{+}{ }_{-} \mathrm{GAPDH}$ and GAPN, because further oxidation of 1,3-BPG to 3-PG generates ATP. Moreover, while the oxidation of GAP by $\mathrm{NADP}^{+}{ }_{-} \mathrm{GAPDH}$ is reversible, the oxidation by GAPN is not. Hence, $\mathrm{NADP}^{+}$GAPDH, in contrast to GAPN, is active in both glycolysis and gluconeogenesis. However, in prokaryotes that also contain alternative GAP oxidation enzymes, such as $\mathrm{NAD}^{+}{ }_{-} \mathrm{GAPDH}$, GAPN, or GAP:ferredoxin oxidoreductase (GAPOR) (Figure 4), $\mathrm{NADP}^{+}{ }_{-} \mathrm{GAPDH}$ is primarily involved in gluconeogenesis and does not appear to play a role in generating NADPH (Schäfer and Schönheit, 1993; Koksharova et al., 1998; Fillinger et al., 2000; Brunner et al., 2001; Matsubara et al., 2011; Ito et al., 2012).

As with GAPN, the significance of $\mathrm{NADP}^{+}{ }_{-} \mathrm{GAPDH}$ as a source of NADPH has been demonstrated. Overexpression 
of $\mathrm{NADP}^{+}{ }_{-} \mathrm{GAPDH}$ or replacement of the native $\mathrm{NAD}^{+}$GAPDH with the NADP-variant improved the yield of $\mathrm{NADPH}$-dependent products such as lycopene, $\epsilon$-caprolactone, L-ornithine, or coenzyme $\mathrm{Q}_{10}$ (Martinez et al., 2008; Huang et al., 2011; Jiang et al., 2013; Wang et al., 2013c). Moreover, metabolic flux analysis of the exchange mutant revealed that the oxPPP branch and TCA fluxes were significantly reduced, presumably to avoid NADPH excess (Martinez et al., 2008). In addition, an attempt in C. glutamicum to alter the cofactor specificity of native $\mathrm{NAD}^{+}{ }_{-} \mathrm{GAPDH}$ to $\mathrm{NADP}^{+}$through protein engineering resulted in a $60 \%$ increase in lysine production (Bommareddy et al., 2014).

\section{NADP $^{+}$-dependent Glucose Dehydrogenase}

Similar to GAPN and GAPDH, other non-canonical $\mathrm{NADP}^{+}$-dependent enzymes, such as $\mathrm{NADP}^{+}$-dependent glucose dehydrogenase $\left(\mathrm{NADP}^{+}{ }_{-} \mathrm{GDH}\right)$, might make a larger contribution to NADPH generation than previously thought. Glucose dehydrogenases (GDHs, EC:1.1.1.47 and EC:1.1.1.119) are responsible for the first step of the modified ED pathways found in some archaea and bacteria (Table 1), i.e., the semiphosphorylated ED, the non-phosphorylated ED, and the branched ED pathways (Figure 5) (Brasen et al., 2014).
GDHs are responsible for a main difference between modified ED pathways and the classical ED pathway. GDHs catalyze the direct oxidation of glucose into gluconolactone. In contrast, in the classical ED, glucose is phosphorylated before its oxidation into 6-P-gluconolactone (Brasen et al., 2014).

$$
\begin{aligned}
& \text { L-glucose }+\mathrm{NADP}^{+} \rightarrow \text { L-glucono-1,5-lactone }+\mathrm{NADPH} \\
& \qquad+\mathrm{H}^{+} \\
& \Delta_{r} G^{\prime \mathrm{m}}=-2.4 \pm 2.2 \mathrm{~kJ} / \mathrm{mol}
\end{aligned}
$$

Two different classes of GDHs are capable of using $\mathrm{NADP}^{+}$as cofactor: EC:1.1.1.47, which shows dual cosubstrate specificity with a preference for $\mathrm{NADP}^{+}$, and EC:1.1.1.119, which is strictly dependent on $\mathrm{NADP}^{+}$. GDHs belonging to these groups have been found in extremely halophilic and thermoacidophilic archaea, as well as in bacteria such as Bacillus subtilis, Bacillus megaterium, and Gluconobacter oxydans (Pauly and Pfleiderer, 1975; Adachi and Ameyama, 1981; Lampel et al., 1986; Brasen et al., 2014).

$\mathrm{NADP}^{+}{ }_{-}$GDHs have been used for NADPH regeneration in various production systems, such as the in vitro synthesis of poly(3-hydroxybutyrate) or L-leucovorin (Eguchi et al., 1992; Satoh et al., 2003). In addition, $\mathrm{NADP}^{+}{ }_{-}$GDHs are important

\section{Classical ED pathway}

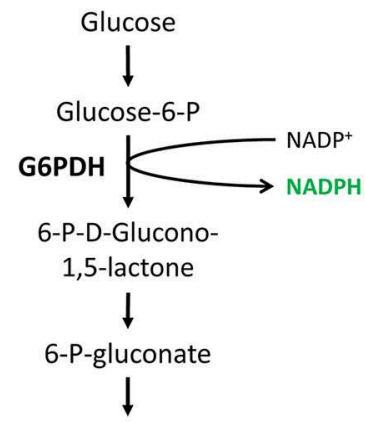

2-keto-3-deoxy-6-

phosphogluconate

\section{Modified ED pathways}

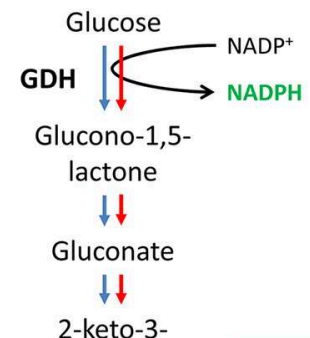

2-keto-3deoxygluconate $\downarrow$

2-keto-3-deoxy-6phosphogluconate

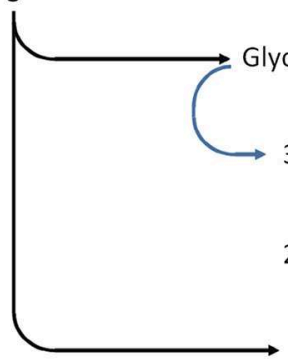

Glyceraldehyde-3-P

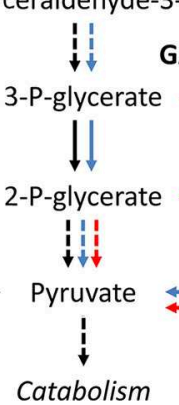

GAPN
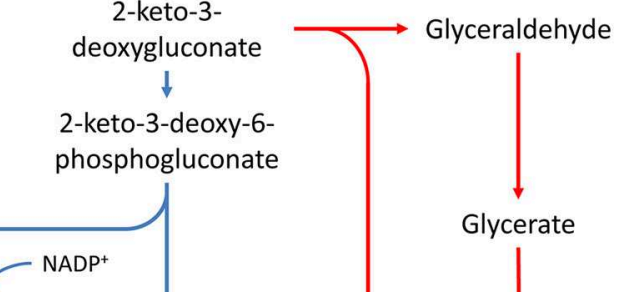

Glycerate

FIGURE 5 | Classical ED pathway compared to modified ED pathways. Solid and dashed arrows represent single and lumped enzymatic reactions, respectively. Shown are the classical ED pathway (in black), the semiphosphorylated ED pathway (in blue), the non-phosphorylated ED pathway (in red), and the branched ED pathway that includes the semi- and non-phosphorylated ED pathways. Only the glucose degradation directions are shown. Abbreviated enzymes (in bold text): G6PDH, glucose-6-phosphate dehydrogenase; GAPN, non-phosphorylating glyceraldehyde-3-phosphate dehydrogenase; GDH, glucose dehydrogenase. 
components of many commercial glucose-sensing assays. As such, they have been utilized for blood glucose monitoring (Ferri et al., 2011). Moreover, $\mathrm{NADP}^{+}{ }_{-}$GDHs have also been used as NADPH regenerators in various whole-cell, or in vivo, production systems. The GDHs of B. megaterium and B. subtilis, for example, have been expressed in several $E$. coli strains for the synthesis of various products, including indigo, $S$-sulfoxide, and ethyl (R/S)-4-chloro-3-hydroxybutanoate (Kataoka et al., 1998, 1999; Kizaki et al., 2001; Yun et al., 2005; Lu and Mei, 2007; Xu et al., 2007; Park et al., 2010; Zhang et al., 2011).

\section{NADPH-generating Reactions Not Coupled to Carbon Metabolism}

\section{Transhydrogenases}

Pyridine nucleotide transhydrogenase $(\mathrm{TH})$ directly catalyzes the reversible hydride transfer between $\mathrm{NAD}(\mathrm{H})$ and $\mathrm{NADP}(\mathrm{H})$. There are two different isoforms: the energy-independent soluble transhydrogenase (STH, EC:1.6.1.1) and the energy-dependent, or proton-translocating, membrane-bound transhydrogenase $\left(\mathrm{H}^{+}-\mathrm{TH}, \mathrm{EC}: 1.6 .1 .2\right)$ (Figure 6). Soluble transhydrogenases from Gammaproteobacteria such as Escherichia coli, Azotobacter vinelandii, Pseudomonas fluorescens, and Pseudomonas aeruginosa have been studied in some detail (Cohen and Kaplan,

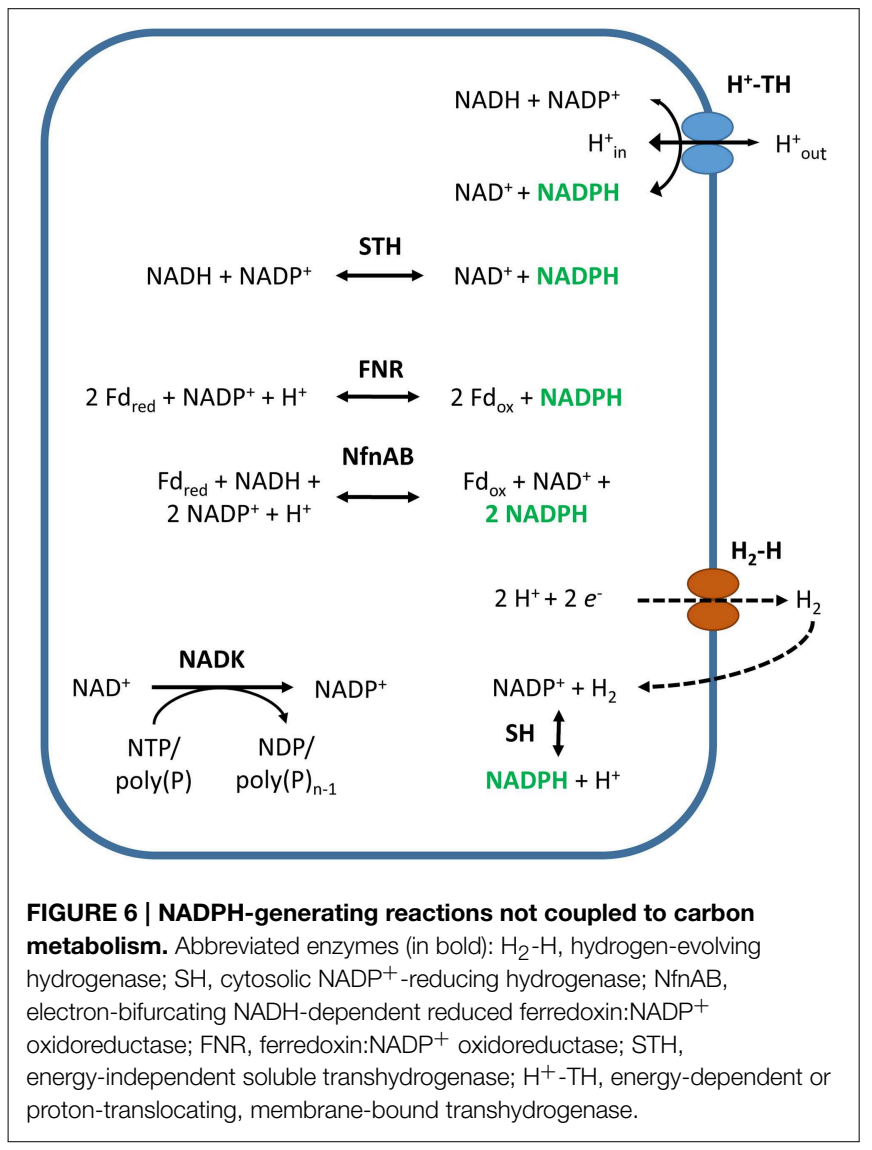

1970; Voordouw et al., 1979; French et al., 1997; Boonstra et al., 1999). In contrast, proton-translocating, membrane-bound transhydrogenases have been investigated extensively, reviewed in (Bizouarn et al., 2000, 2002; Jackson, 2003, 2012; Pedersen et al., 2008; Jackson and Obiozo, 2009; Lee et al., 2013b). They are widely distributed in the mitochondria of eukaryotes and in certain bacteria, but are very rare in archaea (Table 1) (Jackson and Obiozo, 2009; Jackson, 2012). Bacteria with multiple copies of the transhydrogenase genes are not uncommon, and some species, particularly among the Enterobacteriaceae, contain both isoforms (Sauer et al., 2004).

The two transhydrogenase isoforms transfer electrons between $\mathrm{NAD}(\mathrm{H})$ and $\mathrm{NADP}(\mathrm{H})$ in the following reaction:

$$
\begin{aligned}
& \mathrm{NADH}+\mathrm{NADP}^{+} \leftrightarrow \mathrm{NAD}^{+}+\mathrm{NADPH} \\
& \Delta_{r} G^{\prime \mathrm{m}}=1.0 \pm 0.7 \mathrm{~kJ} / \mathrm{mol}
\end{aligned}
$$

However, in contrast to STHs, $\mathrm{H}^{+}-\mathrm{TH}$ s couple the electron transfer reaction to the translocation of a proton across the membrane, according to the reaction:

$$
\mathrm{H}_{\text {out }}^{+}+\mathrm{NADH}+\mathrm{NADP}^{+} \leftrightarrow \mathrm{H}_{\text {in }}^{+}+\mathrm{NAD}^{+}+\mathrm{NADPH}
$$

Where "out" and "in" denote the periplasmic space and cytosol, respectively. Although the reaction is in principle reversible, the electrochemical proton gradient $(\Delta p)$ across the membrane under most physiological conditions strongly favors NADPH formation (Hoek and Rydstrom, 1988; Bizouarn et al., 2000; Jackson, 2003; Pedersen et al., 2008).

Since the discovery of transhydrogenases, there has been much debate about their physiological role (Bragg et al., 1972; Voordouw et al., 1983; Harold, 1986; Hoek and Rydstrom, 1988; Jackson et al., 1998; Pedersen et al., 2008). Given the type of reaction they catalyze, transhydrogenases might play an important role in maintaining the redox balance within microorganisms. Various studies have shown that several bacterial species require STH for growth under metabolic conditions with excess NADPH formation (Canonaco et al., 2001; Hua et al., 2003; Sauer et al., 2004; Zhao et al., 2008; Fuhrer and Sauer, 2009). Moreover, mutant bacteria suffering from a disturbed redox balance due to an increased NADPH concentration often benefit from the heterologous expression of STH (Boonstra et al., 2000; Angermayr et al., 2012; Qi et al., 2014; Reddy et al., 2015). These observations support the idea that the physiological role of STH is to convert NADPH into $\mathrm{NADH}$ to prevent an excess of NADPH (Voordouw et al., 1983), a notion that is generally accepted and is supported by actual $\mathrm{NAD}^{+} / \mathrm{NADH}$ and $\mathrm{NADP}^{+} / \mathrm{NADPH}$ ratios (see above), which indicate that the formation of NADPH from NADH will generally require energy input.

However, Sanchez et al. have reported that the NADPHrequiring production of poly(3-hydroxybutyrate) in E. coli benefitted from the overexpression of STH (Sanchez et al., 2006). This result is contrary to the generally accepted physiological role of STH and suggests that the enzyme catalyzes the opposite reaction. Moreover, recent reports have shown that STH is 
able to catalyze the opposite reaction and that overexpression of the enzyme can improve NADPH-dependent production yields (Lee et al., 2010; Decorosi et al., 2011; Jan et al., 2013; He et al., 2014). Additionally, although STH disruption and overexpression mutants often have disturbed or improved redox balances, respectively, similar mutants that do not show any effect have also been described (Chin et al., 2009; Yamauchi et al., 2014). Together, these examples show that we have yet to achieve a thorough understanding of the physiological role of STH and that its role is strongly dependent on species, culture conditions, and genotypes.

Similarly, the physiological role of $\mathrm{H}^{+}-\mathrm{TH}$ has been debated in the literature. It has often been reported that the $\mathrm{H}^{+}-\mathrm{TH}$ isoform is a major source of NADPH, needed for the biosynthesis of amino acids, for example, or the reduction of glutathione (required to minimize oxidative damage caused by free radicals generated in the respiratory chain) (Bragg et al., 1972; Voordouw et al., 1983; Hoek and Rydstrom, 1988; Hickman et al., 2002; Hua et al., 2003; Sauer et al., 2004; Fuhrer and Sauer, 2009; Imam et al., 2013; He et al., 2014). In E. coli, $\mathrm{H}^{+}-\mathrm{TH}$ has been shown to provide about $40 \%$ of the total NADPH during growth on glucose in batch cultures (Sauer et al., 2004). Moreover, its expression is induced when there is demand for NADPH, and it is required for optimal growth on carbon sources whose metabolism does not directly generate NADPH (Sauer et al., 2004; Imam et al., 2013). Additionally, Fuhrer and Sauer calculated that it is very unlikely, from a thermodynamic point of view, that $\mathrm{H}^{+}$THs catalyze NADPH oxidation. They concluded that the $\mathrm{NADP}^{+}$reduction catalyzed by $\mathrm{H}^{+}-\mathrm{TH}$ is irreversible under physiological conditions in various bacterial species (Fuhrer and Sauer, 2009). Reports such as these contribute to the general view that the physiological role of $\mathrm{H}^{+}-\mathrm{TH}$ is reduction of $\mathrm{NADP}^{+}$ at the expense of NADH. However, other reports suggest that $\mathrm{H}^{+}-\mathrm{TH}$ catalyzes the opposite reaction or show that disruption or overexpression has no measurable effect (Chin et al., 2009; Jan et al., 2013; Yamauchi et al., 2014).

THs require the cofactors $\mathrm{NAD}(\mathrm{H})$ and $\mathrm{NADP}(\mathrm{H})$ for activity. In addition, and in contrast to $\mathrm{H}^{+}-\mathrm{THs}$, STHs also require a flavin (flavin adenine dinucleotide, FAD) cofactor (Middleditch et al., 1972; Boonstra et al., 1999; Cao et al., 2011). THs generally do no required other cofactors or metal ions. In fact, metal ions have even been reported to inhibit $\mathrm{TH}$ activity (Whitehead et al., 2005, 2009; Cao et al., 2011). Nevertheless, submillimolar concentrations of $\mathrm{Ca}^{2+}$ and $\mathrm{Mg}^{2+}$ have been reported to stimulate the $\mathrm{H}^{+}$-THs of Rhodobacter capsulatus and E. coli (Cotton et al., 1989; Lever et al., 1991; Chang et al., 1992). Similarly, saturating concentrations of $\mathrm{Ca}^{2+}$ have been reported to release the phosphate-induced inhibition of the $\mathrm{NADP}^{+}$ reducing reaction and to cause full activation of the enzyme in Azotobacter vinelandii and Pseudomonas aeruginosa, respectively (Hojeberg and Rydstrom, 1977; Voordouw et al., 1980).

Because of their ability to generate NADPH, STHs and $\mathrm{H}^{+}$THs have been overexpressed to improve the production yields of NADPH-dependent metabolites. For example, overexpression of STH increased NADPH-dependent poly(3-hydroxybutyrate) production by $82 \%$ in an engineered E. coli strain (Sanchez et al., 2006). Moreover, the overexpression of STH in two other engineered E. coli strains increased (S)-2-chloropropionate and thymidine production 150 and $100 \%$, respectively (Lee et al., 2010; Jan et al., 2013). Similarly, overexpression of $\mathrm{H}^{+}$-TH has significantly improved the yields of various NADPHdependent products, such as chiral alcohols, isobutanol, and 3hydroxypropionic acid in E. coli (Weckbecker and Hummel, 2004; Bastian et al., 2011; Rathnasingh et al., 2012; Shi et al., 2013) and L-valine and L-lysine in C. glutamicum (Kabus et al., 2007; Bartek et al., 2011).

\section{Ferredoxin:NADP ${ }^{+}$Oxidoreductase}

Ferredoxin:NADP ${ }^{+}$oxidoreductases (FNRs, EC:1.18.1.2) are ubiquitous flavoenzymes (Table 1) that catalyze the reversible transfer of reducing equivalents between the one-electron carrier ferredoxin (Fd) and the two-electron carrying $\operatorname{NADP}(\mathrm{H})$, according to the following reaction (Figure 6):

$$
\begin{aligned}
& 2 \mathrm{Fd}_{\mathrm{red}}+\mathrm{NADP}^{+}+\mathrm{H}^{+} \leftrightarrow 2 \mathrm{Fd}_{\mathrm{ox}}+\mathrm{NADPH} \\
& \Delta_{r} G^{\prime \mathrm{m}}=-15.6 \pm 11.7 \mathrm{~kJ} / \mathrm{mol}
\end{aligned}
$$

FNRs are present in all three domains of life (Ma and Adams, 2001a; Ceccarelli et al., 2004; Santangelo et al., 2011; Yan et al., 2014). They are mainly known for their essential role in photosynthetic organisms (plants, algae, and cyanobacteria), in which they connect the $\mathrm{Fd}_{\text {red-generating reactions of }}$ photosynthesis to NADPH-requiring carbon assimilation (Shin and Arnon, 1965; Goss and Hanke, 2014). In addition to enabling the flux of electrons from the photosystem into other metabolic pathways, FNRs might also avert this efflux of electrons and mediate the return of Fd-bound electrons to the plastoquinone pool of the photosynthetic system. By doing so, FNRs contribute to the so-called cyclic electron flow, which is essential for balancing the ATP/NADPH ratio generated by the photosystems (Munekage et al., 2004; Shikanai, 2007; Kramer and Evans, 2011; Mulo, 2011; Goss and Hanke, 2014).

In non-photosynthetic tissues and organisms, FNRs participate in the electron transfer chains of various other metabolic processes such as nitrogen fixation, sulfate assimilation, isoprenoid biosynthesis, osmotic and oxidative stress responses, and iron-sulfur cluster biogenesis (Arakaki et al., 1997; Krapp et al., 2002; Seeber et al., 2005; Giro et al., 2006; Lee et al., 2007b; Balconi et al., 2009; Tang et al., 2010; Lewis et al., 2013). However, in contrast to the FNRs involved in photosynthesis, the physiological direction of FNRs involved in these processes is toward the production of $\mathrm{Fd}_{\text {red }}$. As a result, FNRs are sometimes classified as autotrophic (all photosynthetic FNRs) and heterotrophic (all other FNRs) (Arakaki et al., 1997), which, from a protein-family point of view, is not entirely correct.

FNRs are generally classified into two phylogenetically and structurally unrelated protein families that are subdivided into four subclasses: the plant-type FNRs comprising the plastidictype and bacterial-type subclasses and the glutathione (GR)-type FNRs comprising the mitochondrial adrenodoxin reductases (AdR-like) and oxygenase-coupled NADH:ferredoxin reductases (ONFR-like) (Carrillo and Ceccarelli, 2003; Ceccarelli et al., 2004; Karplus and Faber, 2004; Aliverti et al., 2008; Musumeci et al., 
2012). In addition, a third type of FNR has been reported, the so-called thioredoxin reductase-like FNR (TRLF), which functions as an FNR but has structural homology to NADPHdependent thioredoxin reductases (Seo and Sakurai, 2002; Seo et al., 2004; Komori et al., 2010; Muraki et al., 2010; Yan et al., 2014). Interestingly, a novel type of FNR has recently been reported, the electron-bifurcating $\mathrm{NADH}$-dependent reduced ferredoxin:NADP ${ }^{+}$oxidoreductase $(\mathrm{NfnAB})$, which couples the exergonic reduction of $\mathrm{NADP}^{+}$with $\mathrm{Fd}_{\text {red }}$ and the endergonic reduction of $\mathrm{NADP}^{+}$with $\mathrm{NADH}$ in a reversible reaction (reaction 11 and Figure 6) (Wang et al., 2010; Huang et al., 2012; Rydzak et al., 2014). Genome analyses have revealed the $N f n A B$ genes are present in many anaerobic bacteria and archaea (Huang et al., 2012; Buckel and Thauer, 2013), a finding that might reflect the importance of a postulated $\mathrm{NfnAB}$ function: $\mathrm{NfnAB}$ and other electron-bifurcating reactions have been implicated as a third mode of energy conservation, in addition to substrate level phosphorylation and electron transport phosphorylation (Buckel and Thauer, 2013).

$$
\begin{aligned}
\mathrm{Fd}_{\text {red }}+\mathrm{NADH}+2 \mathrm{NADP}^{+}+\mathrm{H}^{+} \leftrightarrow & \mathrm{Fd}_{\mathrm{ox}}+\mathrm{NAD}^{+} \\
& +2 \mathrm{NADPH}
\end{aligned}
$$

Despite what the names imply, both subdivisions of the planttype FNRs (plastidic-type and bacterial-type) as well as FNRs of the GR-type, TRLF-type, and "NfnAB-type" are found in prokaryotes (Ceccarelli et al., 2004; Aliverti et al., 2008; Komori et al., 2010). Unfortunately, the literature does not always make clear the class to which an FNR belongs, generating confusion and making it difficult to judge the true NADPH-generating potential of FNRs found in different prokaryotes. Nevertheless, under normal physiological conditions, it appears that only the plastidic-type FNRs, found in cyanobacteria, for example, and the novel "NfnAB-type" have significant effects on NADPH availability in prokaryotes.

The reaction catalyzed by the different FNR types is in principle reversible, as demonstrated by various in vitro studies, as well as by in vivo studies in cyanobacteria and the thermophilic bacterium Hydrogenobacter thermophilus TK-6. Cyanobacteria contain a single FNR that is responsible for $\mathrm{NADP}^{+}$reduction in vegetative cells as well as for Fd reduction in heterocysts (Razquin et al., 1996). A similar situation exists in H. thermophilus TK6, where a single FNR catalyzes either the forward or reverse reaction depending on the specific type of $\mathrm{Fd}$ involved in the reaction. A [4Fe-4S]-containing $\mathrm{Fd}$ is involved in the forward $\left(\mathrm{NADP}^{+}\right.$reducing) reaction, whereas a $[2 \mathrm{Fe}-2 \mathrm{~S}]$-containing $\mathrm{Fd}$ is involved in the reverse reaction (Ikeda et al., 2009). Such insights might facilitate the development of rational engineering approaches aimed at gaining directional control of the reaction. Elucidating the reaction mechanisms of various FNR-types is a topic of many studies and has been reviewed extensively (Arakaki et al., 1997; Onda et al., 2000; Aliverti et al., 2001, 2008; Carrillo and Ceccarelli, 2003; Medina and Gomez-Moreno, 2004; Martinez-Julvez et al., 2009; Yeom et al., 2009; Musumeci et al., 2012).

FNRs, in general, contain a non-covalently bound flavin (FAD) cofactor as a prosthetic group, but a flavin mononucleotide (FMN)-containing FNR has also been characterized (Ikeda et al., 2009). The FAD group can alternate between an oxidized, one-electron-reduced semiquinone and a fully reduced hydroquinone state, thereby mediating the reversible electron change between the one-electron carrier $\mathrm{Fd}$ and the two-electron carrying $\mathrm{NADP}(\mathrm{H})$ (Carrillo and Ceccarelli, 2003). The iron-sulfur-containing Fd can sometimes be substituted by the flavin mononucleotide (FMN)-containing flavodoxin (under iron-depleted conditions in some bacteria) or, in the case of the GR-type FNRs, by the mitochondrial ironsulfur-containing adrenodoxin (Yamazaki and Ichikawa, 1990; Ceccarelli et al., 2004; Sancho, 2006; Ewen et al., 2011). Moreover, a novel rubrerythrin-like protein, named ferriperoxin (Fpx), has been described that exhibits NADPH- and FNR-dependent peroxidase activity in the thermophilic hydrogen-oxidizing bacterium $H$. thermophilus (Sato et al., 2012). Whereas most FNRs are NADP $(\mathrm{H})$-dependent, an $\mathrm{NAD}(\mathrm{H})$-dependent variant also exists, the ONFR-like subtype of the GR-type FNRs (EC:1.18.1.3) (Aliverti et al., 2008). However, because this group of FNRs is not involved in NADPH availability, it will not be discussed further in this review.

\section{NADP $^{+}$-dependent Hydrogenase}

Hydrogenases $\left(\mathrm{H}_{2}\right.$ ases $)$ are metalloenzymes that catalyze the reversible oxidation of hydrogen gas into two protons and two electrons:

$$
\mathrm{H}_{2} \leftrightarrow 2 \mathrm{H}^{+}+2 e^{-}
$$

$\mathrm{H}_{2}$ ases enable organisms to utilize $\mathrm{H}_{2}$ as a source of reducing power or to use protons as terminal electron acceptors, generating $\mathrm{H}_{2}$. According to the metal atoms at their active site, $\mathrm{H}_{2}$ ases can be classified into three types: $[\mathrm{NiFe}]-\mathrm{H}_{2}$ ases, $[\mathrm{FeFe}]-\mathrm{H}_{2}$ ases, and $[\mathrm{Fe}]-\mathrm{H}_{2}$ ases. The latter were formerly known as metal-free or iron-sulfur-free $\mathrm{H}_{2}$ ases; they are involved in $\mathrm{CO}_{2}$ reduction with $\mathrm{H}_{2}$ to methane and are only found in methanogenic archaea (Lyon et al., 2004; Vignais and Colbeau, 2004; Shima and Thauer, 2007; Trchounian et al., 2012; Trchounian and Gary Sawers, 2014; Peters et al., 2015). [NiFe] $-\mathrm{H}_{2}$ ases are generally responsible for $\mathrm{H}_{2}$ oxidation and are widely distributed among both aerobic and anaerobic bacteria and archaea; they have been identified in 28.9 and $57.8 \%$ of the available complete bacterial and archaeal genomes, respectively. [FeFe]- $\mathrm{H}_{2}$ ases, in contrast, are generally responsible for $\mathrm{H}_{2}$ evolution and are only found in anaerobic bacteria; they have been identified in $9.8 \%$ of the available complete bacterial genomes (Peters et al., 2015). Alignment of the sequence motifs that coordinate the active site, separates $[\mathrm{NiFe}]-\mathrm{H}_{2}$ ases into at least four, and possibly five, functional groups that are, in general, consistent with the physiological roles of the enzymes (Vignais et al., 2001; Vignais and Colbeau, 2004; Vignais and Billoud, 2007; Peters et al., 2015). Thus, $\mathrm{H}_{2}$ ases are a diverse group of enzymes. They are cytosolic or membrane bound, involved in $\mathrm{H}_{2}$ oxidation and/or evolution, and able to use a variety of electron acceptors and donors. It is beyond the scope of this review to address all of the different types of $\mathrm{H}_{2}$ ases. We will focus on those involved in NADPH generation in prokaryotes. For more information 
about $\mathrm{H}_{2}$ ases in general, the reader is referred to various excellent reviews, such as those by Vignais and Colbeau (2004), Shima and Thauer (2007), and Peters et al. (2015).

$\mathrm{H}_{2}$ ases that use the cofactor $\mathrm{NADP}^{+}$as an electron acceptor are not common, but have been identified in some bacteria and archaea (Table 1). Cytosolic $\mathrm{NADP}^{+}$-reducing hydrogenases (EC:1.12.1.3, SH) are present in the sulfate-reducing bacterium Desulfovibrio fructosovorans and the hyperthermophilic archaea Pyrococcus furiosus and Thermococcus kodakarensis (Malki et al., 1995; Kanai et al., 2003; Nouailler et al., 2006; Van Haaster et al., 2008). Moreover, cytosolic bidirectional $\mathrm{NAD}(\mathrm{P})^{+}-\mathrm{H}_{2}$ ases and a membrane-bound $\mathrm{NAD}(\mathrm{P})^{+}-\mathrm{H}_{2}$ ase, known to use both $\mathrm{NAD}^{+}$ and $\mathrm{NADP}^{+}$as substrates, have been found in cyanobacteria and Klebsiella pneumonia, respectively (Steuber et al., 1999; Schmitz et al., 2002; Wells et al., 2011). Many of these $\mathrm{H}_{2}$ ases recycle the $\mathrm{H}_{2}$ produced by $\mathrm{H}_{2}$-evolving $\mathrm{H}_{2}$ ases by coupling the oxidation of $\mathrm{H}_{2}$ to the reduction of $\mathrm{NADP}^{+}$(Figure 6) (Steuber et al., 1999; Silva et al., 2000; Van Haaster et al., 2008; Kanai et al., 2011; Santangelo et al., 2011; Schut et al., 2012), according to the following reaction:

$$
\begin{aligned}
& \mathrm{H}_{2}+\mathrm{NADP}^{+} \leftrightarrow \mathrm{H}^{+}+\mathrm{NADPH} \\
& \Delta_{r} G^{\prime \mathrm{m}}=-16.5 \pm 5.9 \mathrm{~kJ} / \mathrm{mol}
\end{aligned}
$$

$\mathrm{H}_{2}$ recycling might have a distinct energetic advantage because the $\mathrm{NADP}^{+}$-reducing $\mathrm{H}_{2}$ ase could provide reductant in the form of NADPH without interfering with the energy balance through electron transport phosphorylation (Schut et al., 2012). However, various studies have shown that disruption of $\mathrm{NADP}^{+}$-reducing $\mathrm{H}_{2}$ ases has minor effects, suggesting that the role of the enzymes is not that important for overall growth (Casalot et al., 2002; Kanai et al., 2011; Lipscomb et al., 2011; Santangelo et al., 2011; Schut et al., 2012; Lauterbach et al., 2013).

Like most $\mathrm{H}_{2}$ ases, $\mathrm{NADP}^{+}$-reducing $\mathrm{H}_{2}$ ases require metal ions and cofactors for their activity. They contain multiple ironsulfur clusters ([Fe-S]), which are coordinated in the active site by carbon monoxide $(\mathrm{CO})$ and cyanide $\left(\mathrm{CN}^{-}\right)$groups. Moreover, various $\mathrm{H}_{2}$ ases capable of reducing $\mathrm{NADP}^{+}$belong to the [NiFe]$\mathrm{H}_{2}$ ases, making the availability of $\mathrm{Ni}$ essential as well (Ma and Adams, 2001b; Kanai et al., 2003; Germer et al., 2009; Peters et al., 2015). In addition, the enzymes have been reported to contain flavin cofactors: FAD in the case of T. kodakarensis and P. furiosus (Ma et al., 2000; Ma and Adams, 2001b; Kanai et al., 2003) and FMN in the case of D. fructosovorans (Malki et al., 1995).

The requirement for these different ligands, metals, and cofactors makes the biosynthesis of multisubunit $\mathrm{H}_{2}$ ases a complex and dynamic process, involving various maturation proteins (Bock et al., 2006; Forzi and Sawers, 2007; Watanabe et al., 2012; Peters et al., 2015). It is thus no surprise that reports about the practical applications of $\mathrm{NADP}^{+}$-reducing $\mathrm{H}_{2}$ ases for NADPH generation are limited. Nevertheless, the potential of these enzymes to improve the production yields of NADPH-dependent metabolites has been demonstrated. For example, two prochiral model substrates, acetophenone and (2S)-hydroxy-1-phenyl-propanone, were quantitatively reduced to the corresponding $(S)$-alcohol and $(1 R, 2 S)$-diol by an
$\mathrm{NADPH}$-dependent alcohol dehydrogenase in an in vitro system containing $\mathrm{H}_{2}$ and the partially purified $\mathrm{NADP}^{+}$-reducing $\mathrm{H}_{2}$ ase of P. furiosus (Mertens et al., 2003). Although in vitro examples like this demonstrate the potential of $\mathrm{NADP}^{+}-\mathrm{H}_{2}$ ases, expression of heterologous $[\mathrm{NiFe}]-\mathrm{H}_{2}$ ases outside of a closely related host is still challenging (English et al., 2009). It often results in an inactive enzyme or activity that is detectable only in vitro (Voordouw et al., 1987; Grzeszik et al., 1997; Sun et al., 2010). Nevertheless, successful expression of heterologous $[\mathrm{NiFe}]-\mathrm{H}_{2}$ ase has been reported (Wells et al., 2011).

\section{NAD ${ }^{+}$Kinase and NADH Kinase}

$\mathrm{NAD}^{+}$kinase (NADK, EC:2.7.1.23) catalyzes the conversion of $\mathrm{NAD}^{+}$to $\mathrm{NADP}^{+}$. It is the sole enzyme leading to de novo $\mathrm{NADP}^{+}$biosynthesis (Figures 1, 6). As such, NADK is essential for $\mathrm{NADP}^{+}$and NADPH availability. Together with $\mathrm{NADP}^{+}$phosphatase (NADPase), which is thought to catalyze the opposite reaction (the conversion of $\mathrm{NADP}^{+}$to $\mathrm{NAD}^{+}$), NADK is crucial for the regulation of the intracellular balance of $\operatorname{NAD}(\mathrm{H})$ and $\operatorname{NADP}(\mathrm{H})$ (Kawai and Murata, 2008; Shi et al., 2009). Although NADPase activity has been detected in various organisms (Reidl et al., 2000; Kawai et al., 2004), to our knowledge, no enzyme that functions solely as an NADPase has been isolated to date. However, some enzymes that exhibit NADPase activity in addition to another activity have been isolated, such as the bifunctional $\mathrm{NADP}^{+}$phosphatase/NAD ${ }^{+}$ kinase, discovered in the archaeon Methanococcus jannaschii (Kawai et al., 2005; Fukuda et al., 2007).

NADK activity was enriched in extracts from the yeast Saccharomyces cerevisiae for the first time in 1950 (Kornberg, 1950) and has since been purified from various organisms (Mcguinness and Butler, 1985; Magni et al., 1999). However, it was not until 2000 that the gene encoding NADK was identified by Kawai et al. in Micrococcus flavus and Mycobacterium tuberculosis H37Rv (Kawai et al., 2000). Since then, NADKs from various organisms have been studied in detail, and although the exact physiological functions, related pathways, and regulatory mechanisms have not always clearly been elucidated, some reviews of NADK structure, function, and potential applications are available (Magni et al., 2006; Pollak et al., 2007; Kawai and Murata, 2008; Shi et al., 2009; Agledal et al., 2010).

NADKs are ubiquitous enzymes (Table 1). Homologs, according to literature, can be found in almost all eukaryotes and prokaryotes, with the exception of the intracellular parasite Chlamydia trachomatis (Grose et al., 2006; Kawai and Murata, 2008; Szaszák et al., 2011). The discrepancy between the distribution shown in Table 1 and that described in the literature might reflect the rapidly increasing availability of prokaryotic genomes and errors inherent to automated genome annotation (Bakke et al., 2009). Functionally and structurally, NADKs are weakly related to other kinases, suggesting that they belong to a kinase superfamily (Labesse et al., 2002). With the exception of the NADKs of gram-negative bacteria, the enzymes accept $\mathrm{NAD}^{+}$and its reduced form, NADH (Kawai and Murata, 2008). Nevertheless, they are generally referred to as $\mathrm{NAD}^{+}$kinases (EC:2.7.1.23) because they usually have a strong preference for the oxidized form. NADKs with a preference for the reduced 
form exist as well (EC:2.7.1.86) (Outten and Culotta, 2003; Strand et al., 2003; Turner et al., 2005), but have not to our knowledge been found in prokaryotes.

Aside from $\mathrm{NAD}(\mathrm{H})$, NADKs also need a phosphoryl donor for catalysis. The preferred phosphoryl donor often is a nucleoside triphosphate, particularly ATP, but many bacterial and archaeal NADKs can also utilize the ancient inorganic energy carrier poly(P) (Kawai et al., 2000, 2005; Garavaglia et al., 2003; Sakuraba et al., 2005). In addition, some bacterial enzymes can utilize ADP or glucose-6-phosphate (Bark et al., 1993; Lindner et al., 2010). However, the use of glucose-6-phosphate as a phosphoryl donor has not been investigated further. Finally, NADKs often also require divalent cations such as $\mathrm{Mg}^{2+}, \mathrm{Mn}^{2+}$, $\mathrm{Zn}^{2+}$, or $\mathrm{Ca}^{2+}$ for their activity (Kawai et al., 2000, 2001; Garavaglia et al., 2003; Sakuraba et al., 2005). The NADK of Corynebacterium glutamicum, however, does not require divalent cations when using ATP as phosphoryl donor, but the enzyme is stimulated in their presence. When using poly $(\mathrm{P})$ as phosphoryl donor, divalent cations are required for activity (Lindner et al., 2010).

According to the phosphoryl donor specificity, NADK orthologs are subdivided into several types. The classification typically applied divides the NADK orthologs into: (I) poly(P)/ATP NADKs, which can use poly(P) and ATP as phosphoryl donors and (II) ATP NADKs, which are specific for ATP (Mori et al., 2005; Nakamichi et al., 2013). Poly(P)/ATP NADKs have been identified in gram-positive bacteria such as Mycobacterium tuberculosis, Micrococcus flatus, and Bacillus subtilis (Kawai et al., 2000; Garavaglia et al., 2003) and in archaea such as Methanococcus jannaschii and Pyrococcus horikoshii (Kawai et al., 2005; Sakuraba et al., 2005). ATP NADKs have been found in gram-negative $\alpha$ - and $\gamma$-Proteobacteria such as Sphingomonas sp. A1, Salmonella enterica, and E. coli and in eukaryotes (Kawai et al., 2001; Ochiai et al., 2004; Grose et al., 2006; Nakamichi et al., 2013). A slightly different classification system is sometimes applied, dividing the NADK orthologs into: (I) ATP NADKs, which are strictly dependent on ATP, (II) NTP NADKs, which use ATP in addition to other nucleoside triphosphates, and (III) poly(P)/NTP NADKs, which use nucleoside triphosphates and poly(P) (Shi et al., 2009). The existence of these slightly different classification systems can make it difficult to ascertain the type of NADK being discussed. However, because no strict ATP NADKs (as defined in the latter system) have been identified in prokaryotes to date, it is not an issue in this review. The reaction catalyzed by NADKs can be described as either:

$\mathrm{NAD}^{+}+$nucleoside triphosphate (NTP, preferably ATP) $\rightarrow$

$$
\mathrm{NADP}^{+}+\mathrm{NDP}
$$

or

$$
\mathrm{NAD}^{+}+\mathrm{NTP} / \operatorname{poly}(\mathrm{P}) \rightarrow \mathrm{NADP}^{+}+\mathrm{NDP} / \operatorname{poly}(\mathrm{P})_{\mathrm{n}-1}
$$

NADK is the sole enzyme leading to de novo $\mathrm{NADP}^{+}$ biosynthesis. It has a central role in the regulation of the $\mathrm{NAD}(\mathrm{H}) / \mathrm{NADP}(\mathrm{H})$ balance because it can directly phosphorylate $\mathrm{NADH}$ to form NADPH or cooperate with various $\mathrm{NADP}^{+}$reducing enzymes to form $\mathrm{NAD}(\mathrm{H}) / \mathrm{NADP}(\mathrm{H})$ metabolic networks that ultimately convert NADH into NADPH (Singh et al., 2007, 2008; Shi et al., 2009). In view of the importance of NADK, it is not surprising that disruption of NADK is lethal in various prokaryotes (Gerdes et al., 2002; Thanassi et al., 2002; Kobayashi et al., 2003; Sassetti et al., 2003; Zalacain et al., 2003; Grose et al., 2006; Poncet-Montange et al., 2007).

Because of its essential role in $\mathrm{NADP}^{+}$biosynthesis and the regulation of the $\mathrm{NAD}(\mathrm{H}) / \mathrm{NADP}(\mathrm{H})$ balance, NADKs have attracted attention as a potential strategy by which to improve the biosynthesis of industrially valuable metabolites. Several studies have shown that overexpression of NADKencoding genes can increase the production yields of various NADPH-dependent biosynthetic pathways, such as poly(3hydroxybutyrate) production and thymidine production in $E$. coli (Lee et al., 2009, 2010; Li et al., 2009), lysine and isoleucine production in C. glutamicum (Lindner et al., 2010; Shi et al., 2012), and arginine production in Corynebacterium crenatum (Rahman et al., 2012). These results suggest that increased $\mathrm{NADP}^{+}$availability, resulting from NADK overexpression, disturbs the intracellular redox balance, subsequently affecting the expression of $\mathrm{NADP}^{+}$-reducing enzymes (Lee et al., 2009; Li et al., 2009; Lee et al., 2010). However, a comparable attempt to improve isobutanol production in E. coli showed that NADK overexpression alone is not always sufficient and that the co(over)expression of an $\mathrm{NADP}^{+}$reducing enzyme might be required to increase NADPH availability (Shi et al., 2013). Similarly, combined overexpression of the NADK gene from $E$. coli and the $\mathrm{NADP}^{+}{ }_{-}$GAPDH gene from Bacillus subtilis in E. coli increased 2-chloropropionic acid production yield (Wang et al., 2013c). In addition to increasing NADPH availability indirectly by overexpressing NADK, a more direct approach has also been applied. For example, the production yields of GDP-L-fucose and $\varepsilon$-caprolactone in $E$. coli were increased by introducing the NADH kinase (EC:2.7.1.86) gene from the yeast $S$. cerevisiae (Lee et al., 2013a).

\section{Final Remarks and Conclusion}

$\mathrm{NADPH}$ is an essential reducing agent in all organisms. It plays an important role in various biological processes and is the driving force behind numerous biosynthetic enzymatic reactions of importance to industry. However, efficient NADPH regeneration is often a bottleneck that limits the productivity of such biotransformation processes. A thorough understanding of the reactions involved in the generation of NADPH is thus essential to increase the availability of NADPH and enhance productivity in engineered production strains.

This review has provided an overview of the major canonical NADPH-generating reactions as well as recently described NADPH-generating reactions (Table 1), and it has summarized how these different reactions have been applied to improve NADPH availability. However, additional NADPHgenerating enzymes, such as gluconate 5-dehydrogenase or the 
recently discovered $\mathrm{NADP}^{+}$-specific electron-bifurcating [FeFe]hydrogenase might also contribute to the overall NADPH supply (Klasen et al., 1995; Wang et al., 2013b). Similarly, enzymes generally considered to consume NADPH or enzymes newly developed to regenerate $\mathrm{NADPH}$, such as glutamate dehydrogenase and F420-dependent $\mathrm{NADP}^{+}$reductases or phosphite dehydrogenase, respectively, can occasionally become important NADPH suppliers (Berk and Thauer, 1997; Lee et al., 2013b; Yokooji et al., 2013).

Although various NADPH-generating enzymes have been overexpressed successfully, no general strategy that guarantees improved NADPH supply exists. Cells usually contain various integrated, network-wide, redox balancing systems, such that engineering of $\mathrm{NADPH}$-generating pathways can result in unexpected metabolic perturbations. Thus, strategies often need

\section{References}

Adachi, O., and Ameyama, M. (1981). d-Glucose dehydrogenase from Gluconobacter suboxydans: solubilization, purification and characterization. Agric. Biol. Chem. 45, 159-163.

Agledal, L., Niere, M., and Ziegler, M. (2010). The phosphate makes a difference: cellular functions of NADP. Redox Rep. 15, 2-10. doi: 10.1179/174329210X12650506623122

Ahmed, H., Ettema, T. J. G., Tjaden, B., Geerling, A. C. M., van der Oost, J., and Siebers, B. (2005). The semi-phosphorylative Entner-Doudoroff pathway in hyperthermophilic archaea: a re-evaluation. Biochem. J. 390, 529-540. doi: 10.1042/BJ20041711

Aliverti, A., Faber, R., Finnerty, C. M., Ferioli, C., Pandini, V., Negri, A., et al. (2001). Biochemical and crystallographic characterization of ferredoxin-NADP $(+)$ reductase from nonphotosynthetic tissues. Biochemistry 40, 14501-14508. doi: 10.1021/bi011224c

Aliverti, A., Pandini, V., Pennati, A., de Rosa, M., and Zanetti, G. (2008). Structural and functional diversity of ferredoxin-NADP+ reductases. Arch. Biochem. Biophys. 474, 283-291. doi: 10.1016/j.abb.2008.02.014

Amador-Noguez, D., Brasg, I. A., Feng, X. J., Roquet, N., and Rabinowitz, J. D. (2011). Metabolome remodeling during the acidogenic-solventogenic transition in Clostridium acetobutylicum. Appl. Environ. Microbiol. 77, 7984-7997. doi: 10.1128/AEM.05374-11

Andersen, K. B., and von Meyenburg, K. (1977). Charges of nicotinamide adenine nucleotides and adenylate energy charge as regulatory parameters of the metabolism in Escherichia coli. J. Biol. Chem. 252, 4151-4156.

Angermayr, S. A., Paszota, M., and Hellingwerf, K. J. (2012). Engineering a cyanobacterial cell factory for production of lactic acid. Appl. Environ. Microbiol. 78, 7098-7106. doi: 10.1128/AEM.01587-12

Aoshima, M., and Igarashi, Y. (2008). Nondecarboxylating and decarboxylating isocitrate dehydrogenases: oxalosuccinate reductase as an ancestral form of isocitrate dehydrogenase. J. Bacteriol. 190, 2050-2055. doi: 10.1128/JB.01 799-07

Aoshima, M., Ishii, M., and Igarashi, Y. (2004). A novel biotin protein required for reductive carboxylation of 2-oxoglutarate by isocitrate dehydrogenase in Hydrogenobacter thermophilus TK-6. Mol. Microbiol. 51, 791-798. doi: 10.1046/j.1365-2958.2003.03863.x

Arakaki, A. K., Ceccarelli, E. A., and Carrillo, N. (1997). Plant-type ferredoxinNADP+ reductases: a basal structural framework and a multiplicity of functions. FASEB J. 11, 133-140.

Arnér, E. S. J., and Holmgren, A. (2000). Physiological functions of thioredoxin and thioredoxin reductase. Eur. J. Biochem. 267, 6102-6109. doi: 10.1046/j.14321327.2000.01701.x

Arutyunov, D., Schmalhausen, E., Orlov, V., Rahuel-Clermont, S., Nagradova, N., Branlant, G., et al. (2013). An unusual effect of NADP+ on the thermostability of the nonphosphorylating glyceraldehyde-3-phosphate dehydrogenase from to be optimized individually, taking the culture conditions and genetic background of the strains into consideration. Future research involving a systems biology approach is thus required to improve our understanding of the individual NADPH-generating enzymes and their effect on various metabolic backgrounds, in order to predict which approaches will increase NADPH availability in various biotransformation processes.

\section{Acknowledgments}

This work is part of the Open Programme ("Biological hydrogen production beyond current limits" file number 820.02.011), which is financed by the Netherlands Organisation for Scientific Research (NWO).
Streptococcus mutans. Biochem. Cell Biol. 91, 295-302. doi: 10.1139/bcb-20120104

Asadollahi, M. A., Maury, J., Patil, K. R., Schalk, M., Clark, A., and Nielsen, J. (2009). Enhancing sesquiterpene production in Saccharomyces cerevisiae through in silico driven metabolic engineering. Metab. Eng. 11, 328-334. doi: 10.1016/j.ymben.2009.07.001

Bakke, P., Carney, N., Deloache, W., Gearing, M., Ingvorsen, K., Lotz, M., et al. (2009). Evaluation of three automated genome annotations for Halorhabdus utahensis. PLoS ONE 4:e6291. doi: 10.1371/journal.pone.00 06291

Balconi, E., Pennati, A., Crobu, D., Pandini, V., Cerutti, R., Zanetti, G., et al. (2009). The ferredoxin-NADP+ reductase/ferredoxin electron transfer system of Plasmodium falciparum. FEBS J. 276, 3825-3836. doi: 10.1111/j.17424658.2009.07100.x

Banerjee, S., Nandyala, A., Podili, R., Katoch, V., and Hasnain, S. (2005). Comparison of Mycobacterium tuberculosis isocitrate dehydrogenases (ICD1 and ICD-2) reveals differences in coenzyme affinity, oligomeric state, $\mathrm{pH}$ tolerance and phylogenetic affiliation. BMC Biochem. 6, 1-14. doi: 10.1186/1471-2091-6-20

Bark, K., Kampfer, P., Sponner, A., and Dott, W. (1993). Polyphosphate-dependent enzymes in some coryneform bacteria isolated from sewage sludge. FEMS Microbiol. Lett. 107, 133-138. doi: 10.1111/j.1574-6968.1993.tb06019.x

Bartek, T., Blombach, B., Lang, S., Eikmanns, B. J., Wiechert, W., Oldiges, M., et al. (2011). Comparative 13C metabolic flux analysis of pyruvate dehydrogenase complex-deficient, L-valine-producing Corynebacterium glutamicum. Appl. Environ. Microbiol. 77, 6644-6652. doi: 10.1128/AEM.00575-11

Bastian, S., Liu, X., Meyerowitz, J. T., Snow, C. D., Chen, M. M. Y., and Arnold, F. H. (2011). Engineered ketol-acid reductoisomerase and alcohol dehydrogenase enable anaerobic 2-methylpropan-1-ol production at theoretical yield in Escherichia coli. Metab. Eng. 13, 345-352. doi: 10.1016/j.ymben.2011.02.004

Becker, J., Klopprogge, C., Herold, A., Zelder, O., Bolten, C. J., and Wittmann, C. (2007). Metabolic flux engineering of l-lysine production in Corynebacterium glutamicum-over expression and modification of G6P dehydrogenase. J. Biotechnol. 132, 99-109. doi: 10.1016/j.jbiotec.2007.05.026

Becker, J., Klopprogge, C., Schroder, H., and Wittmann, C. (2009). Metabolic engineering of the tricarboxylic acid cycle for improved lysine production by Corynebacterium glutamicum. Appl. Environ. Microbiol. 75, 7866-7869. doi: 10.1128/AEM.01942-09

Becker, J., Klopprogge, C., Zelder, O., Heinzle, E., and Wittmann, C. (2005) Amplified expression of fructose 1,6-Bisphosphatase in Corynebacterium glutamicum increases in vivo flux through the pentose phosphate pathway and lysine production on different carbon sources. Appl. Environ. Microbiol. 71, 8587-8596. doi: 10.1128/AEM.71.12.8587-8596.2005

Begley, T. P., Kinsland, C., Mehl, R. A., Osterman, A., Dorrestein, P., and Gerald Litwack, T. B. (2001). The biosynthesis of nicotinamide adenine dinucleotides in bacteria. Vitam. Horm. 61, 103-119. doi: 10.1016/s0083-6729(01)61003-3 
Beh, M., Strauss, G., Huber, R., Stetter, K.-O., and Fuchs, G. (1993). Enzymes of the reductive citric acid cycle in the autotrophic eubacterium Aquifex pyrophilus and in the archaebacterium Thermoproteus neutrophilus. Arch. Microbiol. 160, 306-311. doi: 10.1007/BF00292082

Bennett, B. D., Kimball, E. H., Gao, M., Osterhout, R., Van Dien, S. J., and Rabinowitz, J. D. (2009). Absolute metabolite concentrations and implied enzyme active site occupancy in Escherichia coli. Nat. Chem. Biol. 5, 593-599. doi: 10.1038/nchembio. 186

Berk, H., and Thauer, R. K. (1997). Function of coenzyme F420-dependent NADP reductase in methanogenic archaea containing an NADP-dependent alcohol dehydrogenase. Arch. Microbiol. 168, 396-402. doi: 10.1007/s002030050514

$\mathrm{Bi}$, J., Wang, H., and Xie, J. (2011). Comparative genomics of NAD(P) biosynthesis and novel antibiotic drug targets. J. Cell. Physiol. 226, 331-340. doi: $10.1002 /$ jcp. 22419

Bizouarn, T., Althage, M., Pedersen, A., Tigerström, A., Karlsson, J., Johansson, C., et al. (2002). The organization of the membrane domain and its interaction with the $\mathrm{NADP}(\mathrm{H})$-binding site in proton-translocating transhydrogenase from E. coli. Biochim. Biophys. Acta Bioenerg. 1555, 122-127. doi: 10.1016/S00052728(02)00266-9

Bizouarn, T., Meuller, J., Axelsson, M., and Rydström, J. (2000). The transmembrane domain and the proton channel in proton-pumping transhydrogenases. Biochim. Biophys. Acta Bioenerg. 1459, 284-290. doi: 10.1016/S0005-2728(00)00163-8

Bock, A., King, P. W., Blokesch, M., and Posewitz, M. C. (2006). Maturation of hydrogenases. Adv. Microb. Physiol. 51, 1-71. doi: 10.1016/S00652911(06)51001-X

Bologna, F. P., Andreo, C. S., and Drincovich, M. F. (2007). Escherichia coli malic enzymes: two isoforms with substantial differences in kinetic properties, metabolic regulation, and structure. J. Bacteriol. 189, 5937-5946. doi: 10.1128/JB.00428-07

Bommareddy, R. R., Chen, Z., Rappert, S., and Zeng, A.-P. (2014). A de novo NADPH generation pathway for improving lysine production of Corynebacterium glutamicum by rational design of the coenzyme specificity of glyceraldehyde 3-phosphate dehydrogenase. Metab. Eng. 25, 30-37. doi: 10.1016/j.ymben.2014.06.005

Boonstra, B., French, C. E., Wainwright, I., and Bruce, N. C. (1999). The udhA gene of Escherichia coli encodes a soluble pyridine nucleotide transhydrogenase. J. Bacteriol. 181, 1030-1034.

Boonstra, B., Rathbone, D. A., French, C. E., Walker, E. H., and Bruce, N. C. (2000). Cofactor regeneration by a soluble pyridine nucleotide transhydrogenase for biological production of hydromorphone. Appl. Environ. Microbiol. 66, 5161-5166. doi: 10.1128/AEM.66.12.5161-5166.2000

Boyd, D. A., Cvitkovitch, D. G., and Hamilton, I. R. (1995). Sequence, expression, and function of the gene for the nonphosphorylating, NADP-dependent glyceraldehyde-3-phosphate dehydrogenase of Streptococcus mutans. J. Bacteriol. 177, 2622-2627.

Bragg, P. D., Davies, P. L., and Hou, C. (1972). Function of energy-dependent transhydrogenase in Escherichia coli. Biochem. Biophys. Res. Commun. 47, 1248-1255. doi: 10.1016/0006-291X(72)90969-2

Brasen, C., Esser, D., Rauch, B., and Siebers, B. (2014). Carbohydrate metabolism in Archaea: current insights into unusual enzymes and pathways and their regulation. Microbiol. Mol. Biol. Rev. 78, 89-175. doi: 10.1128/MMBR.00041-13

Brown, D. I., and Griendling, K. K. (2009). Nox proteins in signal transduction. Free Radic. Biol. Med. 47, 1239-1253. doi: 10.1016/j.freeradbiomed.2009.07.023

Brunner, N. A., Brinkmann, H., Siebers, B., and Hensel, R. (1998). NAD+dependent glyceraldehyde-3-phosphate dehydrogenase from Thermoproteus tenax. The first identified archaeal member of the aldehyde dehydrogenase superfamily is a glycolytic enzyme with unusual regulatory properties. J. Biol. Chem. 273, 6149-6156. doi: 10.1074/jbc.273.11.6149

Brunner, N. A., and Hensel, R. (2001). Nonphosphorylating glyceraldehyde-3phosphate dehydrogenase from Thermoproteus tenax. Methods Enzymol. 331, 117-131. doi: 10.1016/S0076-6879(01)31051-0

Brunner, N. A., Siebers, B., and Hensel, R. (2001). Role of two different glyceraldehyde-3-phosphate dehydrogenases in controlling the reversible Embden-Meyerhof-Parnas pathway in Thermoproteus tenax: regulation on protein and transcript level. Extremophiles 5, 101-109. doi: $10.1007 / \mathrm{s} 007920100181$
Buckel, W., and Thauer, R. K. (2013). Energy conservation via electron bifurcating ferredoxin reduction and proton/ $\mathrm{Na}(+)$ translocating ferredoxin oxidation. Biochim. Biophys. Acta 1827, 94-113. doi: 10.1016/j.bbabio.2012.07.002

Butler, J. R., and Mcguinness, E. T. (1982). Candida utilis NAD+ kinase: purification, properties and affinity gel studies. Int. J. Biochem. 14, 839-844. doi: 10.1016/0020-711X(82)90106-9

Butler, M. J., Bruheim, P., Jovetic, S., Marinelli, F., Postma, P. W., and Bibb, M. J. (2002). Engineering of primary carbon metabolism for improved antibiotic production in Streptomyces lividans. Appl. Environ. Microbiol. 68, 4731-4739. doi: 10.1128/AEM.68.10.4731-4739.2002

Bylund, J., Brown, K. L., Movitz, C., Dahlgren, C., and Karlsson, A. (2010). Intracellular generation of superoxide by the phagocyte NADPH oxidase: how, where, and what for? Free Radic. Biol. Med. 49, 1834-1845. doi: 10.1016/j.freeradbiomed.2010.09.016

Canonaco, F., Hess, T. A., Heri, S., Wang, T., Szyperski, T., and Sauer, U. (2001). Metabolic flux response to phosphoglucose isomerase knock-out in Escherichia coli and impact of overexpression of the soluble transhydrogenase UdhA. FEMS Microbiol. Lett. 204, 247-252. doi: 10.1111/j.1574-6968.2001.tb1 0892.x

Cao, Z., Song, P., Xu, Q., Su, R., and Zhu, G. (2011). Overexpression and biochemical characterization of soluble pyridine nucleotide transhydrogenase from Escherichia coli. FEMS Microbiol. Lett. 320, 9-14. doi: 10.1111/j.15746968.2011.02287.x

Carrillo, N., and Ceccarelli, E. A. (2003). Open questions in ferredoxinNADP+ reductase catalytic mechanism. Eur. J. Biochem. 270, 1900-1915. doi: 10.1046/j.1432-1033.2003.03566.x

Casalot, L., De Luca, G., Dermoun, Z., Rousset, M., and de Philip, P. (2002). Evidence for a fourth hydrogenase in Desulfovibrio fructosovorans. J. Bacteriol. 184, 853-856. doi: 10.1128/JB.184.3.853-856.2002

Ceccarelli, E. A., Arakaki, A. K., Cortez, N., and Carrillo, N. (2004), Functional plasticity and catalytic efficiency in plant and bacterial ferredoxin-NADP $(\mathrm{H})$ reductases. Biochim. Biophys. Acta 1698, 155-165. doi: 10.1016/j.bbapap.2003.12.005

Celton, M., Goelzer, A., Camarasa, C., Fromion, V., and Dequin, S. (2012). A constraint-based model analysis of the metabolic consequences of increased NADPH oxidation in Saccharomyces cerevisiae. Metab. Eng. 14, 366-379. doi: 10.1016/j.ymben.2012.03.008

Centeno-Leija, S., Huerta-Beristain, G., Giles-Gomez, M., Bolivar, F., Gosset, G., and Martinez, A. (2014). Improving poly-3-hydroxybutyrate production in Escherichia coli by combining the increase in the NADPH pool and acetyl-CoA availability. Antonie Van Leeuwenhoek 105, 687-696. doi: 10.1007/s10482-0140124-5

Centeno-Leija, S., Utrilla, J., Flores, N., Rodriguez, A., Gosset, G., and Martinez, A. (2013). Metabolic and transcriptional response of Escherichia coli with a NADP(+)-dependent glyceraldehyde 3-phosphate dehydrogenase from Streptococcus mutans. Antonie Van Leeuwenhoek 104, 913-924. doi: 10.1007/s10482-013-0010-6

Chang, D. Y., Hou, C., and Bragg, P. D. (1992). Anomalous effect of uncouplers on respiratory chain-linked transhydrogenation in Escherichia coli membranes: evidence for a localized proton pathway? Arch. Biochem. Biophys. 293, 246-253. doi: 10.1016/0003-9861(92)90392-A

Chang, G.-G., and Tong, L. (2003). Structure and function of malic enzymes, a new class of oxidative decarboxylases. Biochemistry 42, 12721-12733. doi: $10.1021 /$ bi035251+

Chemler, J. A., Fowler, Z. L., Mchugh, K. P., and Koffas, M. A. G. (2010). Improving NADPH availability for natural product biosynthesis in Escherichia coli by metabolic engineering. Metab. Eng. 12, 96-104. doi: 10.1016/j.ymben.2009.07.003

Chen, R., and Jeong, S. S. (2000). Functional prediction: identification of protein orthologs and paralogs. Protein Sci. 9, 2344-2353. doi: 10.1110/ps.9.12. 2344

Chenault, H. K., Simon, E. S., and Whitesides, G. M. (1988). Cofactor regeneration for enzyme-catalysed synthesis. Biotechnol. Genet. Eng. Rev. 6, 221-270. doi: 10.1080/02648725.1988.10647849

Chenault, H. K., and Whitesides, G. M. (1987). Regeneration of nicotinamide cofactors for use in organic synthesis. Appl. Biochem. Biotechnol. 14, 147-197. doi: $10.1007 / \mathrm{BF} 02798431$ 
Chin, J. W., and Cirino, P. C. (2011). Improved NADPH supply for xylitol production by engineered Escherichia Coli with glycolytic mutations. Biotechnol. Prog. 27, 333-341. doi: 10.1002/btpr.559

Chin, J. W., Khankal, R., Monroe, C. A., Maranas, C. D., and Cirino, P. C. (2009). Analysis of NADPH supply during xylitol production by engineered Escherichia coli. Biotechnol. Bioeng. 102, 209-220. doi: 10.1002/bit.22060

Chini, E. N., and De Toledo, F. G. S. (2002). Nicotinic acid adenine dinucleotide phosphate: a new intracellular second messenger? Am. J. Physiol. Cell Physiol. 282, C1191-C1198. doi: 10.1152/ajpcell.00475.2001

Choi, J.-C., Shin, H.-D., and Lee, Y.-H. (2003). Modulation of 3-hydroxyvalerate molar fraction in poly(3-hydroxybutyrate-3-hydroxyvalerate) using Ralstonia eutropha transformant co-amplifying phbC and NADPH generation-related zwf genes. Enzyme Microb. Technol. 32, 178-185. doi: 10.1016/S01410229(02)00274-0

Christiansen, T., Christensen, B., and Nielsen, J. (2002). Metabolic network analysis of Bacillus clausii on minimal and semirich medium using (13)C-labeled glucose. Metab. Eng. 4, 159-169. doi: 10.1006/mben.2001. 0219

Churamani, D., Carrey, E. A., Dickinson, G. D., and Patel, S. (2004). Determination of cellular nicotinic acid-adenine dinucleotide phosphate (NAADP) levels. Biochem. J. 380, 449-454. doi: 10.1042/BJ20031754

Cohen, P. T., and Kaplan, N. O. (1970). Purification and properties of the pyridine nucleotide transhydrogenase from Pseudomonas aeruginosa. J. Biol. Chem. 245, 2825-2836.

Conway, T. (1992). The entner-doudoroff pathway: history, physiology and molecular biology. FEMS Microbiol. Rev. 9, 1-27. doi: 10.1111/j.15746968.1992.tb05822.x

Cotton, N. P., Lever, T. M., Nore, B. F., Jones, M. R., and Jackson, J. B. (1989). The coupling between protonmotive force and the $\mathrm{NAD}(\mathrm{P})+$ transhydrogenase in chromatophores from photosynthetic bacteria. Eur. J. Biochem. 182, 593-603. doi: 10.1111/j.1432-1033.1989.tb14868.x

Cozzone, A. J. (1998). Regulation of acetate metabolism by protein phosphorylation in enteric bacteria. Annu. Rev. Microbiol. 52, 127-164. doi: 10.1146/annurev.micro.52.1.127

Crow, V. L., and Wittenberger, C. L. (1979). Separation and properties of NAD+and NADP+-dependent glyceraldehyde-3-phosphate dehydrogenases from Streptococcus mutans. J. Biol. Chem. 254, 1134-1142.

Dauner, M., Storni, T., and Sauer, U. (2001). Bacillus subtilis metabolism and energetics in carbon-limited and excess-carbon chemostat culture. J. Bacteriol. 183, 7308-7317. doi: 10.1128/JB.183.24.7308-7317.2001

Davis, W. B. (1980). Identification of a nicotinamide adenine dinucleotide glycohydrolase and an associated inhibitor in isoniazid-susceptible and resistant Mycobacterium phlei. Antimicrob. Agents Chemother. 17, 663-668. doi: 10.1128/AAC.17.4.663

Decorosi, F., Lori, L., Santopolo, L., Tatti, E., Giovannetti, L., and Viti, C. (2011). Characterization of a $\mathrm{Cr}(\mathrm{VI})$-sensitive Pseudomonas corrugata 28 mutant impaired in a pyridine nucleotide transhydrogenase gene. Res. Microbiol. 162, 747-755. doi: 10.1016/j.resmic.2011.06.014

Driscoll, B. T., and Finan, T. M. (1997). Properties of NAD(+)- and $\mathrm{NADP}(+)$-dependent malic enzymes of Rhizobium (Sinorhizobium) meliloti and differential expression of their genes in nitrogen-fixing bacteroids. Microbiology 143(Pt 2), 489-498. doi: 10.1099/00221287-143-2-489

Eguchi, T., Kuge, Y., Inoue, K., Yoshikawa, N., Mochida, K., and Uwajima, T. (1992). NADPH regeneration by glucose dehydrogenase from Gluconobacter scleroides for 1-leucovorin synthesis. Biosci. Biotechnol. Biochem. 56, 701-703. doi: 10.1271/bbb.56.701

Eikmanns, B. J., Rittmann, D., and Sahm, H. (1995). Cloning, sequence analysis, expression, and inactivation of the Corynebacterium glutamicum icd gene encoding isocitrate dehydrogenase and biochemical characterization of the enzyme. J. Bacteriol. 177, 774-782.

English, C. M., Eckert, C., Brown, K., Seibert, M., and King, P. W. (2009). Recombinant and in vitro expression systems for hydrogenases: new frontiers in basic and applied studies for biological and synthetic $\mathrm{H} 2$ production. Dalton Trans. 9970-9978. doi: 10.1039/b913426n

Espariz, M., Repizo, G., Blancato, V., Mortera, P., Alarcon, S., and Magni, C. (2011). Identification of malic and soluble oxaloacetate decarboxylase enzymes in Enterococcus faecalis. FEBS J. 278, 2140-2151. doi: 10.1111/j.17424658.2011.08131.x
Esser, D., Kouril, T., Talfournier, F., Polkowska, J., Schrader, T., Bräsen, C., et al. (2013). Unraveling the function of paralogs of the aldehyde dehydrogenase super family from Sulfolobus solfataricus. Extremophiles 17, 205-216. doi: 10.1007/s00792-012-0507-3

Ettema, T. J. G., Ahmed, H., Geerling, A. C. M., Van Der Oost, J., and Siebers, B. (2008). The non-phosphorylating glyceraldehyde-3-phosphate dehydrogenase (GAPN) of Sulfolobus solfataricus: a key-enzyme of the semi-phosphorylative branch of the Entner-Doudoroff pathway. Extremophiles 12, 75-88. doi: 10.1007/s00792-007-0082-1

Everse, J., Griffin, J. B., and Kaplan, N. O. (1975). The pyridine nucleosidase from Bacillus subtilis. Kinetic properties and enzyme-inhibitor interactions. Arch. Biochem. Biophys. 169, 714-723. doi: 10.1016/0003-9861(75) 90216-7

Ewen, K. M., Kleser, M., and Bernhardt, R. (2011). Adrenodoxin: the archetype of vertebrate-type [2Fe-2S] cluster ferredoxins. Biochim. Biophys. Acta Proteins Proteomics 1814, 111-125. doi: 10.1016/j.bbapap.2010.06.003

Fabris, M., Matthijs, M., Rombauts, S., Vyverman, W., Goossens, A., and Baart, G. J. E. (2012). The metabolic blueprint of Phaeodactylum tricornutum reveals a eukaryotic Entner-Doudoroff glycolytic pathway. Plant J. 70, 1004-1014. doi: 10.1111/j.1365-313X.2012.04941.x

Ferri, S., Kojima, K., and Sode, K. (2011). Review of glucose oxidases and glucose dehydrogenases: a bird's eye view of glucose sensing enzymes. J. Diabetes Sci. Technol. 5, 1068-1076. doi: 10.1177/193229681100500507

Fillinger, S., Boschi-Muller, S., Azza, S. D., Dervyn, E., Branlant, G., and Aymerich, S. (2000). Two Glyceraldehyde-3-phosphate dehydrogenases with opposite physiological roles in a nonphotosynthetic bacterium. J. Biol. Chem. 275, 14031-14037. doi: 10.1074/jbc.275.19.14031

Fischer, E., and Sauer, U. (2003). A novel metabolic cycle catalyzes glucose oxidation and anaplerosis in hungry Escherichia coli. J. Biol. Chem. 278, 46446-46451. doi: 10.1074/jbc.M307968200

Flamholz, A., Noor, E., Bar-Even, A., and Milo, R. (2012). eQuilibrator-the biochemical thermodynamics calculator. Nucleic Acids Res. 40, D770-D775. doi: 10.1093/nar/gkr874

Foreman, J., Demidchik, V., Bothwell, J. H. F., Mylona, P., Miedema, H., Torres, M. A., et al. (2003). Reactive oxygen species produced by NADPH oxidase regulate plant cell growth. Nature 422, 442-446. doi: 10.1038/nature01485

Forzi, L., and Sawers, R. G. (2007). Maturation of [NiFe]-hydrogenases in Escherichia coli. Biometals 20, 565-578. doi: 10.1007/s10534-006-9048-5

French, C. E., Boonstra, B., Bufton, K. A., and Bruce, N. C. (1997). Cloning, sequence, and properties of the soluble pyridine nucleotide transhydrogenase of Pseudomonas fluorescens. J. Bacteriol. 179, 2761-2765.

Frenkel, R. (1975). Regulation and physiological functions of malic enzymes. Curr. Top. Cell. Regul. 9, 157-181. doi: 10.1016/B978-0-12-152809-6.50012-3

Fuhrer, T., Fischer, E., and Sauer, U. (2005). Experimental identification and quantification of glucose metabolism in seven bacterial species. J. Bacteriol. 187, 1581-1590. doi: 10.1128/JB.187.5.1581-1590.2005

Fuhrer, T., and Sauer, U. (2009). Different biochemical mechanisms ensure network-wide balancing of reducing equivalents in microbial metabolism. J. Bacteriol. 191, 2112-2121. doi: 10.1128/JB.01523-08

Fukuda, C., Kawai, S., and Murata, K. (2007). NADP(H) Phosphatase activities of archaeal inositol monophosphatase and eubacterial 3 '-Phosphoadenosine 5'-Phosphate phosphatase. Appl. Environ. Microbiol. 73, 5447-5452. doi: 10.1128/AEM.02703-06

Fukuda, W., Ismail, Y. S., Fukui, T., Atomi, H., and Imanaka, T. (2005). Characterization of an archaeal malic enzyme from the hyperthermophilic archaeon Thermococcus kodakaraensis KOD1. Archaea 1, 293-301. doi: $10.1155 / 2005 / 250757$

Garavaglia, S., Galizzi, A., and Rizzi, M. (2003). Allosteric regulation of Bacillus subtilis NAD kinase by quinolinic acid. J. Bacteriol. 185, 4844-4850. doi: 10.1128/JB.185.16.4844-4850.2003

Garrido-Pertierra, A., Martinez Marcos, C., Martin Fernandez, M., and RuizAmil, M. (1983). Properties and function of malate enzyme from Pseudomonas putida. Biochimie 65, 629-635. doi: 10.1016/S0300-9084(84)80026-7

Gazzaniga, F., Stebbins, R., Chang, S. Z., Mcpeek, M. A., and Brenner, C. (2009). Microbial NAD metabolism: lessons from comparative genomics. Microbiol. Mol. Biol. Rev. 73, 529-541. doi: 10.1128/MMBR.00042-08

Gerdes, S. Y., Scholle, M. D., D'souza, M., Bernal, A., Baev, M. V., Farrell, M., et al. (2002). From genetic footprinting to antimicrobial drug targets: 
examples in cofactor biosynthetic pathways. J. Bacteriol. 184, 4555-4572. doi: 10.1128/JB.184.16.4555-4572.2002

Germer, F., Zebger, I., Saggu, M., Lendzian, F., Schulz, R., and Appel, J. (2009). Overexpression, isolation, and spectroscopic characterization of the bidirectional [NiFe] hydrogenase from Synechocystis sp. PCC 6803. J. Biol. Chem. 284, 36462-36472. doi: 10.1074/jbc.M109.028795

Ghosh, J., Anderson, P. J., Chandrasekaran, S., and Caparon, M. G. (2010). Characterization of Streptococcus pyogenes beta-NAD+ glycohydrolase: reevaluation of enzymatic properties associated with pathogenesis. J. Biol. Chem. 285, 5683-5694. doi: 10.1074/jbc.M109.070300

Giro, M., Carrillo, N., and Krapp, A. R. (2006). Glucose-6-phosphate dehydrogenase and ferredoxin-NADP $(\mathrm{H})$ reductase contribute to damage repair during the soxRS response of Escherichia coli. Microbiology 152, 1119-1128. doi: 10.1099/mic.0.28612-0

Goss, T., and Hanke, G. (2014). The end of the line: can ferredoxin and ferredoxin $\mathrm{NADP}(\mathrm{H})$ oxidoreductase determine the fate of photosynthetic electrons? Curr. Protein Pept. Sci. 15, 385-393. doi: 10.2174/13892037156661403271 13733

Gossmann, T. I., Ziegler, M., Puntervoll, P., De Figueiredo, L. F., Schuster, S., and Heiland, I. (2012). NAD+ biosynthesis and salvage - a phylogenetic perspective. FEBS J. 279, 3355-3363. doi: 10.1111/j.1742-4658.2012.08559.x

Gourdon, P., Baucher, M. F., Lindley, N. D., and Guyonvarch, A. (2000). Cloning of the malic enzyme gene from Corynebacterium glutamicum and role of the enzyme in lactate metabolism. Appl. Environ. Microbiol. 66, 2981-2987. doi: 10.1128/AEM.66.7.2981-2987.2000

Grose, J. H., Joss, L., Velick, S. F., and Roth, J. R. (2006). Evidence that feedback inhibition of NAD kinase controls responses to oxidative stress. Proc. Natl. Acad. Sci. U.S.A. 103, 7601-7606. doi: 10.1073/pnas.0602494103

Grzeszik, C., Lubbers, M., Reh, M., and Schlegel, H. G. (1997). Genes encoding the NAD-reducing hydrogenase of Rhodococcus opacus MR11. Microbiology143(Pt 4), 1271-1286. doi: 10.1099/00221287-143-4-1271

Guo, Z.-P., Zhang, L., Ding, Z.-Y., Wang, Z.-X., and Shi, G.-Y. (2011). Improving ethanol productivity by modification of glycolytic redox factor generation in glycerol-3-phosphate dehydrogenase mutants of an industrial ethanol yeast. J. Ind. Microbiol. Biotechnol. 38, 935-943. doi: 10.1007/s10295-010-0864-9

Hansen, E. J., and Juni, E. (1975). Isolation of mutants of Escherichia coli lacking NAD- and NADP-linked malic. Biochem. Biophys. Res. Commun. 65, 559-566. doi: 10.1016/S0006-291X(75)80183-5

Harold, F. M. (1986). The Vital Force: A Study of Bioenergetics. New York, NY: W. H. Freeman.

He, L., Xiao, Y., Gebreselassie, N., Zhang, F., Antoniewicz, M. R., Tang, Y. J., et al. (2014). Central metabolic responses to the overproduction of fatty acids in Escherichia coli based on 13C-metabolic flux analysis. Biotechnol. Bioeng. 111, 575-585. doi: 10.1002/bit.25124

Hickman, J. W., Barber, R. D., Skaar, E. P., and Donohue, T. J. (2002). Link between the membrane-bound pyridine nucleotide transhydrogenase and glutathionedependent processes in Rhodobacter sphaeroides. J. Bacteriol. 184, 400-409. doi: 10.1128/JB.184.2.400-409.2002

Hoek, J. B., and Rydstrom, J. (1988). Physiological roles of nicotinamide nucleotide transhydrogenase. Biochem. J. 254, 1-10.

Hojeberg, B., and Rydstrom, J. (1977). Ca2+-dependent allosteric regulation of nicotinamide nucleotide transhydrogenase from Pseudomonas aeruginosa. Eur. J. Biochem. 77, 235-241. doi: 10.1111/j.1432-1033.1977.tb11662.x

Hong, S. H., and Lee, S. Y. (2001). Metabolic flux analysis for succinic acid production by recombinant Escherichia coli with amplified malic enzyme activity. Biotechnol. Bioeng. 74, 89-95. doi: 10.1002/bit.1098

Hsieh, J.-Y., and Hung, H.-C. (2009). Engineering of the cofactor specificities and isoform-specific inhibition of malic enzyme. J. Biol. Chem. 284, 4536-4544. doi: 10.1074/jbc.M807008200

Hua, Q., Yang, C., Baba, T., Mori, H., and Shimizu, K. (2003). Responses of the central metabolism in Escherichia coli to phosphoglucose isomerase and glucose-6-phosphate dehydrogenase knockouts. J. Bacteriol. 185, 7053-7067. doi: 10.1128/JB.185.24.7053-7067.2003

Huang, H., Wang, S., Moll, J., and Thauer, R. K. (2012). Electron bifurcation involved in the energy metabolism of the acetogenic bacterium Moorella thermoacetica growing on glucose or H2 plus CO2. J. Bacteriol. 194, 3689-3699. doi: 10.1128/JB.00385-12
Huang, M., Wang, Y., Liu, J., and Mao, Z. (2011). Multiple strategies for metabolic engineering of Escherichia coli for efficient production of coenzyme. Chin. J. Chem. Eng. 19, 316-326. doi: 10.1016/S1004-9541(11)60171-7

Hügler, M., Menendez, C., Schägger, H., and Fuchs, G. (2002). Malonylcoenzyme a reductase from Chloroflexus aurantiacus, a key enzyme of the 3-Hydroxypropionate cycle for autotrophic CO2 Fixation. J. Bacteriol. 184, 2404-2410. doi: 10.1128/JB.184.9.2404-2410.2002

Iddar, A., Valverde, F., Assobhei, O., Serrano, A., and Soukri, A. (2005). Widespread occurrence of non-phosphorylating glyceraldehyde-3-phosphate dehydrogenase among gram-positive bacteria. Int. Microbiol. 8, 251-258.

Iddar, A., Valverde, F., Serrano, A., and Soukri, A. (2002). Expression, purification, and characterization of recombinant nonphosphorylating NADP-dependent glyceraldehyde-3-phosphate dehydrogenase from Clostridium acetobutylicum. Protein Expr. Purif. 25, 519-526. doi: 10.1016/S1046-5928(02)00032-3

Iddar, A., Valverde, F., Serrano, A., and Soukri, A. (2003). Purification of recombinant non-phosphorylating NADP-dependent glyceraldehyde-3phosphate dehydrogenase from Streptococcus pyogenes expressed in E. coli. Mol. Cell. Biochem. 247, 195-203. doi: 10.1023/A:1024112027440

Ikeda, T., Nakamura, M., Arai, H., Ishii, M., and Igarashi, Y. (2009). FerredoxinNADP reductase from the thermophilic hydrogen-oxidizing bacterium, Hydrogenobacter thermophilus TK-6. FEMS Microbiol. Lett. 297, 124-130. doi: 10.1111/j.1574-6968.2009.01667.x

Imam, S., Noguera, D. R., and Donohue, T. J. (2013). Global insights into energetic and metabolic networks in Rhodobacter sphaeroides. BMC Syst. Biol. 7:89. doi: 10.1186/1752-0509-7-89

Inoue, H., Tamura, T., Ehara, N., Nishito, A., Nakayama, Y., Maekawa, M., et al. (2002). Biochemical and molecular characterization of the $\mathrm{NAD}(+)$-dependent isocitrate dehydrogenase from the chemolithotroph Acidithiobacillus thiooxidans. FEMS Microbiol. Lett. 214, 127-132. doi: 10.1111/j.1574-6968.2002.tb11335.x

Ito, F., Chishiki, H., Fushinobu, S., and Wakagi, T. (2012). Comparative analysis of two glyceraldehyde-3-phosphate dehydrogenases from a thermoacidophilic archaeon, Sulfolobus tokodaii. FEBS Lett. 586, 3097-3103. doi: 10.1016/j.febslet.2012.07.059

Iwakura, M., Tokushige, M., Katsuki, H., and Muramatsu, S. (1978). Studies on regulatory functions of malic enzymes. V. Comparative studies of malic enzymes in bacteria. J. Biochem. 83, 1387-1394.

Jackson, B., Brocker, C., Thompson, D. C., Black, W., Vasiliou, K., Nebert, D. W., et al. (2011). Update on the aldehyde dehydrogenase gene (ALDH) superfamily. Hum. Genomics 5, 283-303. doi: 10.1186/1479-7364-5-4-283

Jackson, J. B. (2003). Proton translocation by transhydrogenase. FEBS Lett. 545, 18-24. doi: 10.1016/S0014-5793(03)00388-0

Jackson, J. B. (2012). A review of the binding-change mechanism for protontranslocating transhydrogenase. Biochim. Biophys. Acta 1817, 1839-1846. doi: 10.1016/j.bbabio.2012.04.006

Jackson, J. B., and Obiozo, U. M. (2009). "Proton-translocating transhydrogenase in photosynthetic bacteria," in The Purple Phototrophic Bacteria, eds C. N. Hunter, F. Daldal, M. Thurnauer, and J. T. Beatty (Dordrecht: Springer), 495-508.

Jackson, J. B., Quirk, P. G., Cotton, N. P., Venning, J. D., Gupta, S., Bizouarn, T., et al. (1998). Interdomain hydride transfer in proton-translocating transhydrogenase. Biochim. Biophys. Acta 1365, 79-86. doi: 10.1016/S00052728(98)00046-2

Jain, M. K., R., and Datta, and, J. G., Zeikus (1989). "High-value organic acids fermentation - emerging processes and products," in Bioprocess Engineering: The First Generation, ed T. K. Ghose (Chichester: Ellis Horwood Ltd), 366-389.

Jan, J., Martinez, I., Wang, Y., Bennett, G. N., and San, K.-Y. (2013). Metabolic engineering and transhydrogenase effects on NADPH availability in Escherichia coli. Biotechnol. Prog. 29, 1124-1130. doi: 10.1002/btpr.1765

Jiang, L.-Y., Zhang, Y.-Y., Li, Z., and Liu, J.-Z. (2013). Metabolic engineering of Corynebacterium glutamicum for increasing the production of L-ornithine by increasing NADPH availability. J. Ind. Microbiol. Biotechnol. 40, 1143-1151. doi: $10.1007 /$ s10295-013-1306-2

Jiao, Z., Baba, T., Mori, H., and Shimizu, K. (2003). Analysis of metabolic and physiological responses to gnd knockout in Escherichia coli by using C-13 tracer experiment and enzyme activity measurement. FEMS Microbiol. Lett. 220, 295-301. doi: 10.1016/S0378-1097(03)00133-2 
Jonsbu, E., Christensen, B., and Nielsen, J. (2001). Changes of in vivo fluxes through central metabolic pathways during the production of nystatin by Streptomyces noursei in batch culture. Appl. Microbiol. Biotechnol. 56, 93-100. doi: $10.1007 / \mathrm{s} 002530100613$

Kabir, M. M., and Shimizu, K. (2003). Fermentation characteristics and protein expression patterns in a recombinant Escherichia coli mutant lacking phosphoglucose isomerase for poly(3-hydroxybutyrate) production. Appl. Microbiol. Biotechnol. 62, 244-255. doi: 10.1007/s00253-003-1257-z

Kabir, M. M., and Shimizu, K. (2004). Metabolic regulation analysis of icd-gene knockout Escherichia coli based on 2D electrophoresis with MALDI-TOF mass spectrometry and enzyme activity measurements. Appl. Microbiol. Biotechnol. 65, 84-96. doi: 10.1007/s00253-004-1627-1

Kabus, A., Georgi, T., Wendisch, V. F., and Bott, M. (2007). Expression of the Escherichia coli pntAB genes encoding a membrane-bound transhydrogenase in Corynebacterium glutamicum improves L-lysine formation. Appl. Microbiol. Biotechnol. 75, 47-53. doi: 10.1007/s00253-006-0804-9

Kanai, T., Ito, S., and Imanaka, T. (2003). Characterization of a cytosolic NiFe-hydrogenase from the hyperthermophilic archaeon Thermococcus kodakaraensis KOD1. J. Bacteriol. 185, 1705-1711. doi: 10.1128/JB.185.5.17051711.2003

Kanai, T., Matsuoka, R., Beppu, H., Nakajima, A., Okada, Y., Atomi, H., et al. (2011). Distinct physiological roles of the three [NiFe]-hydrogenase orthologs in the hyperthermophilic archaeon Thermococcus kodakarensis. J. Bacteriol. 193, 3109-3116. doi: 10.1128/JB.01072-10

Kanao, T., Kawamura, M., Fukui, T., Atomi, H., and Imanaka, T. (2002). Characterization of isocitrate dehydrogenase from the green sulfur bacterium Chlorobium limicola. A carbon dioxide-fixing enzyme in the reductive tricarboxylic acid cycle. Eur. J. Biochem./FEBS 269, 1926-1931. doi: 10.1046/j.1432-1033.2002.02849.x

Kao, K. C., Tran, L. M., and Liao, J. C. (2005). A global regulatory role of gluconeogenic genes in Escherichia coli revealed by transcriptome network analysis. J. Biol. Chem. 280, 36079-36087. doi: 10.1074/jbc.M508202200

Karplus, P. A., and Faber, H. R. (2004). Structural aspects of plant ferredoxin: $\mathrm{NADP}(+)$ oxidoreductases. Photosyn. Res. 81, 303-315. doi: 10.1023/B:PRES.0000036884.57303.2e

Kataoka, M., Sri Rohani, L. P., Wada, M., Kita, K., Yanase, H., Urabe, I., et al. (1998). Escherichia coli transformant expressing the glucose dehydrogenase gene from Bacillus megaterium as a cofactor regenerator in a chiral alcohol production system. Biosci. Biotechnol. Biochem. 62, 167-169. doi: 10.1271/bbb.62.167

Kataoka, M., Yamamoto, K., Kawabata, H., Wada, M., Kita, K., Yanase, H., et al. (1999). Stereoselective reduction of ethyl 4-chloro-3-oxobutanoate by Escherichia coli transformant cells coexpressing the aldehyde reductase and glucose dehydrogenase genes. Appl. Microbiol. Biotechnol. 51, 486-490. doi: $10.1007 / \mathrm{s} 002530051421$

Kawai, S., Fukuda, C., Mukai, T., and Murata, K. (2005). MJ0917 in archaeon Methanococcus jannaschii is a novel NADP phosphatase/NAD kinase. J. Biol. Chem. 280, 39200-39207. doi: 10.1074/jbc.M506426200

Kawai, S., Mori, S., Mukai, T., Hashimoto, W., and Murata, K. (2001). Molecular characterization of Escherichia coli NAD kinase. Eur. J. Biochem. 268, 4359-4365. doi: 10.1046/j.1432-1327.2001.02358.x

Kawai, S., Mori, S., Mukai, T., and Murata, K. (2004). Cytosolic NADP phosphatases I and II from Arthrobacter sp. strain KM: implication in regulation of NAD+/NADP+ balance. J. Basic Microbiol. 44, 185-196. doi: 10.1002/jobm.200310362

Kawai, S., Mori, S., Mukai, T., Suzuki, S., Yamada, T., Hashimoto, W., et al. (2000). Inorganic Polyphosphate/ATP-NAD Kinase of Micrococcus flavus and Mycobacterium tuberculosis H37Rv. Biochem. Biophys. Res. Commun. 276, 57-63. doi: 10.1006/bbrc.2000.3433

Kawai, S., and Murata, K. (2008). Structure and function of NAD kinase and NADP phosphatase: key enzymes that regulate the intracellular balance of $\operatorname{NAD}(\mathrm{H})$ and $\operatorname{NADP}(\mathrm{H})$. Biosci. Biotechnol. Biochem. 72, 919-930. doi: 10.1271/bbb. 70738

Kawai, S., Suzuki, H., Yamamoto, K., Inui, M., Yukawa, H., and Kumagai, H. (1996). Purification and characterization of a malic enzyme from the ruminal bacterium Streptococcus bovis ATCC 15352 and cloning and sequencing of its gene. Appl. Environ. Microbiol. 62, 2692-2700.
Kelly, G. J., and Gibbs, M. (1973). Nonreversible d-glyceraldehyde 3phosphate dehydrogenase of plant tissues. Plant Physiol. 52, 111-118. doi: $10.1104 /$ pp.52.2.111

Kim, Y. M., Cho, H.-S., Jung, G. Y., and Park, J. M. (2011). Engineering the pentose phosphate pathway to improve hydrogen yield in recombinant Escherichia coli. Biotechnol. Bioeng. 108, 2941-2946. doi: 10.1002/bit.23259

Kizaki, N., Yasohara, Y., Hasegawa, J., Wada, M., Kataoka, M., and Shimizu, S. (2001). Synthesis of optically pure ethyl (S)-4-chloro-3-hydroxybutanoate by Escherichia coli transformant cells coexpressing the carbonyl reductase and glucose dehydrogenase genes. Appl. Microbiol. Biotechnol. 55, 590-595. doi: 10.1007/s002530100599

Klasen, R., Bringer-Meyer, S., and Sahm, H. (1995). Biochemical characterization and sequence analysis of the gluconate:NADP 5-oxidoreductase gene from Gluconobacter oxydans. J. Bacteriol. 177, 2637-2643.

Kletzien, R. F., Harris, P. K., and Foellmi, L. A. (1994). Glucose-6-phosphate dehydrogenase: a "housekeeping" enzyme subject to tissue-specific regulation by hormones, nutrients, and oxidant stress. FASEB J. 8, 174-181.

Kobayashi, K., Ehrlich, S. D., Albertini, A., Amati, G., Andersen, K. K., Arnaud, M., et al. (2003). Essential Bacillus subtilis genes. Proc. Natl. Acad. Sci. U.S.A. 100, 4678-4683. doi: 10.1073/pnas.0730515100

Koh, H.-J., Lee, S.-M., Son, B.-G., Lee, S.-H., Ryoo, Z. Y., Chang, K.-T., et al. (2004). Cytosolic NADP+-dependent isocitrate dehydrogenase plays a key role in lipid metabolism. J. Biol. Chem. 279, 39968-39974. doi: 10.1074/jbc.M402260200

Koksharova, O., Schubert, M., Shestakov, S., and Cerff, R. (1998). Genetic and biochemical evidence for distinct key functions of two highly divergent GAPDH genes in catabolic and anabolic carbon flow of the cyanobacterium Synechocystis sp. PCC 6803. Plant Mol. Biol. 36, 183-194. doi: 10.1023/A:1005925732743

Komori, H., Seo, D., Sakurai, T., and Higuchi, Y. (2010). Crystal structure analysis of Bacillus subtilis ferredoxin- $\mathrm{NADP}(+)$ oxidoreductase and the structural basis for its substrate selectivity. Protein Sci. 19, 2279-2290. doi: $10.1002 /$ pro. 508

Kornberg, A. (1950). Enzymatic synthesis of triphosphopyridine nucleotide. J. Biol. Chem. 182, 805-813.

Kramer, D. M., and Evans, J. R. (2011). The importance of energy balance in improving photosynthetic productivity. Plant Physiol. 155, 70-78. doi: 10.1104/pp.110.166652

Krapp, A. R., Rodriguez, R. E., Poli, H. O., Paladini, D. H., Palatnik, J. F., and Carrillo, N. (2002). The flavoenzyme ferredoxin (flavodoxin)-NADP $(\mathrm{H})$ reductase modulates $\mathrm{NADP}(\mathrm{H})$ homeostasis during the soxRS response of Escherichia coli. J. Bacteriol. 184, 1474-1480. doi: 10.1128/JB.184.5.14741480.2002

Kuo, C. C., Tsai, L. C., Chin, T. Y., Chang, G. G., and Chou, W. Y. (2000). Lysine residues 162 and 340 are involved in the catalysis and coenzyme binding of NADP(+)-dependent malic enzyme from pigeon. Biochem. Biophys. Res. Commun. 270, 821-825. doi: 10.1006/bbrc.2000.2502

Kurnasov, O., Goral, V., Colabroy, K., Gerdes, S., Anantha, S., Osterman, A., et al. (2003). NAD biosynthesis: identification of the tryptophan to quinolinate pathway in bacteria. Chem. Biol. 10, 1195-1204. doi: 10.1016/j.chembiol.2003.11.011

Labesse, G., Douguet, D., Assairi, L., and Gilles, A. M. (2002). Diacylglyceride kinases, sphingosine kinases and NAD kinases: distant relatives of 6phosphofructokinases. Trends Biochem. Sci. 27, 273-275. doi: 10.1016/S09680004(02)02093-5

Lakshmi, T. M., and Helling, R. B. (1976). Selection for citrate synthase deficiency in icd mutants of Escherichia coli. J. Bacteriol. 127, 76-83.

Lamed, R., and Zeikus, J. G. (1981). Thermostable, ammonium-activated malic enzyme of Clostridium thermocellum. Biochim. Biophys. Acta 660, 251-255. doi: 10.1016/0005-2744(81)90167-4

Lampel, K. A., Uratani, B., Chaudhry, G. R., Ramaley, R. F., and Rudikoff, S. (1986). Characterization of the developmentally regulated Bacillus subtilis glucose dehydrogenase gene. J. Bacteriol. 166, 238-243.

Landete, J. M., Garcia-Haro, L., Blasco, A., Manzanares, P., Berbegal, C., Monedero, V., et al. (2010). Requirement of the Lactobacillus casei MaeKR two-component system for L-malic acid utilization via a malic enzyme pathway. Appl. Environ. Microbiol. 76, 84-95. doi: 10.1128/AEM. 02145-09 
Lauterbach, L., Lenz, O., and Vincent, K. A. (2013). H(2)-driven cofactor regeneration with $\mathrm{NAD}(\mathrm{P})(+)$-reducing hydrogenases. FEBS J. 280, 3058-3068. doi: $10.1111 /$ febs. 12245

Lee, H. C. (1997). Mechanisms of calcium signaling by cyclic ADP-ribose and NAADP. Physiol. Rev. 77, 1133-1164.

Lee, H. C., Kim, J. S., Jang, W., and Kim, S. Y. (2009). Thymidine production by overexpressing NAD+ kinase in an Escherichia coli recombinant strain. Biotechnol. Lett. 31, 1929-1936. doi: 10.1007/s10529-009-0097-z

Lee, H. C., Kim, J. S., Jang, W., and Kim, S. Y. (2010). High NADPH/NADP+ ratio improves thymidine production by a metabolically engineered Escherichia coli strain. J. Biotechnol. 149, 24-32. doi: 10.1016/j.jbiotec.2010.06.011

Lee, J.-N., Shin, H.-D., and Lee, Y.-H. (2003). Metabolic engineering of pentose phosphate pathway in Ralstonia eutropha for enhanced biosynthesis of poly- $\beta$-hydroxybutyrate. Biotechnol. Prog. 19, 1444-1449. doi: 10.1021/ bp034060v

Lee, W.-H., Chin, Y.-W., Han, N. S., Kim, M.-D., and Seo, J.-H. (2011). Enhanced production of GDP-L-fucose by overexpression of NADPH regenerator in recombinant Escherichia coli. Appl. Microbiol. Biotechnol. 91, 967-976. doi: 10.1007/s00253-011-3271-x

Lee, W.-H., Kim, J.-W., Park, E.-H., Han, N. S., Kim, M.-D., and Seo, J.-H. (2013a). Effects of NADH kinase on NADPH-dependent biotransformation processes in Escherichia coli. Appl. Microbiol. Biotechnol. 97, 1561-1569. doi: 10.1007/s00253-012-4431-3

Lee, W. H., Kim, M. D., Jin, Y. S., and Seo, J. H. (2013b). Engineering of NADPH regenerators in Escherichia coli for enhanced biotransformation. Appl. Microbiol. Biotechnol. 97, 2761-2772. doi: 10.1007/s00253-013-4750-z

Lee, W.-H., Park, J.-B., Park, K., Kim, M.-D., and Seo, J.-H. (2007a). Enhanced production of ?-caprolactone by overexpression of NADPH-regenerating glucose 6-phosphate dehydrogenase in recombinant Escherichia coli harboring cyclohexanone monooxygenase gene. Appl. Microbiol. Biotechnol. 76, 329-338. doi: 10.1007/s00253-007-1016-7

Lee, Y., Yeom, J., Kang, Y.-S., Kim, J., Sung, J.-S., Jeon, C. O., et al. (2007b). Molecular characterization of fprB (ferredoxin-NADP+ reductase) in Pseudomonas putida KT2440. J. Microbiol. Biotechnol. 17, 1504-1512.

Lerondel, G., Doan, T., Zamboni, N., Sauer, U., and Aymerich, S. (2006). YtsJ has the major physiological role of the four paralogous malic enzyme isoforms in Bacillus subtilis. J. Bacteriol. 188, 4727-4736. doi: 10.1128/JB.00167-06

Lever, T. M., Palmer, T., Cunningham, I. J., Cotton, N. P., and Jackson, J. B. (1991). Purification and properties of the $\mathrm{H}(+)$-nicotinamide nucleotide transhydrogenase from Rhodobacter capsulatus. Eur. J. Biochem. 197, 247-255. doi: 10.1111/j.1432-1033.1991.tb15905.x

Levy, H. R. (1979). Glucose-6-phosphate dehydrogenases. Adv. Enzymol. Relat. Areas Mol. Biol. 48, 97-192. doi: 10.1002/9780470122938.ch3

Lewis, T. A., Glassing, A., Harper, J., and Franklin, M. J. (2013). Role for ferredoxin:NAD $(\mathrm{P}) \mathrm{H}$ oxidoreductase (FprA) in sulfate assimilation and siderophore biosynthesis in Pseudomonads. J. Bacteriol. 195, 3876-3887. doi: 10.1128/JB.00528-13

Li, Z.-J., Cai, L., Wu, Q., and Chen, G.-Q. (2009). Overexpression of NAD kinase in recombinant Escherichia coli harboring the phbCAB operon improves poly(3hydroxybutyrate) production. Appl. Microbiol. Biotechnol. 83, 939-947. doi: 10.1007/s00253-009-1943-6

Lim, S.-J., Jung, Y.-M., Shin, H.-D., and Lee, Y.-H. (2002). Amplification of the NADPH-related genes zwf and gnd for the oddball biosynthesis of PHB in an E. coli transformant harboring a cloned phbCAB operon. J. Biosci. Bioeng. 93, 543-549. doi: 10.1016/S1389-1723(02)80235-3

Lindahl, R. (1992). Aldehyde dehydrogenases and their role in carcinogenesis. Crit. Rev. Biochem. Mol. Biol. 27, 283-335. doi: 10.3109/10409239209082565

Lindner, S. N., Niederholtmeyer, H., Schmitz, K., Schoberth, S. M., and Wendisch, V. F. (2010). Polyphosphate/ATP-dependent NAD kinase of Corynebacterium glutamicum: biochemical properties and impact of ppnK overexpression on lysine production. Appl. Microbiol. Biotechnol. 87, 583-593. doi: $10.1007 / \mathrm{s} 00253-010-2481-y$

Lipscomb, G. L., Stirrett, K., Schut, G. J., Yang, F., Jenney, F. E. Jr., Scott, R. A., et al. (2011). Natural competence in the hyperthermophilic archaeon Pyrococcus furiosus facilitates genetic manipulation: construction of markerless deletions of genes encoding the two cytoplasmic hydrogenases. Appl. Environ. Microbiol. 77, 2232-2238. doi: 10.1128/AEM.02624-10
Liu, W., and Wang, P. (2007). Cofactor regeneration for sustainable enzymatic biosynthesis. Biotechnol. Adv. 25, 369-384. doi: 10.1016/j.biotechadv.2007.03.002

Lloyd, A. J., and Weitzman, D. (1988). Purification and characterization of NADlinked isocitrate dehydrogenase from Methylophilus methylotrophus. Biochem. Soc. Trans. 16, 871-872. doi: 10.1042/bst0160871

London, J., Meyer, E. Y., and Kulczyk, S. (1971). Comparative biochemical and immunological study of malic enzyme from two species of lactic acid bacteria: evolutionary implications. J. Bacteriol. 106, 126-137.

Lorentzen, E., Hensel, R., Knura, T., Ahmed, H., and Pohl, E. (2004). Structural Basis of allosteric regulation and substrate specificity of the non-phosphorylating glyceraldehyde 3-phosphate dehydrogenase from Thermoproteus tenax. J. Mol. Biol. 341, 815-828. doi: 10.1016/j.jmb.2004. 05.032

Lu, Y., and Mei, L. (2007). Co-expression of P450 BM3 and glucose dehydrogenase by recombinant Escherichia coli and its application in an NADPH-dependent indigo production system. J. Ind. Microbiol. Biotechnol. 34, 247-253. doi: 10.1007/s10295-006-0193-1

Lyon, E. J., Shima, S., Buurman, G., Chowdhuri, S., Batschauer, A., Steinbach, K., et al. (2004). UV-A/blue-light inactivation of the 'metal-free' hydrogenase (Hmd) from methanogenic archaea. Eur. J. Biochem. 271, 195-204. doi: 10.1046/j.1432-1033.2003.03920.x

Ma, K., and Adams, M. W. (2001a). Ferredoxin:NADP oxidoreductase from Pyrococcus furiosus. Meth. Enzymol. 334, 40-45. doi: 10.1016/S00766879(01)34456-7

Ma, K., and Adams, M. W. W. (2001b). "Hydrogenases I and II from Pyrococcus furiosus," in Methods in Enzymology, eds R. M. K. Michael and W. W. Adams (Academic Press), 208-216.

Ma, K., Weiss, R., and Adams, M. W. W. (2000). Characterization of hydrogenase II from the hyperthermophilic archaeon Pyrococcus furiosus and assessment of its role in sulfur reduction. J. Bacteriol. 182, 1864-1871. doi: 10.1128/JB.182.7.1864-1871.2000

Magni, G., Amici, A., Emanuelli, M., Orsomando, G., Raffaelli, N., and Ruggieri, S. (2004). Enzymology of NAD+ homeostasis in man. Cell. Mol. Life Sci. 61, 19-34. doi: 10.1007/s00018-003-3161-1

Magni, G., Amici, A., Emanuelli, M., Raffaelli, N., and Ruggieri, S. (1999). Enzymology of NAD+ synthesis. Adv. Enzymol. Relat. Areas Mol. Biol. 73 , 135-182. doi: 10.1002/9780470123195.ch5

Magni, G., Orsomando, G., and Raffaelli, N. (2006). Structural and functional properties of NAD kinase, a key enzyme in NADP biosynthesis. Mini Rev. Med. Chem. 6, 739-746. doi: 10.2174/138955706777698688

Mailloux, R. J., Bériault, R., Lemire, J., Singh, R., Chénier, D. R., Hamel, R. D., et al. (2007). The tricarboxylic acid cycle, an ancient metabolic network with a novel twist. PLoS ONE 2:e690. doi: 10.1371/journal.pone.0000690

Malki, S., Saimmaime, I., De Luca, G., Rousset, M., Dermoun, Z., and Belaich, J. P. (1995). Characterization of an operon encoding an NADP-reducing hydrogenase in Desulfovibrio fructosovorans. J. Bacteriol. 177, 2628-2636.

Marchitti, S. A., Brocker, C., Stagos, D., and Vasiliou, V. (2008). Non-P450 aldehyde oxidizing enzymes: the aldehyde dehydrogenase superfamily. Exp. Opin. Drug Metab. Toxicol. 4, 697-720. doi: 10.1517/17425255.4.6.697

Martinez, I., Zhu, J., Lin, H., Bennett, G. N., and San, K.-Y. (2008). Replacing Escherichia coli NAD-dependent glyceraldehyde 3-phosphate dehydrogenase (GAPDH) with a NADP-dependent enzyme from Clostridium acetobutylicum facilitates NADPH dependent pathways. Metab. Eng. 10, 352-359. doi: 10.1016/j.ymben.2008.09.001

Martinez-Julvez, M., Medina, M., and Velazquez-Campoy, A. (2009). Binding thermodynamics of ferredoxin:NADP+ reductase: two different protein substrates and one energetics. Biophys. J. 96, 4966-4975. doi: 10.1016/j.bpj.2009.02.061

Marx, A., Eikmanns, B. J., Sahm, H., De Graaf, A. A., and Eggeling, L. (1999). Response of the central metabolism in Corynebacterium glutamicum to the use of an NADH-dependent glutamate dehydrogenase. Metab. Eng. 1, 35-48. doi: 10.1006/mben.1998.0106

Marx, A., Hans, S., Mockel, B., Bathe, B., De Graaf, A. A., Mccormack, A. C., et al. (2003). Metabolic phenotype of phosphoglucose isomerase mutants of Corynebacterium glutamicum. J. Biotechnol. 104, 185-197. doi: 10.1016/S01681656(03)00153-6 
Mateos, M., and Serrano, A. (1992). Occurrence of phosphorylating and non-phosphorylating NADP+-dependent glyceraldehyde-3-phosphate dehydrogenases in photosynthetic organisms. Plant Sci. 84, 163-170. doi: 10.1016/0168-9452(92)90130-E

Mather, L. H., and Knight, M. (1972). A heat-stable nicotinamide-adenine dinucleotide glycohydrolase from Pseudomonas putida KB1. Partial purification and some properties of the enzyme and an inhibitory protein. Biochem. J. 129, 141-152.

Matsubara, K., Yokooji, Y., Atomi, H., and Imanaka, T. (2011). Biochemical and genetic characterization of the three metabolic routes in Thermococcus kodakarensis linking glyceraldehyde 3-phosphate and 3-phosphoglycerate. Mol. Microbiol. 81, 1300-1312. doi: 10.1111/j.1365-2958.2011.07762.x

Matsuda, F., Ishii, J., Kondo, T., Ida, K., Tezuka, H., and Kondo, A. (2013). Increased isobutanol production in Saccharomyces cerevisiae by eliminating competing pathways and resolving cofactor imbalance. Microb. Cell Fact. 12:119. doi: 10.1186/1475-2859-12-119

Matula, T. I., Mcdonald, I. J., and Martin, S. M. (1969). CO2 fixation by malic enzyme in a species of Micrococcus. Biochem. Biophys. Res. Commun. 34, 795-802. doi: 10.1016/0006-291X(69)90250-2

Mcdermott, T. R., and Kahn, M. L. (1992). Cloning and mutagenesis of the Rhizobium meliloti isocitrate dehydrogenase gene. J. Bacteriol. 174, 4790-4797.

Mcguinness, E. T., and Butler, J. R. (1985). NAD+ kinase-a review. Int. J. Biochem. 17, 1-11. doi: 10.1016/0020-711X(85)90079-5

Medina, M., and Gomez-Moreno, C. (2004). Interaction of FerredoxinNADP $(+)$ Reductase with its substrates: optimal interaction for efficient electron transfer. Photosyn. Res. 79, 113-131. doi: 10.1023/B:PRES.0000015386. $67746.2 \mathrm{c}$

Mertens, R., Greiner, L., Van Den Ban, E. C. D., Haaker, H. B. C. M., and Liese, A. (2003). Practical applications of hydrogenase I from Pyrococcus furiosus for NADPH generation and regeneration. J. Mol. Catal. B 24-25, 39-52. doi: 10.1016/S1381-1177(03)00071-7

Meyer, F. M., and Stulke, J. (2013). Malate metabolism in Bacillus subtilis: distinct roles for three classes of malate-oxidizing enzymes. FEMS Microbiol. Lett. 339, 17-22. doi: 10.1111/1574-6968.12041

Middleditch, L. E., Atchison, R. W., and Chung, A. E. (1972). Pyridine nucleotide transhydrogenase from Azotobacter vinelandii. Some aspects of its structure. J. Biol. Chem. 247, 6802-6809.

Miller, W. L., and Auchus, R. J. (2011). The molecular biology, biochemistry, and physiology of human steroidogenesis and its disorders. Endocr. Rev. 32, 81-151. doi: 10.1210/er.2010-0013

Minard, K. I., and Mcalister-Henn, L. (2005). Sources of NADPH in yeast vary with carbon source. J. Biol. Chem. 280, 39890-39896. doi: 10.1074/jbc.M509461200

Moreira Dos Santos, M., Raghevendran, V., Kotter, P., Olsson, L., and Nielsen, J. (2004). Manipulation of malic enzyme in Saccharomyces cerevisiae for increasing NADPH production capacity aerobically in different cellular compartments. Metab. Eng. 6, 352-363. doi: 10.1016/j.ymben.2004.06.002

Mori, S., Kawai, S., Shi, F., Mikami, B., and Murata, K. (2005). Molecular conversion of NAD kinase to NADH kinase through single amino acid residue substitution. J. Biol. Chem. 280, 24104-24112. doi: 10.1074/jbc.M502518200

Morimoto, Y., Honda, K., Ye, X., Okano, K., and Ohtake, H. (2014). Directed evolution of thermotolerant malic enzyme for improved malate production. J. Biosci. Bioeng. 117, 147-152. doi: 10.1016/j.jbiosc.2013.07.005

Moritz, B., Striegel, K., De Graaf, A. A., and Sahm, H. (2000). Kinetic properties of the glucose-6-phosphate and 6-phosphogluconate dehydrogenases from Corynebacterium glutamicum and their application for predicting pentose phosphate pathway flux in vivo. Eur. J. Biochem. 267, 3442-3452. doi: 10.1046/j.1432-1327.2000.01354.x

Mulo, P. (2011). Chloroplast-targeted ferredoxin-NADP $(+)$ oxidoreductase (FNR): structure, function and location. Biochim. Biophys. Acta 1807, 927-934. doi: 10.1016/j.bbabio.2010.10.001

Munekage, Y., Hashimoto, M., Miyake, C., Tomizawa, K.-I., Endo, T., Tasaka, M., et al. (2004). Cyclic electron flow around photosystem I is essential for photosynthesis. Nature 429, 579-582. doi: 10.1038/nature02598

Murakami, K., Iwata, S., Haneda, M., and Yoshino, M. (1997). Role of metal cations in the regulation of NADP-linked isocitrate dehydrogenase from porcine heart. Biometals 10, 169-174. doi: 10.1023/A:1018395510334

Muraki, N., Seo, D., Shiba, T., Sakurai, T., and Kurisu, G. (2010). Asymmetric dimeric structure of ferredoxin- $\mathrm{NAD}(\mathrm{P})+$ oxidoreductase from the green sulfur bacterium Chlorobaculum tepidum: implications for binding ferredoxin and NADP+. J. Mol. Biol. 401, 403-414. doi: 10.1016/j.jmb.2010.06.024

Muro-Pastor, M. I., and Florencio, F. J. (1994). NADP (+)-isocitrate dehydrogenase from the Cyanobacterium Anabaena sp. strain PCC 7120: purification and characterization of the enzyme and cloning, sequencing, and disruption of the icd gene. J. Bacteriol. 176, 2718-2726.

Muro-Pastor, M. I., Reyes, J. C., and Florencio, F. J. (2005). Ammonium assimilation in cyanobacteria. Photosyn. Res. 83, 135-150. doi: 10.1007/s11120004-2082-7

Musumeci, M. A., Ceccarelli, E. A., and Catalano-Dupuy, D. L. (2012). "The plant-type ferredoxin-NADP+ reductases," in Advances in Photosynthesis Fundamental Aspects, ed D. M. Najafpour (Rijeka: InTech), 539-562. doi: $10.5772 / 28665$

Nakamichi, Y., Yoshioka, A., Kawai, S., and Murata, K. (2013). Conferring the ability to utilize inorganic polyphosphate on ATP-specific NAD kinase. Sci. Rep. 3, 2632. doi: $10.1038 /$ srep02632

Nakamura, M., Bhatnagar, A., and Sadoshima, J. (2012). Overview of pyridine nucleotides review series. Circ. Res. 111, 604-610. doi: 10.1161/CIRCRESAHA.111.247924

Netzer, R., Krause, M., Rittmann, D., Peters-Wendisch, P. G., Eggeling, L., Wendisch, V. F., et al. (2004). Roles of pyruvate kinase and malic enzyme in Corynebacterium glutamicum for growth on carbon sources requiring gluconeogenesis. Arch. Microbiol. 182, 354-363. doi: 10.1007/s00203-004$0710-4$

Nicolas, C., Kiefer, P., Letisse, F., Kromer, J., Massou, S., Soucaille, P., et al. (2007). Response of the central metabolism of Escherichia coli to modified expression of the gene encoding the glucose-6-phosphate dehydrogenase. FEBS Lett. 581, 3771-3776. doi: 10.1016/j.febslet.2007.06.066

Noor, E., Bar-Even, A., Flamholz, A., Lubling, Y., Davidi, D., and Milo, R. (2012). An integrated open framework for thermodynamics of reactions that combines accuracy and coverage. Bioinformatics 28, 2037-2044. doi: 10.1093/bioinformatics/bts317

Noor, E., Haraldsdóttir, H. S., Milo, R., and Fleming, R. M. T. (2013). Consistent estimation of gibbs energy using component contributions. PLoS Comput. Biol. 9:e1003098. doi: 10.1371/journal.pcbi.1003098

Nordberg, J., and Arnér, E. S. J. (2001). Reactive oxygen species, antioxidants, and the mammalian thioredoxin system. Free Radic. Biol. Med. 31, 1287-1312. doi: 10.1016/S0891-5849(01)00724-9

Nouailler, M., Morelli, X., Bornet, O., Chetrit, B., Dermoun, Z., and Guerlesquin, F. (2006). Solution structure of HndAc: a thioredoxin-like domain involved in the NADP-reducing hydrogenase complex. Protein Sci. 15, 1369-1378.

Obanye, A. I. C., Hobbs, G., Gardner, D. C. J., and Oliver, S. G. (1996). Correlation between carbon flux through the pentose phosphate pathway and production of the antibiotic methylenomycin in Streptomyces coelicolor A3(2). Microbiology (Reading Engl). 142, 133-137. doi: 10.1099/13500872-142-1-133

Ochiai, A., Mori, S., Kawai, S., and Murata, K. (2004). Overexpression, purification, and characterization of ATP-NAD kinase of Sphingomonas sp. A1. Protein Expr. Purif. 36, 124-130. doi: 10.1016/j.pep.2004.03.012

Ogawa, T., Murakami, K., Mori, H., Ishii, N., Tomita, M., and Yoshin, M. (2007). Role of phosphoenolpyruvate in the NADP-isocitrate dehydrogenase and isocitrate lyase reaction in Escherichia coli. J. Bacteriol. 189, 1176-1178. doi: 10.1128/JB.01628-06

Oh, M.-K., Rohlin, L., Kao, K. C., and Liao, J. C. (2002). Global expression profiling of acetate-grown Escherichia coli. J. Biol. Chem. 277, 13175-13183. doi: 10.1074/jbc.M110809200

Olavarría, K., Valdés, D., and Cabrera, R. (2012). The cofactor preference of glucose-6-phosphate dehydrogenase from Escherichia coli - modeling the physiological production of reduced cofactors. FEBS J. 279, 2296-2309. doi: 10.1111/j.1742-4658.2012.08610.x

Onda, Y., Matsumura, T., Kimata-Ariga, Y., Sakakibara, H., Sugiyama, T., and Hase, T. (2000). Differential interaction of maize root ferredoxin:NADP $(+)$ oxidoreductase with photosynthetic and non-photosynthetic ferredoxin isoproteins. Plant Physiol. 123, 1037-1045. doi: 10.1104/pp.123.3.1037

Outten, C. E., and Culotta, V. C. (2003). A novel NADH kinase is the mitochondrial source of NADPH in Saccharomyces cerevisiae. EMBO J. 22, 2015-2024. doi: 10.1093/emboj/cdg211

Owen, O. E., Kalhan, S. C., and Hanson, R. W. (2002). The key role of anaplerosis and cataplerosis for citric acid cycle 
function. J. Biol. Chem. 277, 30409-30412. doi: 10.1074/jbc.R2000 06200

Papagianni, M. (2012). Recent advances in engineering the central carbon metabolism of industrially important bacteria. Microb. Cell Fact. 11:50. doi: 10.1186/1475-2859-11-50

Park, H. J., Jung, J., Choi, H., Uhm, K.-N., and Kim, H. K. (2010). Enantioselective bioconversion using Escherichia coli cells expressing Saccharomyces cerevisiae reductase and Bacillus subtilis glucose dehydrogenase. J. Microbiol. Biotechnol. 20, 1300-1306. doi: 10.4014/jmb.1003.03025

Patel, S., Ramakrishnan, L., Rahman, T., Hamdoun, A., Marchant, J. S., Taylor, C. W., et al. (2011). The endo-lysosomal system as an NAADP-sensitive acidic $\mathrm{Ca}(2+)$ store: role for the two-pore channels. Cell Calcium 50, 157-167. doi: 10.1016/j.ceca.2011.03.011

Paul, L., Mishra, P., Blumenthal, R., and Matthews, R. (2007). Integration of regulatory signals through involvement of multiple global regulators: control of the Escherichia coli gltBDF operon by Lrp, IHF, Crp, and ArgR. BMC Microbiol. 7:2. doi: 10.1186/1471-2180-7-2

Pauly, H. E., and Pfleiderer, G. (1975). D-glucose dehydrogenase from Bacillus megaterium M 1286: purification, properties and structure. Hoppe-Seyler's $Z$. Physiol. Chem. 356, 1613-1623. doi: 10.1515/bchm2.1975.356.2.1613

Pedersen, A., Karlsson, G. B., and Rydstrom, J. (2008). Proton-translocating transhydrogenase: an update of unsolved and controversial issues. J. Bioenerg. Biomembr. 40, 463-473. doi: 10.1007/s10863-008-9170-x

Penyige, A., Deak, E., Kalmanczhelyi, A., and Barabas, G. (1996). Evidence of a role for NAD+-glycohydrolase and ADP-ribosyltransferase in growth and differentiation of Streptomyces griseus NRRL B-2682: inhibition by m-aminophenylboronic acid. Microbiology 142(Pt 8), 1937-1944. doi: 10.1099/13500872-142-8-1937

Peralta-Yahya, P. P., Zhang, F., Del Cardayre, S. B., and Keasling, J. D. (2012). Microbial engineering for the production of advanced Biofuels 488, 320-328. doi: 10.1038 /nature11478

Peters, J. W., Schut, G. J., Boyd, E. S., Mulder, D. W., Shepard, E. M., Broderick, J. B., et al. (2015). [FeFe]- and [NiFe]-hydrogenase diversity, mechanism, and maturation. Biochim. Biophys. Acta Mol. Cell Res. 1853, 1350-1369. doi: 10.1016/j.bbamcr.2014.11.021

Petersen, S., De Graaf, A. A., Eggeling, L., Möllney, M., Wiechert, W., and Sahm, H. (2000). In vivo quantification of parallel and bidirectional fluxes in the anaplerosis of Corynebacterium glutamicum. J. Biol. Chem. 275, 35932-35941. doi: $10.1074 /$ jbc.M908728199

Pollak, N., Dölle, C., and Ziegler, M. (2007). The power to reduce: pyridine nucleotides - small molecules with a multitude of functions. Biochem. J. 402, 205-218. doi: 10.1042/BJ20061638

Poncet-Montange, G., Assairi, L., Arold, S., Pochet, S., and Labesse, G. (2007). NAD kinases use substrate-assisted catalysis for specific recognition of NAD. J. Biol. Chem. 282, 33925-33934. doi: 10.1074/jbc.M701394200

Purwantini, E., and Daniels, L. (1996). Purification of a novel coenzyme F420-dependent glucose-6-phosphate dehydrogenase from Mycobacterium smegmatis. J. Bacteriol. 178, 2861-2866.

Purwantini, E., Gillis, T. P., and Daniels, L. (1997). Presence of F420-dependent glucose-6-phosphate dehydrogenase in Mycobacterium and Nocardia species, but absence from Streptomyces and Corynebacterium species and methanogenic Archaea. FEMS Microbiol. Lett. 146, 129-134. doi: 10.1111/j.1574-6968.1997.tb10182.x

Qi, H., Li, S., Zhao, S., Huang, D., Xia, M., and Wen, J. (2014). Model-driven redox pathway manipulation for improved isobutanol production in Bacillus subtilis complemented with experimental validation and metabolic profiling analysis. PLOS ONE 9:e93815. doi: 10.1371/journal.pone.0093815

Rahman, M. M. Q., Zhao, Q., Dou, W., Zhiming, R., and Xu, Z. (2012). Over-expression of NAD kinase in Corynebacterium crenatum and its impact on L-Arginine biosynthesis. Tropic. J. Pharm. Res. 11, 909-916. doi: 10.4314/tjpr.v1li6.6

Rathnasingh, C., Raj, S. M., Lee, Y., Catherine, C., Ashok, S., and Park, S. (2012). Production of 3-hydroxypropionic acid via malonyl-CoA pathway using recombinant Escherichia coli strains. J. Biotechnol. 157, 633-640. doi: 10.1016/j.jbiotec.2011.06.008

Razquin, P., Fillat, M. F., Schmitz, S., Stricker, O., Bohme, H., Gomez-Moreno, C., et al. (1996). Expression of ferredoxin-NADP+ reductase in heterocysts from Anabaena sp. Biochem. J. 316(Pt 1), 157-160.
Reddy, G. K., Lindner, S. N., and Wendisch, V. F. (2015). Metabolic Engineering an ATP-neutral EMP pathway in Corynebacterium glutamicum: adaptive point mutation in NADH dehydrogenase restores growth. Appl. Environ. Microbiol. 81, 1996-2005. doi: 10.1128/AEM.03116-14

Reidl, J., Schlor, S., Kraiss, A., Schmidt-Brauns, J., Kemmer, G., and Soleva, E. (2000). NADP and NAD utilization in Haemophilus influenzae. Mol. Microbiol. 35, 1573-1581. doi: 10.1046/j.1365-2958.2000.01829.x

Richhardt, J., Bringer, S., and Bott, M. (2013). Role of the pentose phosphate pathway and the Entner-Doudoroff pathway in glucose metabolism of Gluconobacter oxydans 621H. Appl. Microbiol. Biotechnol. 97, 4315-4323. doi: 10.1007/s00253-013-4707-2

Riedel, C., Rittmann, D., Dangel, P., Mockel, B., Petersen, S., Sahm, H., et al. (2001). Characterization of the phosphoenolpyruvate carboxykinase gene from Corynebacterium glutamicum and significance of the enzyme for growth and amino acid production. J. Mol. Microbiol. Biotechnol. 3, 573-583.

Poulsen, B. R., Nohr, J., Douthwaite, S., Hansen, L. V., Iversen, J. J. L., Visser, J., et al. (2005). Increased NADPH concentration obtained by metabolic engineering of the pentose phosphate pathway in Aspergillus niger. FEBS J. 272, 1313-1325. doi: 10.1111/j.1742-4658.2005.04554.x

Rydzak, T., Grigoryan, M., Cunningham, Z. J., Krokhin, O. V., Ezzati, P., Cicek, N., et al. (2014). Insights into electron flux through manipulation of fermentation conditions and assessment of protein expression profiles in Clostridium thermocellum. Appl. Microbiol. Biotechnol. 98, 6497-6510. doi: 10.1007/s00253-014-5798-0

Sahm, H., Eggeling, L., and De Graaf, A. A. (2000). Pathway analysis and metabolic engineering in Corynebacterium glutamicum. Biol. Chem. 381, 899-910. doi: 10.1515/BC.2000.111

Sakuraba, H., Kawakami, R., and Ohshima, T. (2005). First Archaeal Inorganic Polyphosphate/ATP-Dependent NAD Kinase, from Hyperthermophilic Archaeon Pyrococcus horikoshii: cloning, expression, and characterization. Appl. Environ. Microbiol. 71, 4352-4358. doi: 10.1128/AEM.71.8.4352-4358.2005

Sakuraba, H., Satomura, T., Kawakami, R., Yamamoto, S., Kawarabayasi, Y., Kikuchi, H., et al. (2002). L-Aspartate oxidase is present in the anaerobic hyperthermophilic archaeon Pyrococcus horikoshii OT-3: characteristics and role in the de novo biosynthesis of nicotinamide adenine dinucleotide proposed by genome sequencing. Extremophiles 6, 275-281. doi: 10.1007/s00792-0010254-3

Saliola, M., Tramonti, A., Lanini, C., Cialfi, S., De Biase, D., and Falcone, C. (2012). Intracellular NADPH levels affect the oligomeric state of the glucose 6-phosphate dehydrogenase. Eukaryot. Cell 11, 1503-1511. doi: 10.1128/EC.00211-12

Sanchez, A. M., Andrews, J., Hussein, I., Bennett, G. N., and San, K.-Y. (2006). Effect of overexpression of a soluble pyridine nucleotide transhydrogenase (UdhA) on the production of poly(3-hydroxybutyrate) in Escherichia coli. Biotechnol. Prog. 22, 420-425. doi: 10.1021/bp050375u

Sancho, J. (2006). Flavodoxins: sequence, folding, binding, function and beyond. Cell. Mol. Life Sci. 63, 855-864. doi: 10.1007/s00018-0055514-4

Santangelo, T. J., Cubonova, L., and Reeve, J. N. (2011). Deletion of alternative pathways for reductant recycling in Thermococcus kodakarensis increases hydrogen production. Mol. Microbiol. 81, 897-911. doi: 10.1111/j.13652958.2011.07734.x

Sassetti, C. M., Boyd, D. H., and Rubin, E. J. (2003). Genes required for mycobacterial growth defined by high density mutagenesis. Mol. Microbiol. 48, 77-84. doi: 10.1046/j.1365-2958.2003.03425.x

Sato, T., and Atomi, H. (2011). Novel metabolic pathways in Archaea. Curr. Opin. Microbiol. 14, 307-314. doi: 10.1016/j.mib.2011.04.014

Sato, Y., Kameya, M., Fushinobu, S., Wakagi, T., Arai, H., Ishii, M., et al. (2012). A novel enzymatic system against oxidative stress in the thermophilic hydrogenoxidizing bacterium Hydrogenobacter thermophilus. PLoS ONE 7:e34825. doi: 10.1371/journal.pone.0034825

Satoh, Y., Tajima, K., Tannai, H., and Munekata, M. (2003). Enzymecatalyzed poly(3-hydroxybutyrate) synthesis from acetate with CoA recycling and NADPH regeneration in vitro. J. Biosci. Bioeng. 95, 335-341. doi: 10.1016/S1389-1723(03)80064-6

Sauer, U., Canonaco, F., Heri, S., Perrenoud, A., and Fischer, E. (2004). The soluble and membrane-bound transhydrogenases UdhA and PntAB have divergent 
functions in NADPH metabolism of Escherichia coli. J. Biol. Chem. 279, 6613-6619. doi: 10.1074/jbc.M311657200

Sauer, U., and Eikmanns, B. J. (2005). The PEP-pyruvate-oxaloacetate node as the switch point for carbon flux distribution in bacteria. FEMS Microbiol. Rev. 29, 765-794. doi: 10.1016/j.femsre.2004.11.002

Schäfer, T., and Schönheit, P. (1993). Gluconeogenesis from pyruvate in the hyperthermophilic archaeon Pyrococcus furiosus: involvement of reactions of the Embden-Meyerhof pathway. Arch. Microbiol. 159, 354-363. doi: $10.1007 / B F 00290918$

Schmitz, O., Boison, G., Salzmann, H., Bothe, H., Schutz, K., Wang, S.-H., et al. (2002). HoxE-a subunit specific for the pentameric bidirectional hydrogenase complex (HoxEFUYH) of cyanobacteria. Biochim. Biophys. Acta 1554, 66-74. doi: 10.1016/S0005-2728(02)00214-1

Schut, G. J., Nixon, W. J., Lipscomb, G. L., Scott, R. A., and Adams, M. W. W. (2012). Mutational analyses of the enzymes involved in the metabolism of hydrogen by the hyperthermophilic archaeon Pyrococcus furiosus. Front. Microbiol. 3:163. doi: 10.3389/fmicb.2012.00163

Seeber, F., Aliverti, A., and Zanetti, G. (2005). The plant-type ferredoxinNADP+ reductase/ferredoxin redox system as a possible drug target against apicomplexan human parasites. Curr. Pharm. Des. 11, 3159-3172. doi: $10.2174 / 1381612054864957$

Seo, D., Kamino, K., Inoue, K., and Sakurai, H. (2004). Purification and characterization of ferredoxin-NADP+ reductase encoded by Bacillus subtilis yumC. Arch. Microbiol. 182, 80-89. doi: 10.1007/s00203-004-0701-5

Seo, D., and Sakurai, H. (2002). Purification and characterization of ferredoxin$\mathrm{NAD}(\mathrm{P})(+)$ reductase from the green sulfur bacterium Chlorobium tepidum. Biochim. Biophys. Acta 1597, 123-132. doi: 10.1016/S0167-4838(02)00269-8

Shi, A., Zhu, X., Lu, J., Zhang, X., and Ma, Y. (2013). Activating transhydrogenase and NAD kinase in combination for improving isobutanol production. Metab. Eng. 16, 1-10. doi: 10.1016/j.ymben.2012.11.008

Shi, F., Huan, X., Wang, X., and Ning, J. (2012). Overexpression of NAD kinases improves the L-isoleucine biosynthesis in Corynebacterium glutamicum ssp. lactofermentum. Enzyme Microb. Technol. 51, 73-80. doi: 10.1016/j.enzmictec.2012.04.003

Shi, F., Li, Y., and Wang, X. (2009). Molecular properties, functions, and potential applications of NAD kinases. Acta Biochim. Biophys. Sin. (Shanghai). 41, 352-361. doi: 10.1093/abbs/gmp029

Shiba, H., Kawasumi, T., Igarashi, Y., Kodama, T., and Minoda, Y. (1985). The $\mathrm{CO} 2$ assimilation via the reductive tricarboxylic acid cycle in an obligately autotrophic, aerobic hydrogen-oxidizing bacterium, Hydrogenobacter thermophilus. Arch. Microbiol. 141, 198-203. doi: 10.1007/BF00408058

Shikanai, T. (2007). Cyclic electron transport around photosystem I: genetic approaches. Annu. Rev. Plant Biol. 58, 199-217. doi: 10.1146/annurev.arplant.58.091406.110525

Shima, S., and Thauer, R. K. (2007). A third type of hydrogenase catalyzing H2 activation. Chem. Rec. 7, 37-46. doi: 10.1002/tcr.20111

Shin, J.-A., Kwon, Y. D., Kwon, O.-H., Lee, H. S., and Kim, P. (2007). 5Aminolevulinic acid biosynthesis in Escherichia coli coexpressing NADPdependent malic enzyme and 5-aminolevulinate synthase. J. Microbiol. Biotechnol. 17, 1579-1584.

Shin, M., and Arnon, D. I. (1965). Enzymic mechanisms of pyridine nucleotide reduction in chloroplasts. J. Biol. Chem. 240, 1405-1411.

Siebers, B., and Schonheit, P. (2005). Unusual pathways and enzymes of central carbohydrate metabolism in Archaea. Curr. Opin. Microbiol. 8, 695-705. doi: 10.1016/j.mib.2005.10.014

Siedler, S., Bringer, S., and Bott, M. (2011). Increased NADPH availability in Escherichia coli: improvement of the product per glucose ratio in reductive whole-cell biotransformation. Appl. Microbiol. Biotechnol. 92, 929-937. doi: 10.1007/s00253-011-3374-4

Silva, P. J., Van Den Ban, E. C., Wassink, H., Haaker, H., De Castro, B., Robb, F. T., et al. (2000). Enzymes of hydrogen metabolism in Pyrococcus furiosus. Eur. J. Biochem. 267, 6541-6551. doi: 10.1046/j.1432-1327.2000.01745.x

Singh, R., Beriault, R., Middaugh, J., Hamel, R., Chenier, D., Appanna, V. D., et al. (2005). Aluminum-tolerant Pseudomonas fluorescens: ROS toxicity and enhanced NADPH production. Extremophiles 9, 367-373. doi: 10.1007/s00792005-0450-7

Singh, R., Lemire, J., Mailloux, R. J., and Appanna, V. D. (2008). A novel strategy involved anti-oxidative defense: the conversion of NADH into NADPH by a metabolic network. PLoS ONE 3:e2682. doi: 10.1371/annotation/5fac086b3806-4aa9-a5c5-2611b3355f8f

Singh, R., Mailloux, R. J., Puiseux-Dao, S., and Appanna, V. D. (2007). Oxidative stress evokes a metabolic adaptation that favors increased NADPH synthesis and decreased NADH production in Pseudomonas fluorescens. J. Bacteriol. 189, 6665-6675. doi: 10.1128/JB.00555-07

Smith, K. M., Cho, K.-M., and Liao, J. C. (2010). Engineering Corynebacterium glutamicum for isobutanol production. Appl. Microbiol. Biotechnol. 87, 1045-1055. doi: 10.1007/s00253-010-2522-6

Sophos, N. A., Pappa, A., Ziegler, T. L., and Vasiliou, V. (2001). Aldehyde dehydrogenase gene superfamily: the 2000 update. Chem. Biol. Interact. 130132, 323-337. doi: 10.1016/S0009-2797(00)00275-1

Sophos, N. A., and Vasiliou, V. (2003). Aldehyde dehydrogenase gene superfamily: the 2002 update. Chem. Biol. Interact. 143-144, 5-22. doi: 10.1016/S00092797(02)00163-1

Steen, I. H., Lien, T., and Birkeland, N. K. (1997). Biochemical and phylogenetic characterization of isocitrate dehydrogenase from a hyperthermophilic archaeon, Archaeoglobus fulgidus. Arch. Microbiol. 168, 412-420. doi: 10.1007/s002030050516

Steen, I. H., Madern, D., Karlstrom, M., Lien, T., Ladenstein, R., and Birkeland, N. K. (2001). Comparison of isocitrate dehydrogenase from three hyperthermophiles reveals differences in thermostability, cofactor specificity, oligomeric state, and phylogenetic affiliation. J. Biol. Chem. 276, 43924-43931. doi: $10.1074 /$ jbc.M105999200

Steuber, J., Krebs, W., Bott, M., and Dimroth, P. (1999). A Membrane-Bound $\mathrm{NAD}(\mathrm{P})(+)$-Reducing hydrogenase provides reduced pyridine nucleotides during citrate fermentation by Klebsiella pneumoniae. J. Bacteriol. 181, 241-245.

Stokke, R., Madern, D., Fedoy, A.-E., Karlsen, S., Birkeland, N.-K., and Steen, I. H. (2007). Biochemical characterization of isocitrate dehydrogenase from Methylococcus capsulatus reveals a unique NAD+-dependent homotetrameric enzyme. Arch. Microbiol. 187, 361-370. doi: 10.1007/s00203-006$0200-\mathrm{y}$

Stols, L., and Donnelly, M. I. (1997). Production of succinic acid through overexpression of $\mathrm{NAD}(+)$-dependent malic enzyme in an Escherichia coli mutant. Appl. Environ. Microbiol. 63, 2695-2701.

Stournaras, C., Maurer, P., and Kurz, G. (1983). 6-phospho-D-gluconate dehydrogenase from Pseudomonas fluorescens. Properties and subunit structure. Eur. J. Biochem. 130, 391-396. doi: 10.1111/j.14321033.1983.tb07165.x

Strand, M. K., Stuart, G. R., Longley, M. J., Graziewicz, M. A., Dominick, O. C., and Copeland, W. C. (2003). POS5 gene of Saccharomyces cerevisiae encodes a mitochondrial NADH kinase required for stability of mitochondrial DNA. Eukaryot. Cell 2, 809-820. doi: 10.1128/EC.2.4.809-820.2003

Summers, M. L., Wallis, J. G., Campbell, E. L., and Meeks, J. C. (1995). Genetic evidence of a major role for glucose-6-phosphate dehydrogenase in nitrogen fixation and dark growth of the cyanobacterium Nostoc sp. strain ATCC 29133. J. Bacteriol. 177, 6184-6194.

Sun, J., Hopkins, R. C., Jenney, F. E. Jr., Mcternan, P. M., and Adams, M. W. W. (2010). Heterologous expression and maturation of an NADP-Dependent [NiFe]-hydrogenase: a key enzyme in biofuel production. PLoS ONE 5:e10526. doi: 10.1371/journal.pone.0010526

Sung, J. Y., and Lee, Y. N. (2007). Isoforms of glucose 6-phosphate dehydrogenase in Deinococcus radiophilus. J. Microbiol. 45, 318-325.

Szaszák, M., Steven, P., Shima, K., Orzekowsky-Schröder, R., Hüttmann, G., König, I. R., et al. (2011). Fluorescence lifetime imaging unravels $C$. trachomatis metabolism and its crosstalk with the host cell. PLoS Pathog 7:e1002108. doi: 10.1371/journal.ppat.1002108

Szmant, H. H. (1989). Organic Building Blocks of the Chemical Industry. New York, NY: John Wiley \& Sons.

Takeno, S., Murata, R., Kobayashi, R., Mitsuhashi, S., and Ikeda, M. (2010). Engineering of Corynebacterium glutamicum with an NADPH-generating glycolytic pathway for L-lysine production. Appl. Environ. Microbiol. 76, 7154-7160. doi: 10.1128/AEM.01464-10

Talfournier, F., Stines-Chaumeil, C., and Branlant, G. (2011). Methylmalonatesemialdehyde dehydrogenase from Bacillus subtilis: substrate specificity and coenzyme A binding. J. Biol. Chem. 286, 21971-21981. doi: $10.1074 /$ jbc.M110.213280 
Tang, K.-H., Yue, H., and Blankenship, R. E. (2010). Energy metabolism of Heliobacterium modesticaldum during phototrophic and chemotrophic growth. BMC Microbiol. 10:150. doi: 10.1186/1471-2180-10-150

Thanassi, J. A., Hartman-Neumann, S. L., Dougherty, T. J., Dougherty, B. A., and Pucci, M. J. (2002). Identification of 113 conserved essential genes using a highthroughput gene disruption system in Streptococcus pneumoniae. Nucleic Acids Res. 30, 3152-3162. doi: 10.1093/nar/gkf418

Thauer, R. K., Jungermann, K., and Decker, K. (1977). Energy conservation in chemotrophic anaerobic bacteria. Bacteriol. Rev. 41, 100-180

Trchounian, A., and Gary Sawers, R. (2014). Novel insights into the bioenergetics of mixed-acid fermentation: can hydrogen and proton cycles combine to help maintain a proton motive force? IUBMB Life 66, 1-7. doi: 10.1002/iub.1236

Trchounian, K., Poladyan, A., Vassilian, A., and Trchounian, A. (2012). Multiple and reversible hydrogenases for hydrogen production by Escherichia coli: dependence on fermentation substrate, $\mathrm{pH}$ and the $\mathrm{F}(0) \mathrm{F}(1)$-ATPase. Crit. Rev. Biochem. Mol. Biol. 47, 236-249. doi: 10.3109/10409238.2012.655375

Tseng, Y.-M., Harris, B. G., and Jacobson, M. K. (1979). Isolation and characterization of yeast nicotinamide adenine dinucleotide kinase. Biochim. Biophys. Acta 568, 205-214. doi: 10.1016/0005-2744(79)90287-0

Turner, W. L., Waller, J. C., and Snedden, W. A. (2005). Identification, molecular cloning and functional characterization of a novel NADH kinase from Arabidopsis thaliana (thale cress). Biochem. J. 385, 217-223. doi: 10.1042/BJ20040292

Uppada, V., Bhaduri, S., and Noronha, S. B. (2014). Cofactor regeneration-an important aspect of biocatalysis. Curr. Sci. 106, 946.

Van Der Donk, W. A., and Zhao, H. (2003). Recent developments in pyridine nucleotide regeneration. Curr. Opin. Biotechnol. 14, 421-426. doi: 10.1016/S0958-1669(03)00094-6

Van Haaster, D. J., Silva, P. J., Hagedoorn, P.-L., Jongejan, J. A., and Hagen, W. R. (2008). Reinvestigation of the steady-state kinetics and physiological function of the soluble NiFe-hydrogenase I of Pyrococcus furiosus. J. Bacteriol. 190, 1584-1587. doi: 10.1128/JB.01562-07

Vasiliou, V., Pappa, A., and Petersen, D. R. (2000). Role of aldehyde dehydrogenases in endogenous and xenobiotic metabolism. Chem. Biol. Interact. 129, 1-19. doi: 10.1016/S0009-2797(00)00211-8

Veech, R. L., Eggleston, L. V., and Krebs, H. A. (1969). The redox state of free nicotinamide-adenine dinucleotide phosphate in the cytoplasm of rat liver. Biochem. J. 115, 609-619.

Velayudhan, J., and Kelly, D. J. (2002). Analysis of gluconeogenic and anaplerotic enzymes in Campylobacter jejuni: an essential role for phosphoenolpyruvate carboxykinase. Microbiology 148, 685-694.

Vignais, P. M., and Billoud, B. (2007). Occurrence, classification, and biological function of hydrogenases: an overview. Chem. Rev. 107, 4206-4272. doi: $10.1021 / \mathrm{cr} 050196 \mathrm{r}$

Vignais, P. M., Billoud, B., and Meyer, J. (2001). Classification and phylogeny of hydrogenases. FEMS Microbiol. Rev. 25, 455-501. doi: 10.1111/j.15746976.2001.tb00587.x

Vignais, P. M., and Colbeau, A. (2004). Molecular biology of microbial hydrogenases. Curr. Issues Mol. Biol. 6, 159-188.

Voegele, R. T., Mitsch, M. J., and Finan, T. M. (1999). Characterization of two members of a novel malic enzyme class. Biochim. Biophys. Acta 1432, 275-285. doi: 10.1016/S0167-4838(99)00112-0

Voordouw, G., Hagen, W. R., Kruse-Wolters, K. M., Van Berkel-Arts, A., and Veeger, C. (1987). Purification and characterization of Desulfovibrio vulgaris (Hildenborough) hydrogenase expressed in Escherichia coli. Eur. J. Biochem. 162, 31-36. doi: 10.1111/j.1432-1033.1987.tb10537.x

Voordouw, G., van der Vies, S. M., and Themmen, A. P. (1983). Why are two different types of pyridine nucleotide transhydrogenase found in living organisms? Eur. J. Biochem. 131, 527-533.

Voordouw, G., van der Vies, S., Scholten, J. W., and Veeger, C. (1980). Pyridine nucleotide transhydrogenase from Azotobacter vinelandii. Eur. J. Biochem. 107, 337-344. doi: 10.1111/j.1432-1033.1980.tb06034.x

Voordouw, G., Veeger, C., Van Breemen, J. F. L., and Van Bruggen, E. F. J. (1979). Structure of pyridine nucleotide transhydrogenase from Azotobacter vinelandii. Eur. J. Biochem. 98, 447-454. doi: 10.1111/j.1432-1033.1979.tb13205.x

Vu, C. Q., Lu, P. J., Ghen, C. S., and Jacobson, M. K. (1996). 2' -phospho-cyclic ADP-ribose, a calcium-mobilizing agent derived from NADP. J. Biol. Chem. 271, 4747-4754. doi: 10.1074/jbc.271.9.4747
Walsh, K., and Koshland, D. E. (1985). Branch point control by the phosphorylation state of isocitrate dehydrogenase. a quantitative examination of fluxes during a regulatory transition. J. Biol. Chem. 260, 8430-8437.

Wandrey, C. (2004). Biochemical reaction engineering for redox reactions. Chem. Rec. 4, 254-265. doi: 10.1002/tcr.20016

Wang, B., Wang, P., Zheng, E., Chen, X., Zhao, H., Song, P., et al. (2011a). Biochemical properties and physiological roles of NADP-dependent malic enzyme in Escherichia coli. J. Microbiol. 49, 797-802. doi: 10.1007/s12275-0110487-5

Wang, P., Jin, M., Su, R., Song, P., Wang, M., and Zhu, G. (2011b) Enzymatic characterization of isocitrate dehydrogenase from an emerging zoonotic pathogen Streptococcus suis. Biochimie 93, 1470-1475. doi: 10.1016/j.biochi.2011.04.021

Wang, P., Jin, M., and Zhu, G. (2012). Biochemical and molecular characterization of $\mathrm{NAD}(+)$-dependent isocitrate dehydrogenase from the ethanologenic bacterium Zymomonas mobilis. FEMS Microbiol. Lett. 327, 134-141. doi: 10.1111/j.1574-6968.2011.02467.x

Wang, P., Song, P., Jin, M., and Zhu, G. (2013a). Isocitrate dehydrogenase from Streptococcus mutans: biochemical properties and evaluation of a putative phosphorylation Site at Ser102. PLoS ONE 8:e58918. doi: 10.1371/journal.pone.0058918

Wang, S., Huang, H., Kahnt, J., Mueller, A. P., Kopke, M., and Thauer, R. K. (2013b). NADP-specific electron-bifurcating [FeFe]-hydrogenase in a functional complex with formate dehydrogenase in Clostridium autoethanogenum grown on CO. J. Bacteriol. 195, 4373-4386. doi: 10.1128/JB.00678-13

Wang, S., Huang, H., Moll, J., and Thauer, R. K. (2010). NADP+ reduction with reduced ferredoxin and NADP+ Reduction with NADH are coupled via an electron-bifurcating enzyme complex in Clostridium kluyveri. J. Bacteriol. 192, 5115-5123. doi: 10.1128/JB.00612-10

Wang, Y., San, K.-Y., and Bennett, G. N. (2013c). Improvement of NADPH bioavailability in Escherichia coli by replacing $\mathrm{NAD}(+)$-dependent glyceraldehyde-3-phosphate dehydrogenase GapA with NADP (+)-dependent GapB from Bacillus subtilis and addition of NAD kinase. J. Ind. Microbiol. Biotechnol. 40, 1449-1460. doi: 10.1007/s10295-013-1335-x

Wang, Y., San, K.-Y., and Bennett, G. N. (2013d). Improvement of NADPH bioavailability in Escherichia coli through the use of phosphofructokinase deficient strains. Appl. Microbiol. Biotechnol. 97, 6883-6893. doi: 10.1007/s00253-013-4859-0

Watanabe, S., Sasaki, D., Tominaga, T., and Miki, K. (2012). Structural basis of [NiFe] hydrogenase maturation by Hyp proteins. Biol. Chem. 393, 1089-1100. doi: 10.1515/hsz-2012-0197

Weckbecker, A., and Hummel, W. (2004). Improved synthesis of chiral alcohols with Escherichia coli cells co-expressing pyridine nucleotide transhydrogenase, $\mathrm{NADP}+$-dependent alcohol dehydrogenase and NAD+-dependent formate dehydrogenase. Biotechnol. Lett. 26, 1739-1744. doi: 10.1007/s10529-0043746-2

Wells, M. A., Mercer, J., Mott, R. A., Pereira-Medrano, A. G., Burja, A. M., Radianingtyas, H., et al. (2011). Engineering a non-native hydrogen production pathway into Escherichia coli via a cyanobacterial [NiFe] hydrogenase. Metab. Eng. 13, 445-453. doi: 10.1016/j.ymben.2011.01.004

Whitehead, S. J., Iwaki, M., Cotton, N. P. J., Rich, P. R., and Jackson, J. B. (2009). Inhibition of proton-transfer steps in transhydrogenase by transition metal ions. Biochim. Biophys. Acta 1787, 1276-1288. doi: 10.1016/j.bbabio.2009.06.001

Whitehead, S. J., Rossington, K. E., Hafiz, A., Cotton, N. P. J., and Jackson, J. B. (2005). Zinc ions selectively inhibit steps associated with binding and release of NADP $(\mathrm{H})$ during turnover of proton-translocating transhydrogenase. FEBS Lett. 579, 2863-2867. doi: 10.1016/j.febslet.2005.04.026

Wichmann, R., and Vasic-Racki, D. (2005). Cofactor regeneration at the lab scale. Adv. Biochem. Eng. Biotechnol. 92, 225-260. doi: 10.1007/b98911

$\mathrm{Xu}$, Z., Jing, K., Liu, Y., and Cen, P. (2007). High-level expression of recombinant glucose dehydrogenase and its application in NADPH regeneration. J. Ind. Microbiol. Biotechnol. 34, 83-90. doi: 10.1007/s10295-0060168-2

Yamauchi, Y., Hirasawa, T., Nishii, M., Furusawa, C., and Shimizu, H. (2014). Enhanced acetic acid and succinic acid production under microaerobic conditions by Corynebacterium glutamicum harboring Escherichia coli 
transhydrogenase gene pntAB. J. Gen. Appl. Microbiol. 60, 112-118. doi: 10.2323/jgam.60.112

Yamazaki, M., and Ichikawa, Y. (1990). Some properties of the apoenzyme of NADPH-adreno-ferredoxin reductase from bovine adrenocortical mitochondria. Int. J. Biochem. 22, 1147-1152. doi: 10.1016/0020-711X(90)90113-H

Yan, Z., Nam, Y.-W., Fushinobu, S., and Wakagi, T. (2014). Sulfolobus tokodaii ST2133 is characterized as a thioredoxin reductase-like ferredoxin:NADP+ oxidoreductase. Extremophiles 18, 99-110. doi: 10.1007/s00792-013-0601-1

Yang, Z., Zhang, H., Hung, H.-C., Kuo, C.-C., Tsai, L.-C., Yuan, H. S., et al. (2002). Structural studies of the pigeon cytosolic NADP $(+)$-dependent malic enzyme. Protein Sci. 11, 332-341. doi: 10.1110/ps.38002

Yeom, J., Jeon, C. O., Madsen, E. L., and Park, W. (2009). In vitro and in vivo interactions of ferredoxin-NADP+ reductases in Pseudomonas putida. J. Biochem. 145, 481-491. doi: 10.1093/jb/mvn185

Ying, W. (2008). NAD+/NADH and NADP+/NADPH in cellular functions and cell death: regulation and biological consequences. Antioxid. Redox Signal. 10, 179-206. doi: 10.1089/ars.2007.1672

Yokooji, Y., Sato, T., Fujiwara, S., Imanaka, T., and Atomi, H. (2013). Genetic examination of initial amino acid oxidation and glutamate catabolism in the hyperthermophilic archaeon Thermococcus kodakarensis. J. Bacteriol. 195, 1940-1948. doi: 10.1128/JB.01979-12

Yoon, J.-J., Hattori, T., and Shimada, M. (2003). Purification and characterization of NADP-linked isocitrate dehydrogenase from the copper-tolerant woodrotting basidiomycete Fomitopsis palustris. Biosci. Biotechnol. Biochem. 67, 114-120. doi: 10.1271/bbb.67.114

Yun, H., Choi, H.-L., Fadnavis, N. W., and Kim, B.-G. (2005). Stereospecific synthesis of (R)-2-hydroxy carboxylic acids using recombinant E. coli BL21 overexpressing YiaE from Escherichia coli $\mathrm{K} 12$ and glucose dehydrogenase from Bacillus subtilis. Biotechnol. Prog. 21, 366-371. doi: 10.1021/bp04 9694w

Zalacain, M., Biswas, S., Ingraham, K. A., Ambrad, J., Bryant, A., Chalker, A. F., et al. (2003). A global approach to identify novel broad-spectrum antibacterial targets among proteins of unknown function. J. Mol. Microbiol. Biotechnol. 6, 109-126. doi: 10.1159/000076741

Zamboni, N., Fischer, E., Laudert, D., Aymerich, S., Hohmann, H.-P., and Sauer, U. (2004). The Bacillus subtilis yqjI gene encodes the NADP+-dependent 6-Pgluconate dehydrogenase in the pentose phosphate pathway. J. Bacteriol. 186, 4528-4534. doi: 10.1128/JB.186.14.4528-4534.2004

Zhang, J.-D., Li, A.-T., Yu, H.-L., Imanaka, T., and Xu, J.-H. (2011). Synthesis of optically pure S-sulfoxide by Escherichia coli transformant cells coexpressing the P450 monooxygenase and glucose dehydrogenase genes. J. Ind. Microbiol. Biotechnol. 38, 633-641. doi: 10.1007/s10295-010-0809-3
Zhang, J., and Xu, J. H. (2010). Biocatalysis, cofactor regeneration. Encyclopedia Ind. Biotechnol. 1-9. doi: 10.1002/9780470054581.eib073

Zhao, H., and Van Der Donk, W. A. (2003). Regeneration of cofactors for use in biocatalysis. Curr. Opin. Biotechnol. 14, 583-589. doi: 10.1016/j.copbio.2003.09.007

Zhao, H., Wang, P., Huang, E., Ge, Y., and Zhu, G. (2008). Physiologic roles of soluble pyridine nucleotide transhydrogenase in Escherichia coli as determined by homologous recombination. Ann. Microbiol. 58, 275-280. doi: 10.1007/BF03175329

Zhao, J., Baba, T., Mori, H., and Shimizu, K. (2004a). Effect of zwf gene knockout on the metabolism of Escherichia coli grown on glucose or acetate. Metab. Eng. 6, 164-174. doi: 10.1016/j.ymben.2004.02.004

Zhao, J., Baba, T., Mori, H., and Shimizu, K. (2004b). Global metabolic response of Escherichia coli to gnd or zwf gene-knockout, based on 13C-labeling experiments and the measurement of enzyme activities. Appl. Microbiol. Biotechnol. 64, 91-98. doi: 10.1007/s00253-003-1458-5

Zhao, Z., Kuijvenhoven, K., Van Gulik, W. M., Heijnen, J. J., Van Winden, W. A., and Verheijen, P. J. T. (2011). Cytosolic NADPH balancing in Penicillium chrysogenum cultivated on mixtures of glucose and ethanol. Appl. Microbiol. Biotechnol. 89, 63-72. doi: 10.1007/s00253-010-2851-5

Zheng, H., Ohno, Y., Nakamori, T., and Suye, S.-I. (2009). Production of Lmalic acid with fixation of $\mathrm{HCO} 3(-)$ by malic enzyme-catalyzed reaction based on regeneration of coenzyme on electrode modified by layer-by-layer selfassembly method. J. Biosci. Bioeng. 107, 16-20. doi: 10.1016/j.jbiosc.2008.09.009

Zhou, J., Olson, D. G., Argyros, D. A., Deng, Y., Van Gulik, W. M., Van Dijken, J. P., et al. (2013). Atypical glycolysis in Clostridium thermocellum. Appl. Environ. Microbiol. 79, 3000-3008. doi: 10.1128/AEM.04037-12

Zhu, G., Golding, G. B., and Dean, A. M. (2005). The selective cause of an ancient adaptation. Science 307, 1279-1282. doi: 10.1126/science.1106974

Ziegler, M. (2000). New functions of a long-known molecule. Eur. J. Biochem. 267, 1550-1564. doi: 10.1046/j.1432-1327.2000.01187.x

Conflict of Interest Statement: The authors declare that the research was conducted in the absence of any commercial or financial relationships that could be construed as a potential conflict of interest.

Copyright (C) 2015 Spaans, Weusthuis, van der Oost and Kengen. This is an openaccess article distributed under the terms of the Creative Commons Attribution License (CC BY). The use, distribution or reproduction in other forums is permitted, provided the original author(s) or licensor are credited and that the original publication in this journal is cited, in accordance with accepted academic practice. No use, distribution or reproduction is permitted which does not comply with these terms. 